\title{
ÍNDICE RESUMOS
}

ANÁLISE ECONÔMICA EM SISTEMAS SILVIPASTORIS DE
TOURINHOS EM RECRIA NA REGIÃO PRÉ-AMAZÔNICA ................

Adailton Camêlo Costa, Ricardo Alves de Araújo, Rosane Cláudia Rodrigues, Clésio dos Santos Costa, Francisco Naysson de Sousa Santos, Luiza de Nazaré Carneiro da Silva, Ivone Rodrigues da Silva

VIABILIDADE ECONÔMICA DA RECRIA DE TOURINHOS SUPLEMENTADOS COM FARELO DE BABAÇU EM SISTEMAS SILVIPASTORIS NA AMAZÔNIA ORIENTAL

Adailton Camêlo Costa, Ricardo Alves de Araújo, Rosane Cláudia Rodriques, Clésio dos Santos Costa, Francisco Naysson de Sousa Santos, Luiza de Nazaré Carneiro da Silva, Ivone Rodrigues da Silva

EFFECTS OF SUPPLEMENTATION STRATEGIES IN FEMALE CALVES UNDER GRAZING IN THE TROPICS ON NUTRIENTS INTAKE, DIGESTIBILITY, AND EFFICIENCY OF MICROBIAL PROTEIN SYNTHESIS

Ághata Elins Moreira da Silva, Román Enrique Maza Ortega, Deilen Paff Sotelo Moreno, Vinicius Augusto Vieira Pereira, Edson Júnior dos Santos, Anna Flávia Rodrigues da Silva, Mario Fonseca Paulino

EFFECTS OF SUPPLEMENTATION STRATEGIES IN FEMALE CALVES UNDER GRAZING IN THE TROPICS ON PRODUCTIVE PERFORMANCE AND CARCASS CHARACTERISTICS

Ághata Elins Moreira da Silva, Román Enrique Maza Ortega, Thiago Ramalho Moreira, Ícaro Artuso Lage, Jefferson Bello dos Santos, Yuri Rodrigues Rezende, Mario Fonseca Paulino

CONSUMO E DIGESTIBILIDADE DE NUTRIENTES DE NOVILHOS MANTIDOS A PASTO E SUPLEMENTADOS COM DIFERENTES FONTES DE NITROGÊNIO NÃO PROTEICO

Alberto Jefferson da Silva Macêdo, Rafael Henrique de Tonissi e Buschinelli de Goes, Jefferson Rodrigues Gandra, Charles Jhonnatan dos Santos Souza, Thaiano Iranildo de Sousa Silva, Nayara Gonçalves da Silva, Wagner Sousa Alves 
ESTIMATIVA DA EXCREÇÃO DE DERIVADOS DE PURINA DE NOVILHOS A PASTO E SUPLEMENTADOS COM DIFERENTES FONTES DE NITROGÊNIO NÃO PROTÉICO

Alberto Jefferson da Silva Macêdo, Rafael Henrique de Tonissi e Buschinelli de Goes, Jefferson Rodrigues Gandra, Rodrigo Augusto Gressler, Thaiano Iranildo de Sousa Silva, Hulle Lívia Costa Brito, Wagner Sousa Alves

CONSUMO E DIGESTIBILIDADE EM BOVINOS ALIMENTADOS COM GRAMÍNEA TROPICAL E SUPLEMENTAÇÃO INFREQUENTE

Aline Maria Monteiro Canaan Garcia, Malber Nathan Nobre Palma, João Vitor Ribeiro Lovatti, Giselle Priscila Costa, William Lima Santiago dos Reis, Amanda de Souza Assunção, Edenio Detmann

INTERAÇÕES ENTRE FORRAGEM E CONDIÇÃO DE INCUBAÇÃO SOBRE A DIGESTIBILIDADE in vitro UTILIZANDO FERMENTADORA ARTIFICIAL

Aline Maria Monteiro Canaan Garcia, Larissa Frota Camacho, Tadeu Eder Silva, Malber Nathan Nobre Palma, Aline Naime Rodrigues,João Vitor Ribeiro Lovatti, Edenio Detmann

QUAL CAPIM TEM MAIOR DEMANDA DE NITROGÊNIO EM MANUTENÇÃO: MULATO II OU DECUMBENS?

Aline Muller Motta, Luiz Jardel Müller Motta, Victor Gustavo Valiati Dantas, Joadil Gonçalves de Abreu, Carla Heloisa Avelino Cabral, Carlos Eduardo Avelino Cabral

AVALIAÇÃO DA VARIABILIDADE ENTRE ANIMAIS EM ESTUDOS DE DEGRADAÇÃO IN SITU EM BOVINOS

Amanda de Souza Assunção, Edenio Detmann, João Vitor Ribeiro Lovatti, Giselle Priscila Costa, Ana Carolina Rodrigues, Malber Nathan Nobre Palma, Larissa Frota Camacho Amorim

INFLUÊNCIA DA ENSILAGEM DE GRÃOS REIDRATADOS E DO TEOR DE CONCENTRADO SOBRE O CONSUMO, DIGESTIBILIDADE RUMINAL, INTESTINAL E TOTAL DA MATÉRIA ORGÂNICA EM BOVINOS NELORE

Breno de Castro Silva, Sebastião de Campos Valadares Filho, Marcos Vinicius Carneiro Pacheco, Letícia Artuzo Godoi, Ana Clara Baião Menezes, Edenio Detmann, Pedro Veiga Rodrigues Paulino

INFLUÊNCIA DO TEOR DE CONCENTRADO E ENSILAGEM DE GRÃOS DE MILHO OU DE SORGO REIDRATADOS NAS CONCENTRAÇÕES DE ÁCIDOS GRAXOS VOLÁTEIS E GLICOSE SÉRICA EM BOVINOS NELORE

Bruno Corrêa Lage, Sebastião de Campos Valadares Filho, Breno de Castro Silva, Marcos Vinicius Carneiro Pacheco, Flávia Adriane de Sales Silva, Herlon Menegueli Alhadas, Érica Garcia Mafort 

AÇÃO EM VACAS SUBMETIDAS À TRANSFERÊNCIA DE EMBRIÃO .

Bruno Silva do Espirito Santo, Moacir Ferreira Duarte Júnior, Danilo Francisco Campos Pereira, Vinicius Borges Garcia, Luciana Keiko Hatamoto-Zervoudakis, Luis Eduardo Senra e Silva, Ana Maria Bueno Barbosa dos Santos

INFLUÊNCIA DOS TEORES DE FIBRA FISICAMENTE EFETIVA PROVENIENTE DE VOLUMOSO EM DIETAS DE GRÃO INTEIRO

Caio William Magalhães Souza, Herlon Maneguelli Alhadas, Nathália Veloso Trópia, Pauliane Pucetti, Marcos Vinicius Carneiro Pacheco, Breno de Castro Silva, Sebastião de Campos Valadares Filho

ESTIMATIVA DO CONSUMO DE VOLUMOSO PELO FORNECIMENTO DE INDICADOR EM COCHO ELETRÔNICO

Camila Andressa Silva de Oliveira, Adailton Camêlo Costa, Sabrina de Paula Baltazar, Juarez Júnior da Silva Paiva, Mauricio Miguel Estrada, Luciana Navajas Rennó, Mario Luiz Chizzotti

EFFECT OF SUPPLEMENTATION OF GRAZING BEEF HEIFERS AT PRE AND POST-WEANING PERIOD ON METABOLIC PROFILE AND OVARIAN ACTIVITY

Camila de Paula, Román Enrique Maza Ortega, Thiago Ramalho Moreira, Ícaro Artuso Lage, Jefferson Bello dos Santos, Yuri Rodrigues Rezende, Mario Fonseca Paulino

EFFECTS OF SUPPLEMENTATION STRATEGIES IN METABOLIC PROFILE ON THE PREWEANING PERIOD OF GRAZING BEEF FEMALE CALVES

Camila de Paula, Román Enrique Maza Ortega, Deilen Paff Sotelo Moreno, Roberta de Souza Amaral, Edson Júnior dos Santos, Anna Flávia Rodrigues da Silva, Mario Fonseca Paulino

PARÂMETROS GENÉTICOS PARA MOTILIDADE E PERÍMETRO ESCROTAL EM BOVINOS DA RAÇA NELORE.

Carla Galvão Fernandes, Ivan Carvalho Filho, Daniele Botelho Diniz Marques, Túlio Vilar Vilas Boas Oliveira, Layla Cristien de Cassia Miranda Dias, José Domingos Guimarães, Renata Veroneze

EFEITO DO NÍVEL DE PROTEÍNA BRUTA NA TERMINAÇÃO NA QUALIDADE DA CARNE DE BOVINOS NELORE OU $F$ ANGUS $x$ NELORE

Carolina de Oliveira Pacheco'; Lyvian Cardoso Alves; Juliana Chaves; Mário Luiz Chizzotti

INFLUÊNCIA DA RESTRIÇÃO ALIMENTAR NO DESEMPENHO E QUALIDADE DE CARNE DE BOVINOS NELORE E F ANGUS $x$ NELORE

Carolina de Oliveira Pacheco'; Lyvian Cardoso Alves; Juliana Chaves; Mário Luiz Chizzotti 
PRODUTIVIDADE DE CAPIM BRAQUIÁRIA FERTIRRIGADO COM EFLUENTE DE SUINOCULTURA

Cíntia Cármen de Faria Melo, Danilo Silva Amaral, Luís César Dias Drumond

INFLUÊNCIA DA CASTRAÇÃO SOBRE AS CARACTERÍSTICAS DE CARCAÇA DE BOVINOS NELORE SUPERPRECOCES ABATIDOS EM DIFERENTES PESOS CORPORAIS

Débora Evelyn de F. Assis, Luiz Henrique Pereira Silva, Gutierrez José de F. Assis, Mauricio Miguel Estrada, Gustavo B. Carneiro, Germán Dario Ramirez Zamudio, Mario L. Chizzotti

EFEITO DA CONDIÇÃO SEXUAL, PESO CORPORAL AO ABATE E TEMPO DE MATURAÇÃO SOBRE A MACIEZ DA CARNE DE BOVINOS NELORE SUPERPRECOCES

Débora Evelyn de F. Assis, Luiz Henrique Pereira Silva, Gutierrez José de F. Assis, Mauricio Miguel Estrada, Gustavo B. Carneiro, Juliana Chaves da Silva, Mario L. Chizzotti

PRODUCTIVE PERFORMANCE, NUTRIENTS INTAKE AND DIGESTIBILITY OF GRAZING BEEF HEIFERS RECEIVING INCREASING LEVELS OF PROTEIN SUPLEMENT AT PERIPARTUM AND POSTPARTUM PERIODS

Deilen Paff Sotelo Moreno, Thiago Ramalho Moreira, Román Maza Ortega, David Contreras Marquez, Felipe Henrique de Moura, Vinícius Augusto Vieira Pereira, Mário Fonseca Paulino

METABOLIC STATUS OF GRAZING BEEF HEIFERS RECEIVING INCREASING LEVELS OF PROTEIN SUPPLEMENT AT PERIPARTUM AND POSTPARTUM PERIODS

Deilen Paff Sotelo Moreno, Thiago Ramalho Moreira, Román Maza Ortega, David Contreras Marquez, Jéssika Almeida Bitencourt, Júlia de Abreu Lopes, Mário Fonseca Paulino

DESEMPENHO PRODUTIVO E ECONÔMICO DE DOIS GRUPOS GENÉTICOS DE BOVINOS TERMINADOS EM CONFINAMENTO .....

Drielly Coelho Marcondes, Laissa Araujo Guimarães, Severino Delmar Junqueira Villela, Marcos Vendrame Esposito, Charles Paranhos Oliveira, Débora Virgínia Ribeiro

QUALIDADE DA CARNE DE BOVINOS NELORE ALIMENTADOS COM SORGO OU MILHO, SECO OU REIDRATADO

Fabiano Andrade Ferreira, Germán Darío Ramírez Zamudio, Rizielly Saraiva Reis Vilela, Maurício Miguel Estrada, Marcos Vinicius Cameiro Pacheco, Breno de Castro Silva, Mário Luiz Chizzotti

EFFECTS OF INFREQUENT SUPPLEMENTATION WITH NITROGEN AND STARCH ON RUMEN FIBER DEGRADATION AND AMMONIA IN CATTLE FED HIGH-QUALITY TROPICAL GRASS

Giselle Priscila Costa, Edenio Detmann, William Lima Santiago dos Reis, João Vitor Ribeiro Lovatti, Malber Nathan Nobre Palma, Amanda de Souza Assunção, Aline Maria Monteiro Canaan Garcia

xviii 
USO DE CÂMERA DE INFRAVERMELHO NA CLASSIFICAÇÃO E TIPIFICAÇÃO DE CARCAÇAS BOVINAS

Gutierrez J. de F. Assis, André Luis Carvalho Mendes, Débora Evelyn de F. Assis, Gustavo Borges Carneiro, Augusto Matos Corrêa, Luiz Henrique Pereira Silva, Mario Luiz Chizzotti

CORTES PRIMÁRIOS E SECUNDÁRIOS DA CARCAÇA DE BOVINOS DA RAÇA NELORE CLASSIFICADOS PARA DIVERGENTES CLASSES DE CONSUMO ALIMENTAR RESIDUAL (CAR)

Heloisa de Almeida Fidelis, Sarah Figueiredo Martins Bonilha, Maria Eugênia Zerlotti Mercadante, Joslaine Noely dos Santos Gonçalves Cyrillo, Wignez Henrique, Hirasilva Borba

PERDAS ECONÔMICAS POR CONDENAÇÃO TOTAL DE CARCAÇAS DE BOVINOS EM FRIGORÍFICOS LOCALIZADOS NO ESTADO DE MATO GROSSO ENTRE 2007 E 2016

Henrique Castrillon Leiva Rolim, Diego Pierotti Procópio

CONCENTRAÇÕES DE ÁCIDOS ORGÂNICOS E AMÔNIA RUMINAL EM DIETAS CONTENDO DIFERENTES TEORES DE FIBRA FISICAMENTE EFETIVA PROVENIENTE DE VOLUMOSO

Herlon M. Alhadas, Nathália Veloso Trópia, Pauliane Pucetti, Marcos Vinícios C. Pacheco, Ana Clara Baião Menezes, Letícia Arthuso Godoi, Sebastião de Campos Valadares Filho

METABOLIC AND HORMONAL RESPONSES ON PERIPARTUM OF GRAZING BEEF CATTLE SUPPLEMENTED ON PRE-PARTUM .......

Hudson Caio Martins, Samira Silveira Moreira, Júlia Avansi Marques, Bruno Inácio Correa Oliveira, Isabela de Paula Cidrine, Matheus Fellipe de Lana Ferreira, Luciana Navajas Rennó

QUAL É O MÁXIMO DE NITROGÊNIO QUE MODIFICA A ÁREA DE OCUPAÇÃO DO CAPIM MARANDU?

Jenifer Santos de Mattos, Pedro Emanuel da Costa Lourenço, Kyron Cabral Sales, João Bosco de Campos Filho, Lívia Vieira de Barros, Joadil Gonçalves de Abreu, Carlos Eduardo Avelino Cabral

UTILIZAÇÃO DE DIFERENTES FONTES DE GEMA DE OVO NO MEIO DE CRIOPRESERVAÇÃO SEMINAL DE BOVINOS

Jéssica Ligoski Cabral, Tathiana Ferguson Motheo, Luciana Keiko HatamotoZervoudakis, Pedro Paulo Tsuneda, Rafael Moraes de Assis, Marlon Eduardo dos Santos Rodrigues, Gilmar Ferreira Rodrigues

AVALIAÇÃO DA SUPLEMENTAÇÃO MINERAL INJETÁVEL (SUPLENUT®, BIOGÉNESIS BAGÓ) NA MELHORIA DO DESEMPENHO EM BEZERROS E BEZERRAS DA RAÇA NELORE .....

João Paulo Lollato, Milton Maturana Filho, Reuel Luís Gonçalves, Vinícius Tadano Marques, Guillermo A. Mattioli, Juan M. Rodríguez Pérsico, Ed Hoffmann Madureira 
COMPARAÇÃO DE DOIS SUPLEMENTOS MINERAIS E VITAMÍNICOS INJETÁVEIS, NO DESEMPENHO DE FÊMEAS NELORE EM CONFINAMENTO

João Paulo Lollato', Milton Maturana Filho² ${ }^{2}$, Reuel Luiz Gonçalves', Bruno Di Rienzo ${ }^{1}$ Guillermo A. Mattioli ${ }^{3}$, Juan M. Rodríguez Pérsico, Ed Hoffmann Madureira, Lucas Vaz

EFFECTS OF DAILY OR EVERY THREE DAYS PROTEIN OR PROTEIN AND STARCH SUPPLEMENTATION ON INTAKE AND DIGESTIBILITY OF NELLORE HEIFERS FED MEDIUM-QUALITY TROPICAL GRASS

João Vitor Ribeiro Lovatti, William Lima Santiago dos Reis, Malber Nathan Nobre Palma, Giselle Priscila Costa, Aline Maria Monteiro Canaan Garcia, Aline Naime Rodrigues, Edenio Detmann

NUTRITIONAL AND METABOLIC EVALUATION IN NELLORE COWS SUPPLEMENTED DURING PERI AND/OR POSTPARTUM KEEPING IN TROPICAL PASTURE

João Vitor Ribeiro Lovatti, Claudia Batista Sampaio, Aline Souza Trece, Felipe Henrique de Moura, Thiago Ramalho Moreira,Edson Junior dos Santos, Edenio Detmann

SOLUBILIDADE E TIPOS DE COLÁGENOS NA CARNE DE BOVINOS NELORE INTEIROS E CASTRADOS EM DIFERENTES IDADES

Juliana Chaves da Silva, Polyana Galvão Bernardes Coelho, Luiz Pereira Silva, Mauricio Miguel Estrada, Débora Evelyn de Freitas Assis, Mario Luiz Chizzotti, Maria Verônica de Souza

GRUPO GENÉTICO E PONTO ÓTIMO DE ABATE COMO VARIÁVEIS DO RESULTADO ECONÔMICO EM OPERAÇÕES DE CONFINAMENTO

Kárito Augusto Pereira, Fernando de Paula Leonel, Janderson Damaceno dos Reis, Severino Delmar Junqueira Villela, Renata Vaz Ribeiro

RENDIMENTO DE CARCAÇA DE QUATRO GRUPOS GENÉTICOS DE BOVINOS TERMINADOS EM SISTEMA DE CONFINAMENTO .....

Kárito Augusto Pereira, Fernando de Paula Leonel, Janderson Damaceno dos Reis, Severino Delmar Junqueira Villela, Angelo Herbet Moreira Arcanjo, Bruno Grossi Costa Homem

UTILIZAÇÃO DE CASCA DE SOJA EM SUPLEMENTO MÚLTIPLO PARA NOVILHOS NELORE RECRIADOS À PASTO NO PERÍODO DE TRANSIÇÃO SECA-ÁGUAS

Leandro Soares Martins, Flávio Augusto Portela Santos, Lainer Sousa e Leite, Ériton Egídio Lisboa Valente 
GRÃO ÚMIDO DE MILHO EM SUBSTITUIÇÃO AO GRÃO SECO DE MILHO MOÍDO INFLUENCIANDO O DESEMPENHO DE ANIMAIS TERMINADOS EM CONFINAMENTO À PASTO

Leandro Soares Martins, Flávio Augusto Portela Santos, Lainer Sousa e Leite, Ériton Egídio Lisboa Valente

CONSUMO E DIGESTIBILIDADE DO AMIDO EM DIETAS CONTENDO MILHO EM DIFERENTES GRANULOMETRIAS OU GRÃO DE SORGO MOÍDO EM BOVINOS NELORE

Letícia Artuzo Godoi, Sebastião de Campos Valadares Filho, Breno de Castro Silva, Flávia Adriane de Sales Silva, Herlon Meneguelli Alhadas, Edenio Detmann, Luciana Navajas Rennó

EFEITO DO MILHO EM DIFERENTES GRANULOMETRIAS OU GRÃO DE SORGO MOÍDO SOBRE O PH RUMINAL EM BOVINOS NELORE ..

Letícia Artuzo Godoi, Sebastião de Campos Valadares Filho, Diego Zanetti, Marcos Vinicius Carneiro Pacheco, Ana Clara Baião Menezes, Mario Luiz Chizzotti, Pedro Veiga Rodrigues Paulino

RELAÇÃO PROTEÍNA E ENERGIA NA DIETA DE NOVILHAS NO PERÍODO DE TRANSIÇÃO ÁGUAS-SECA

Letícia Brito Alves, Deborah França Pires, Jackelliny Melo de Barros Rosa, Milene Rodrigues Dias, Alyce Raiana Monteiro dos Santos, Carlos Eduardo Avelino Cabral, Carla Heloisa Avelino Cabral

PRINCIPAIS IMPACTOS E CAUSAS DAS CONDENAÇÕES DE VÍSCERAS VERMELHAS COMESTÍVEIS, PERTENCENTES A BOVINOS DE CORTE, ABATIDOS EM UM MATADOURO FRIGORIFICO SOB INSPEÇÃO ESTADUAL, LOCALIZADO NO NORDESTE BAIANO

Luane Etienne Barreto, Pedro Alexandre Gomes Leite, Thiago Araújo Boulhosa, Bruno Souza Malta

O CAPIM MULATO II ASSEMELHA-SE AO CAPIM MARANDU EM RESPOSTA A ADUBAÇÃO NITROGENADA?

Luiz Jardel Müller Motta, Pedro Emanuel da Costa Lourenço, Lucas Gimenes Mota, Cleiton Barbosa Apolônio Ola, Joadil Gonçalves de Abreu, Carla Heloisa Avelino Cabral, Carlos Eduardo Avelino Cabral

EFEITO DOS TEORES DE FIBRA FISICAMENTE EFETIVA PROVENIENTE DE VOLUMOSO EM DIETAS DE GRÃO DE MILHO INTEIRO SOBRE A EFICIÊNCIA DE USO DA PROTEÍNA E DA ENERGIA EM BOVINOS DE CORTE

Nathália V. Trópia, Herlon M. Alhadas, Caio William M. Souza, Pauliane Pucetti, Lethiane Rocha, Flávia A. Sales, Sebastião de Campos Valadares Filho 
ANÁLISE DAS PERDAS ECONÔMICAS ORIUNDAS DA CONDENAÇÃO TOTAL DE CARCAÇAS DE BOVINOS ABATIDOS NO ESTADO DE SÃO PAULO

Pâmela Gracioli Vilas Boas, Weyber Ferreira de Souza, Aline de Almeida Pedroso, Marcos Paulo Freitas da Silva, Diego Pierotti Procópio

VARIAÇÃO DO PH RUMINAL AO LONGO DO DIA, CONSUMO E DIGESTIBILIDADE RUMINAL DA FDNCP EM RESPOSTA AO TEOR DE CONCENTRADO E AO USO DE SILAGEM DE GRÃOS REIDRATADOS EM DIETAS DE MACHOS NELORE

Pauliane Pucetti, Sebastião de Campos Valadares Filho, Breno de Castro Silva, Nathalia Veloso Trópia, Caio William Magalhães, Erica Garcia Mafort, Luciana Navajas Rennó

ESTIMATIVAS DE PARÂMETROS GENÉTICOS PARA AS CARACTERÍSTICAS REPRODUTIVAS: DIAS PARA O PRIMEIRO PARTO E IDADE AO PRIMEIRO PARTO, EM NOVILHAS NELORE ......

Pedro Vital Brasil Ramos, Túlio Vilar Vilas Boas Oliveira, Fábio Luiz Buranelo Toral, Luisa Crivelli Alvarenga, Talita Estáfani Zunino Santana, Renata Veroneze, Fabyano Fonseca e Silva

ESTIMAÇÃO DE PARÂMETROS GENÉTICOS PARA PESO AO SOBREANO EM BOVINOS DA RAÇA NELORE

Renata Cruz e Sousa, Herta de Oliveira Monteiro Ribeiro, Thais Ferreira dos Santos, Gilberto Romeiro de Oliveira Menezes, Felipe Gomes da Silva

CINÉTICA ESPERMÁTICA E ATIVIDADE CITOQUÍMICA MITOCONDRIAL DO SÊMEN DESCONGELADO DE BOVINOS PANTANEIROS APÓS SUPLEMENTAÇÃO COM ÁCIDO ASCÓRBICO AO MEIO DE CRIOPRESERVAÇÃO

Taiane dos Santos Schmidt, Luciana Keiko Hatamoto -Zervoudakis, Tathiana Ferguson Motheo, Pedro Paulo Tsuneda, Marlon Eduardo dos Santos Rodrigues, Jéssica Ligoski Cabral, Bruno Silva do Espirito Santo

EFEITOS FIXOS E ALEATÓRIOS QUE INFLUENCIAM O PESO A DESMAMA DE BOVINOS DE CORTE

Thais Ferreira dos Santos, Herta de Oliveira Monteiro Ribeiro, Renata Cruz e Sousa, Gilberto Romeiro de Oliveira Menezes, Dr. Felipe Gomes da Silva

NÚMERO MÍNIMO DE OBSERVAÇÕES POR GRUPO DE CONTEMPORÂNEOS

Thais Ferreira dos Santos, Lorena Zulian Andreotti, Herta de Oliveira Monteiro Ribeiro, Renata Cruz e Sousa, Gilberto Romeiro de Oliveira Menezes, Felipe Gomes da Silva 
PARÂMETROS RUMINAIS DE NOVILHOS SUPLEMENTADOS COM MONENSINA E, OU ÓLEO DE COPAÍBA

Wagner Sousa Alves, Rafael Henrique de Tonissi e Buschinelli de Goes, Jefferson Rodrigues Gandra, Rodrigo Augusto Gressler, Thaiano Iranildo de Sousa Silva, Maiara Aparecida Flores Balbueno, Alberto Jefferson da Silva Macêdo

\section{DIGESTIBILIDADE DA DIETA DE NOVILHOS SUPLEMENTADOS} COM MONENSINA E, OU ÓLEO DE COPAÍBA

Wagner Sousa Alves, Rafael Henrique de Tonissi e Buschinelli de Goes, Jefferson Rodrigues Gandra, Charles Jhonnatan dos Santos Souza, Thaiano Iranildo de Sousa Silva, Janaina Aparecida de Lima, Alberto Jefferson da Silva Macêdo

INFLUENCE OF PARK, PRDX, PRDX AND PRDX PROTEINS ON MEAT TENDERNESS IN NELLORE CATTLE

Jessica Moraes Malheiros, Wellington Luiz de Paula Araújo, José Cavalcante Souza Vieira, Camila Pereira Braga, Cruz Elena Henriquez-Valencia, Pedro de Magalhães Padilha, Luis Artur Loyola Chardulo

TWO-DIMENSIONAL ELECTROPHORESIS IN COMBINATION WITH MASS SPECTROMETRY TO STUDY NELLORE CATTLE DIVERGENTLY GROUPED FOR MEAT QUALITY OR FEED EFFICIENCY TRAITS

Welder Angelo Baldassini, Wellington Luiz de Paula Araújo, Ana Bárbara Domingues Sartor, Renata Helena Branco, Sarah Martins Figueiredo Bonilha, Dante Pazzanese Duarte Lanna, Pedro de Magalhães Padilha

PRINCIPAIS CAUSAS DE CONDENAÇÕES TOTAIS DE CARCAÇAS DE BOVINOS EM FRIGORÍFICOS NO ESTADO DE SÃO PAULO NO PERÍODO DE 2006 A 2016

Weyber Ferreira de Souza, Pamela Gracioli Vilas Boas, Diego Pierotti Procópio

COMPACTAÇÃO DE PRÉ-ESTÔMAGOS EM BOVINOS DECORRENTE DA INGESTÃO DE PANICUM MAXIMUM CV. MOMBAÇA

Weyber Ferreira de Souza, Aline de Jesus da Silva, Pamela Gracioli Vilas Boas, Rones Goulart de Paula Júnior, Carlos Eduardo Pereira dos Santos

AVALIAÇÃO DA SUPLEMENTAÇÃO MINERAL E VITAMÍNICA INJETÁVEL (KIT ADAPTADOR® MIN E VIT, BIOGÉNESIS BAGÓ) NA MELHORIA DO DESEMPENHO EM CONFINAMENTOS DE BOVINOS DE CORTE

Milton Maturana Filho, João Paulo Lollato, Reuel Luis Gonçalves, Bruno Di Rienzo, Ed Hoffmann Madureira, Guilhermo Mattioli, Juan Rodriguez Pérsico 
AVALIAÇÃO DA UTILIZAÇÃO DE DOIS SUPLEMENTADOS INJETÁVEIS PARA MELHORIA DE DESEMPENHO GARROTES EM CONFINAMENTOS

Milton Maturana Filho, João Paulo Lollato, Reuel Luis Gonçalves, Bruno Di Rienzo, Elias José Oliveira Da, Guilhermo Mattioli, Juan Rodriguez Pérsico

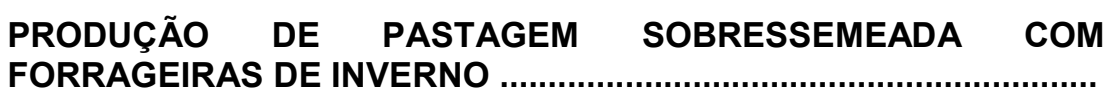

Danilo Silva Amaral, Cíntia Cármen de Faria Melo, Luís César Dias Drumond, Filipe Henrique Gentil

MACIEZ DE TRÊS CORTES COMERCIAIS DE NOVILHOS EM CRESCIMENTO COM DIFERENTES NÍVEIS DE DESEMPENHO ........

Mariana Teixeira Santana, Patrícia Siqueira Leite, Mauricio Miguel Estrada, Luiz Henrique Pereira Silva, Débora E. de Freitas Assis, Pedro Veiga Rodrigues Paulino, Mário Luiz Chizzotti 


\title{
ANÁLISE ECONÔMICA EM SISTEMAS SILVIPASTORIS DE TOURINHOS EM RECRIA NA REGIÃO PRÉ-AMAZÔNICA
}

\author{
Adailton Camêlo Costa ${ }^{1}$, Ricardo Alves de Araújo ${ }^{2}$, Rosane Cláudia \\ Rodrigues $^{3}$, Clésio dos Santos Costa ${ }^{2}$, Francisco Naysson de Sousa \\ Santos ${ }^{4}$, Luiza de Nazaré Carneiro da Silva ${ }^{5}$, Ivone Rodrigues da Silva ${ }^{6}$ \\ ${ }^{1}$ Mestrando em Zootecnia, Universidade Federal de Viçosa. E-mail: adailton07nr@hotmail.com; \\ ${ }^{2}$ Doutorando do Programa de Doutorado Integrado em Zootecnia UFC/UFRPE/UFPB, Departamento \\ de Zootecnia, Campus do Pici - Fortaleza, Ceará. Bolsistas Capes/Embrapa; ${ }^{3}$ Docente da \\ Universidade Federal do Maranhão-UFMA. Campus IV-Chapadinha, Maranhão-Brasil; ${ }^{4}$ Doutorando \\ do Programa de Doutorado Integrado em Zootecnia UFPB/UFC/UFRPE/, Departamento de Zootecnia, \\ Campus de Areia - Areia, Paraíba. Bolsista Capes; ${ }^{5}$ Mestrando do Programa de Pós-graduação em \\ Zootecnia da Universidade Estadual Vale do Acaraú, campus Betânia - Sobral, Ceará-Brasil; \\ ${ }^{6}$ Doutorando do Programa de Doutorado em Ciência Animal da Universidade Federal do Piauí, \\ Departamento de Zootecnia, Campus do Socopo - Teresina, Piauí. Bolsista Capes.
}

A utilização de sistemas silvipastoris (SSP's) pode melhorar a produção animal tanto do ponto de vista produtivo quanto do econômico, pois há a possibilidade de uma renda extra, proveniente da mesma área ou até mesmo devido o maior desempenho dos animais, e consequentemente maior retorno econômico à propriedade. Apesar dos SSP's já serem utilizados em pequena escala por produtores inovadores, eles carecem de uma base científica que suporte seu uso mais amplo e que justifiquem sua viabilidade econômica. Diante do exposto, objetivou-se avaliar a viabilidade econômica da recria de bovinos em sistemas silvipastoris compostos por diferentes densidades de palmeiras de babaçu. $O$ experimento foi conduzido na Fazenda Água-Viva, no município de Matinha-MA, Região Pré-Amazônica Maranhense. A espécie forrageira utilizada foi a Urochloa brizantha cv. Marandu e a espécie arbórea a palmeira de babaçu Attalea speciosa Martius que já se encontravam estabelecidas na propriedade. Foram utilizados 40 bovinos mestiços de Nelore x Guzerá em quatro sistemas, sendo: monocultura e três densidades de palmeiras de babaçu mais capimMarandu, 0, 80, 131, 160 palmeiras ha he $^{-1}$ caracterizando monocultura (MC), baixa densidade (BD), média densidade (MD) e alta densidade de palmeiras (AD), respectivamente. De posse dos 
custos de cada sistema, foram analisados os indicadores técnicos, zootécnicos e econômicos utilizando-se planilhas do Programa Excel $\circledR^{\circ}$. Considerando o preço da arroba em 2017 os animais da AD começaram mais valorizados, porém ao longo do período esse sistema teve os animais menos valorizados ( $R \$ 1.096,84)$. Ao final do período de avaliação os animais mantidos na BD foram os mais valorizados. A expressão dos resultados econômicos pela rentabilidade anual permite avaliar o retorno financeiro da operação em relação ao capital investido. Considerou-se que o investimento com cercas e mão-de-obra e manutenção anual foi igual para todos os ambientes. Percebe-se que dos quatro sistemas avaliados, somente o BD apresentou uma receita por hectare maior ( $R \$$ $2.550,68)$ que os custos ( $R \$ 2.078,98)$, tornando assim o único sistema lucrativo ( $R \$ 471,70)$, porém sem levar em conta o custo de oportunidade da terra. O custo total anual nos sistemas de MC, MD e $A D$ superou as receitas, de maneira que no balanço entre esses componentes houve prejuízo de $\mathrm{R} \$ 382,08 ; \mathrm{R} \$ 235,44$ e $\mathrm{R} \$ 313,92$ por hectare ano-1, respectivamente. Em uma simulação para cinco anos, o Valor Presente Líquido para a taxa de desconto de $12 \%$ a.a. utilizada neste estudo, e obtido para todos os sistemas avaliados, foi positivo. Todos os sistemas apresentaram um valor de Taxa Interna de Retorno superior a $12 \%$. O sistema de BD apresentou melhor resultado comparativamente aos demais. Todos os sistemas analisados tiveram a relação Benefício/custo maior que um, ou seja, todos são viáveis economicamente. O sistema de BD foi bastante atrativo como alternativa de investimento lucrativo, os outros sistemas mostraram ser inviáveis economicamente durante o primeiro ano avaliado.

PALAVRAS-CHAVE: bovinos; babaçu; custos.

AGRADECIMENTOS: À Fundação de Amparo à Pesquisa e ao Desenvolvimento Científico e Tecnológico do Maranhão - FAPEMA e ao Grupo de Estudo e Pesquisa e Extensão FOPAMA. 


\title{
VIABILIDADE ECONÔMICA DA RECRIA DE TOURINHOS SUPLEMENTADOS COM FARELO DE BABAÇU EM SISTEMAS SILVIPASTORIS NA AMAZÔNIA ORIENTAL
}

\author{
Adailton Camêlo Costa ${ }^{1}$, Ricardo Alves de Araújo ${ }^{2}$, Rosane Cláudia \\ Rodrigues $^{3}$, Clésio dos Santos Costa ${ }^{2}$, Francisco Naysson de Sousa \\ Santos ${ }^{4}$, Luiza de Nazaré Carneiro da Silva ${ }^{5}$, Ivone Rodrigues da Silva ${ }^{6}$ \\ ${ }^{1}$ Mestrando em Zootecnia, Universidade Federal de Viçosa. E-mail: adailton07nr@hotmail.com; \\ ${ }^{2}$ Doutorando do Programa de Doutorado Integrado em Zootecnia UFC/UFRPE/UFPB, Departamento de \\ Zootecnia, Campus do Pici - Fortaleza, Ceará. Bolsistas Capes/Embrapa; ${ }^{3}$ Docente da Universidade \\ Federal do Maranhão-UFMA. Campus IV-Chapadinha, Maranhão-Brasil; ${ }^{4}$ Doutorando do Programa de \\ Doutorado Integrado em Zootecnia UFPB/UFC/UFRPE/, Departamento de Zootecnia, Campus de Areia - \\ Areia, Paraíba. Bolsista Capes; ${ }^{5}$ Mestrando do Programa de Pós-graduação em Zootecnia da \\ Universidade Estadual Vale do Acaraú, campus Betânia - Sobral, Ceará-Brasil; ${ }^{6}$ Doutorando do \\ Programa de Doutorado em Ciência Animal da Universidade Federal do Piauí, Departamento de \\ Zootecnia, Campus do Socopo - Teresina, Piauí. Bolsista Capes.
}

O Brasil é considerado um dos maiores produtores de bovinos de corte do mundo. A produção de carne garante atualmente um consumo interno crescente e excedente exportável suficiente para garantir o país na liderança da exportação de carne bovina em relação ao resto do mundo. A melhora do sistema, quando se utiliza os sistemas silvipastoris, pode ser tanto do ponto de vista produtivo quanto do econômico, pois há a possibilidade de uma renda extra proveniente da mesma área ou até mesmo devido o maior desempenho dos animais, e consequentemente maior retorno econômico a propriedade. Diante do exposto e considerando a importância de um levantamento econômico em uma propriedade de gado de corte, este trabalho foi desenvolvido com o objetivo de avaliar a viabilidade econômica na recria de tourinhos em diferentes sistemas silvipastoris de capim-Marandu suplementados com farelo de babaçu em substituição ao farelo de soja. O experimento foi conduzido na Fazenda Água-Viva, no município de Matinha-MA, Região Pré-amazônica Maranhense. A espécie forrageira utilizada foi a Urochloa brizantha cv. Marandu e a espécie arbórea a palmeira de babaçu Attalea speciosa Martius que já se encontravam estabelecidas na propriedade. Os animais 
foram avaliados em três sistemas silvipastoris com diferentes densidades de palmeira de babaçu: 39, 72 e 92 palmeiras ha-1 e três teores de farelo de babaçu (FBa) em substituição ao farelo de soja, que corresponderam a: 10, 20 e 30\%, com base na matéria seca respectivamente. Utilizaram-se 27 animais machos, mestiços (Nelore x Guzerá), inteiros com aproximadamente 10 meses de idade e peso inicial de $219,2 \mathrm{~kg}$. Observou-se que em todos os sistemas os ganhos médios diários ficaram acima de $500 \mathrm{~g}$, exceto os animais criados no sistema de 39 palmeiras ha- 1 e que receberam a dieta com $10 \%$ de farelo de babaçu. Para animais suplementados a pastos, como os observados neste trabalho, permitiriam desenvolvimento ponderal razoável para novilhos mestiços em fase de recria, porém, esses valores ainda são baixos para animais que recebem uma suplementação. Percebe-se que dos nove sistemas avaliados, todos apresentaram uma receita por hectare maior que os custos, tornando assim todos os sistemas avaliados lucrativos. Vale salientar que apesar dos nove sistemas serem lucrativos não podem ser considerados $100 \%$ eficientes, até mesmo por que o período de avaliação foi somente de seis meses, então os gastos com implantação dos sistemas não haviam sido diluídos ainda, e para que isso aconteça há a necessidade de um maior tempo de avaliação. O sistema com 72 palmeiras ha-1 e $30 \%$ do farelo de babaçu em substituição ao farelo soja foi bastante atrativo como alternativa de investimento lucrativo, sendo que os outros sistemas mostraram ser viáveis economicamente durante 0 período de avaliação, porém com menor lucratividade.

PALAVRAS-CHAVE: árvore; integração; suplementação. 


\title{
EFFECTS OF SUPPLEMENTATION STRATEGIES IN FEMALE CALVES UNDER GRAZING IN THE TROPICS ON NUTRIENTS INTAKE, DIGESTIBILITY, AND EFFICIENCY OF MICROBIAL PROTEIN SYNTHESIS
}

\author{
Ághata Elins Moreira da Silva ${ }^{1}$, Román Enrique Maza Ortega ${ }^{2}$, Deilen Paff \\ Sotelo Moreno ${ }^{2}$, Vinicius Augusto Vieira Pereira ${ }^{3}$, Edson Júnior dos \\ Santos $^{3}$, Anna Flávia Rodrigues da Silva ${ }^{3}$, Mario Fonseca Paulino ${ }^{4}$ \\ ${ }^{1}$ Mestranda, UFV; ${ }^{2}$ Doutorando, UFV; ${ }^{3}$ Graduando, UFV; ${ }^{4}$ Professor Titular, UFV
}

During the suckling stage, beef calves under grazing meet their nutritional requirements through nutrients originating maternal milk and the pasture. However, it is observed that after 65-90 days of age, the growth rate of calves may be limited by the milk production of their dams and by the amount of energy and protein in the maternal milk. Besides, tropical grasses, the basal feed source for cattle in the tropics, have several nutrient deficiencies which may restrict pasture intake, digestibility of the forage and metabolic efficiency. As a consequence, the animal may not be able to attain an optimal weight gain rates, and so supplemental nutrients may be needed. Thus, the objective of this study was to evaluate the effects of supplement amounts on intake, digestibility, and efficiency of microbial protein synthesis of female calves under grazing in the tropics. This experiment was carried out at the Department of Animal Science of the Universidade Federal de Viçosa, Viçosa, Minas Gerais, Brazil, between January and June 2015. Forty Nellore female calves with $127.3 \pm 2.7 \mathrm{~kg}$ average body weight (BW) and $3.5 \pm 0.1 \mathrm{~m}$ old and their dams were allocated in paddocks of 15 hectares each. The cow-calf were distributed in a completely randomized design with two treatments and twenty replicates. The treatments were 1) $4 \mathrm{~g} / \mathrm{kg} \mathrm{BW}$ of supplement or 2) 6 $\mathrm{g} / \mathrm{kg}$ BW of supplement. Supplement was composed of corn meal, soybean meal, molasses and mineral mix and formulated to contain $30 \%$ crude protein as fed. The experiment lasted $150 \mathrm{~d}$, with a $14 \mathrm{~d}$ 
period of adaptation. A nine-day trial was carried out the 75 days of experiment to evaluate the intake and digestibility of the animals. To evaluate the microbial protein production and urine urea nitrogen excretion, spot urine samples were collected on the last day of the trial. The dams were milked on days 25, 75, and 125 of experiment to estimate the quantity and composition of daily milk intake by the calves. All statistical procedures were conducted using the MIXED procedure of SAS 9.4. Statistical significance was considered at $P<0.05$, and trends were considered at $0.05<P>0.10$. Forage and organic matter $(\mathrm{OM})$ intake did not affect $(P>0.12)$ by amounts of supplement, though crude protein $(\mathrm{CP})$ and non-fibrous carbohydrates intake were greater $(P<0.04)$ by increasing supplement amount. There was no effect $(P>0.23)$ the amounts of supplement on $\mathrm{OM}$ and $\mathrm{CP}$ digestibility. In addition, production of microbial nitrogen was similar $(P>0.15)$ between treatments, however, the excretion of urea nitrogen in the urine was greater by increasing supplement amount. Additionally, the amounts of supplement used did not affect the milk yield of cows. Thus, increasing supplement amounts on creep-feeding system, does not improve nutritional performance in suckling female calves under grazing in the tropics.

PALAVRAS-CHAVE: beef cattle; nutrition; protein.

AGRADECIMENTOS: UFV, FAPEMIG. 


\title{
EFFECTS OF SUPPLEMENTATION STRATEGIES IN FEMALE CALVES UNDER GRAZING IN THE TROPICS ON PRODUCTIVE PERFORMANCE AND CARCASS CHARACTERISTICS
}

\author{
Ághata Elins Moreira da Silva ${ }^{1}$, Román Enrique Maza Ortega ${ }^{2}$,Thiago \\ Ramalho Moreira ${ }^{3}$, Ícaro Artuso Lage $^{3}$, Jefferson Bello dos Santos ${ }^{3}$, Yuri \\ Rodrigues Rezende ${ }^{3}$, Mario Fonseca Paulino ${ }^{4}$ \\ ${ }^{1}$ Mestranda, UFV; ${ }^{2}$ Doutorando, UFV; ${ }^{3}$ Graduando, UFV; ${ }^{4}$ Professor Titular, UFV
}

Studies in not tropical conditions have shown that suckling heifers fed diets with larger amounts of supplement and protein have higher daily gain rates and, reach puberty earlier. Similarly, several studies in tropical condition on creep-feeding have consistently shown an increase in the weaning weight of calves. However, questions remain about the optimal point among the amounts of supplements that are used, which may influence the biological response of beef female calves and provide better development in the post-weaning period under grazing in the tropics that are subjected to different supplementation strategies. Thus, the objective of this study was to evaluate the effects of supplement amounts on productive performance and carcass characteristics of female calves under grazing in the tropics. The experiment was carried out at the Department of Animal Science of the Universidade Federal de Viçosa, Viçosa, Minas Gerais, Brazil, between January and June 2015. Forty female calves (averaging $3.5 \pm 0.06$ months and $127.3 \pm 2.68 \mathrm{~kg}$ ), and their respective dams were distributed in a completely randomized design with two treatments and twenty replicates. The treatments were 1) $4 \mathrm{~g} / \mathrm{kg}$ body weight (BW) of supplement or 2) $6 \mathrm{~g} / \mathrm{kg} \mathrm{BW}$ of supplement. Supplement was composed of corn meal, soybean meal, molasses and mineral mix and formulated to contain $30 \%$ crude protein as fed. The experiment lasted $150 \mathrm{~d}$, with a $14 \mathrm{~d}$ period of adaptation. For performance evaluation, the animals were weighed at the beginning and end of the experiment after $14 \mathrm{~h}$ of fasting. At the end of the experiment, body measures were taken to evaluate the body growth of the 
animals (rump width, rump length, rib depth, body length, height at withers, and heart girth). In parallel, carcass characteristics were evaluated by ultrasound. Carcass images were obtained between the 12th and 13th ribs over the longissimus muscle to measures the longissimus dorsi muscle area and fat thickness over the longissimus muscle and, between the ischium and pubis to measures the fat thickness over the rump. All statistical procedures were conducted using the MIXED procedure of SAS 9.4. Statistical significance was considered at $\mathrm{P}<0.05$, and trends were considered at $0.05<P>0.10$. Mean daily gain, longissimus dorsi area, fat thickness over rump of the animals did not affect $(P>0.26)$ by amounts of supplement. However, there was trend of increasing $(P=0.074)$ in fat thickness over loin by increase the supplement amount. Although the body growth of animals was similar $(P>0.18)$ between treatments, there was observed a trend of increase $(P=0.064)$ in ratio BW:Height at the withers by increasing supplement amounts. Thus, increasing supplement amounts on creep-feeding system, does not improve productive performance and carcass characteristics in suckling female calves under grazing in the tropics.

PALAVRAS-CHAVE: body measures; development; protein.

AGRADECIMENTOS: UFV, FAPEMIG. 


\title{
CONSUMO E DIGESTIBILIDADE DE NUTRIENTES DE NOVILHOS MANTIDOS A PASTO E SUPLEMENTADOS COM DIFERENTES FONTES DE NITROGÊNIO NÃO PROTEICO
}

\author{
Alberto Jefferson da Silva Macêdo ${ }^{1}$, Rafael Henrique de Tonissi e \\ Buschinelli de Goes², Jefferson Rodrigues Gandra², Charles Jhonnatan \\ dos Santos Souza², Thaiano Iranildo de Sousa Silva ${ }^{2}$, Nayara Gonçalves \\ da Silva ${ }^{2}$, Wagner Sousa Alves ${ }^{1}$ \\ ${ }^{1}$ Universidade Federal de Viçosa, Viçosa, MG, Brasil; ${ }^{2}$ Universidade Federal da Grande Dourados, MS, \\ Brasil
}

A utilização da suplementação proteica utilizando-se fontes de nitrogênio não proteico (NNP) melhora a utilização do pasto. O fornecimento de fontes de nitrogênio ao animal supre as exigências dos microrganismos ruminais principalmente os celulolíticos. Objetivou-se avaliar o efeito da suplementação proteica, utilizando dois tipos de fontes de NNP sobre o consumo e digestibilidade aparente de nutrientes de novilhos mantidos em pasto de $B$. brizantha cv. Marandu. Foram utilizados três novilhos mestiços dotados de cânula ruminal, mantidos em pastagem de capim Marandu durante 72 dias, dispostos em delineamento quadrado latino $(3 \times 3)$. Os tratamentos consistiam no fornecimento de suplementação proteica com $38 \%$ de proteína bruta, alterando-se a fonte de NNP: UC (concentrado $+9 \%$ de ureia convencional), UP (concentrado $+11 \%$ de ureia protegida) e tratamento controle com suplementação mineral (SM). Todos os animais receberam diariamente $20 \mathrm{~g}$ de enzima fibrolítica (Fibrozyme ${ }^{\mathrm{TM}}$ ) diretamente no rúmen. A estimativa de consumo e excreção de matéria seca foi realizado com o uso de indicadores interno (FDNi) e externo (TiO2). Os coeficientes de digestibilidade aparente dos nutrientes, foram obtidos pela relação entre o total de nutrientes absorvidos e a excreção fecal dos mesmos. Os dados foram submetidos para análise de variância e comparados por contrastes ortogonais $\mathrm{C} 1$ : SM vs. UC+UP e C2: UC vs. UP a $5 \%$ de probabilidade. Verificouse que o consumo de forragem expresso em $\mathrm{kg} / \mathrm{dia}$ foi maior para 
UP $(6,41 \mathrm{~kg})$, quando comparado com UC $(4,28 \mathrm{~kg})(\mathrm{C} 2, \mathrm{P}=0,027)$ porém o consumo dos animais suplementados com ureia não diferiu do tratamento $S M(C 1, P=0,457)$. O consumo de suplemento expresso em g/dia foi menor para o SM $(0,10 \mathrm{~g} / \mathrm{dia})(\mathrm{C} 1, \mathrm{P}=0,007)$ e não diferiu entre UC vs. UP $(C 2, P=0,847)$. $O$ consumo total de forragem+suplemento expresso em $\mathrm{kg} / \mathrm{dia}$ foi maior para UP (C2, $P=0,043)$ e não diferiu do $S M$ vs. UC+UP $(C 1, P=0,449)$. $O$ consumo de proteína bruta foi maior para UP $(C 2, P=0,044)$ e menor para $S M(C 1, P=0,004)$. O consumo de FDN foi maior para UP (C2, $P=0,035)$ e não diferiu do $S M$ vs. UC+UP ( $C 1, P=0,349)$. $\mathrm{O}$ consumo de matéria orgânica foi maior para UP $(C 2, P=0,023)$ e não diferiu do SM vs. UC+UP (C1, $P=0,627)$. Para o coeficiente de digestibilidade, verificou-se que a matéria seca apresentou maior coeficiente de digestibilidade para UP $(C 2, \mathrm{P}=0,002)$ com valor de $61,43 \%$ e menor para SM (C1, P=0,004) com valor de $44,08 \%$. A proteína bruta das dietas apresentou maior coeficiente de digestibilidade para UP (C2, $P=0,021)$, com valor de $64,44 \%$ e menor para SM $(C 1, P=0,008)$ com valor de $47,55 \%$. Não houve diferença entre o coeficiente de digestibilidade da FDN para UP e UC (C2, P=0,880) com valor médio de $56 \%$ e houve menor digestibilidade da FDN para SM $(C 1, P=0,005)$ com valor de $47,24 \%$. A matéria orgânica apresentou maior coeficiente de digestibilidade para UP (C2, $\mathrm{P}=0,004)$ com valor de $62,38 \%$ e menor para o controle, SM vs. UC+UP (C1, $\mathrm{P}=0,002)$, com valor de $48,81 \%$. A utilização de ureia protegida potencializou a ingestão de forragem e melhorou a digestibilidade dos componentes nutricionais da dieta, logo, indica-se a substituição da ureia convencional por ureia protegida na constituição de suplemento proteico para novilhos em pastejo.

PALAVRAS-CHAVE: Brachiaria brizantha; bovino de corte; suplementação.

AGRADECIMENTOS: Grupo de Estudos em Nutrição e Produção de Ruminantes - NERU, UFGD, CAPES. 


\title{
ESTIMATIVA DA EXCREÇÃO DE DERIVADOS DE PURINA DE NOVILHOS A PASTO E SUPLEMENTADOS COM DIFERENTES FONTES DE NITROGÊNIO NÃO PROTEICO
}

\author{
Alberto Jefferson da Silva Macêdo ${ }^{1}$, Rafael Henrique de Tonissi e Buschinelli \\ de Goes ${ }^{2}$, Jefferson Rodrigues Gandra ${ }^{2}$, Rodrigo Augusto Gressler ${ }^{2}$, Thaiano \\ Iranildo de Sousa Silva ${ }^{2}$, Hulle Lívia Costa Brito ${ }^{2}$, Wagner Sousa Alves ${ }^{1}$ \\ ${ }^{1}$ Universidade Federal de Viçosa, Viçosa, MG, Brasil; ${ }^{2}$ Universidade Federal da Grande Dourados, \\ MS, Brasil
}

Para melhor aproveitamento de frações fibrosas de volumoso os animais ruminantes devem ser suplementados com fonte de nitrogênio não proteico (NNP). Objetivou-se avaliar o efeito da suplementação proteica, utilizando dois tipos de fontes de NNP sobre a estimativa da excreção de derivados de purina de novilhos mantidos em pasto de B. brizantha cv. Marandu. Foram utilizados três novilhos mestiços dotados de cânula ruminal, mantidos em pastagem capim Marandu durante 72 dias, dispostos em delineamento quadrado latino $(3 \times 3)$. Os tratamentos consistiam no fornecimento de suplementação proteica com $38 \%$ de proteína bruta, alterando-se a fonte de NNP: UC (concentrado $+9 \%$ de ureia convencional) e UP (concentrado $+11 \%$ de ureia protegida); e como tratamento controle foi usado a suplementação mineral (SM). Todos os animais receberam diariamente $20 \mathrm{~g}$ de enzima fibrolítica (Fibrozyme ${ }^{\mathrm{TM}}$ ) diretamente no rúmen. Coletou-se urina na forma spot, quatro horas após fornecimento dos suplementos, o material foi armazenado em duas alíquotas diluídas em ácido sulfúrico para estimativa de creatinina, ácido úrico, alantoína, purinas absorvidas, nitrogênio microbiano, proteína bruta microbiana e concentração de nitrogênio total urinário. Os dados foram submetidos para análise de variância e comparadas por contraste ortogonal, C1: SM vs. UC+UP e C2: UC vs. UP a $5 \%$ de probabilidade. Verificou-se que para a concentração de alantoína em $\mathrm{mmol} / \mathrm{L}$ não houve efeito $(\mathrm{C} 1$, $\mathrm{P}=0,437$ e $\mathrm{C} 2, \mathrm{P}=0,623)$ entre os dois contrastes avaliados, apresentando valores médios de 2,34, 2,30 e 2,30 mmol/L, SM, UC 
e UP, respectivamente. Para ácido úrico houve maior concentração para UP $1,84 \mathrm{mmol} / \mathrm{L}(C 2, P=0,007)$ e menor concentração para $\mathrm{SM} 0,72 \mathrm{mmol} / \mathrm{L}(\mathrm{C} 1, \mathrm{P}=0,005)$. Para o somatório alantoína+ácido úrico houve maior concentração total para UP $4,19 \mathrm{mmol} / \mathrm{L}$ (C2, $\mathrm{P}=0,042)$ e menor concentração total para $\mathrm{SM} 3,03 \mathrm{mmol} / \mathrm{L}(\mathrm{C} 1$, $P=0,019)$. Em relação a excreção de alantoína expressa em $\mathrm{mmol} / \mathrm{dia}$, houve maior excreção para UP $40,55 \mathrm{mmol} / \mathrm{dia}$ (C2, $\mathrm{P}=0,045)$ e menor concentração para $\mathrm{SM} 32,30 \mathrm{mmol} / \mathrm{dia}(\mathrm{C} 1$, $\mathrm{P}=0,014)$. Para ácido úrico expresso em $\mathrm{mmol} / \mathrm{dia}$, houve menor excreção para SM de $9,88 \mathrm{mmol} / \mathrm{dia}(\mathrm{C} 1, \mathrm{P}=0,002)$ e não diferiu $(C 2, P=0,235)$ entre UC e UP com valor médio de $25,23 \mathrm{mmol} / \mathrm{dia}$. Verificou-se maior excreção sobre o total, alantoína+ácido úrico expresso em mmol/dia, sendo maior para UP $69,40 \mathrm{mmol} / \mathrm{dia}$ (C2, $\mathrm{P}=0,013)$ e menor para $\mathrm{SM} 42,18 \mathrm{mmol} / \mathrm{dia}(\mathrm{C} 1, \mathrm{P}=0,007$ ). Verificou-se menor excreção de purinas absorvidas para SM 30,18 $\mathrm{mmol} / \mathrm{dia}(C 1, P=0,014)$ e não houve diferença $(C 2, P=0,302)$ entre UC e UP com valor médio de $54,88 \mathrm{mmol} / \mathrm{dia}$. Para o nitrogênio microbiano expresso em g/dia, verificou-se menor excreção para SM 21,94 g/dia (C1, $P=0,018)$ e não diferiu ( $C 2, P=0,821)$ entre UC e UP, com valor médio de 39,90 g/dia. Verificou-se menor excreção para SM de proteína bruta microbiana $137,16 \mathrm{~g} / \mathrm{dia}(\mathrm{C} 1, \mathrm{P}=0,018)$ e não houve diferença $(C 2, P=0,821)$ entre $U C$ e UP, com valor médio de 249,42 g/dia. A utilização de ureia protegida potencializou a síntese de proteína bruta microbiana, logo, indica-se a utilização da ureia protegida na constituição de suplemento proteico para novilhos em pastejo.

PALAVRAS-CHAVE: alantoína; ácido úrico; proteína microbiana.

AGRADECIMENTOS: Grupo de Estudos em Nutrição e Produção de Ruminantes - NERU, UFGD, CAPES. 


\title{
CONSUMO E DIGESTIBILIDADE EM BOVINOS ALIMENTADOS COM GRAMÍNEA TROPICAL E SUPLEMENTAÇÃO INFREQUENTE
}

\author{
Aline Maria Monteiro Canaan Garcia ${ }^{1}$, Malber Nathan Nobre Palma ${ }^{2}$, João \\ Vitor Ribeiro Lovatti ${ }^{1}$, Giselle Priscila Costa ${ }^{3}$, William Lima Santiago dos \\ Reis $^{2}$, Amanda de Souza Assunção ${ }^{2}$, Edenio Detmann ${ }^{4}$ \\ ${ }^{1}$ Aluno graduação Universidade Federal de Viçosa; ${ }^{2}$ Doutorando Universidade Federal de Viçosa; \\ ${ }^{3}$ Mestranda Universidade Federal de Viçosa; ${ }^{4}$ Professor Universidade Federal de Viçosa.
}

Gramíneas tropicais não associadas a outras estratégias nutricionais, como a suplementação, podem não constituir uma dieta equilibrada à produção animal, havendo carências ou desequilíbrios múltiplos de componentes energéticos e protéicos, sendo a suplementação uma estratégia que permite supri-las. A suplementação infrequente consiste no fornecimento da mesma massa de suplementos ofertados aos animais suplementados diariamente, contudo, de forma acumulada em dias alternados, otimizando o uso da mão de obra e reduzindo os custos. Objetivouse avaliar os efeitos da suplementação infrequente com compostos nitrogenados isolados ou associadas ao amido sobre o consumo e a digestibilidade em bovinos alimentados com gramíneas tropicais. Foram utilizadas cinco novilhas Nelore, com peso corporal médio inicial de $332 \pm 20 \mathrm{~kg}$ fistuladas no rúmen e no abomaso alimentadas ad libitum com feno de Tifton (Cynodon ssp) com $77,7 \mathrm{~g}$ de proteína bruta $(\mathrm{PB}) / \mathrm{kg}$ de matéria seca, em um delineamento em quadrado latino $5 \times 5$. O experimento foi constituído de cinco períodos experimentais, com 27 dias de duração cada, sendo os primeiros 15 dias destinados à adaptação dos animais. Foram avaliados os seguintes tratamentos, com suplementação via rúmen: controle (somente forragem); $\mathrm{PI}$, suplementação infrequente com compostos nitrogenados a cada três dias com quantidade de $660 \mathrm{~g}$ de PB; PIEF, suplementação infrequente com compostos nitrogenados a cada três dias com quantidade de $660 \mathrm{~g}$ PB e suplementação diária de amido $440 \mathrm{~g} / \mathrm{dia}$; PIEl, suplementação infrequente com compostos nitrogenados e amido a cada três dias 
com a quantidade equivalente de $660 \mathrm{~g} / \mathrm{dia}$ de PB e $1320 \mathrm{~g} / \mathrm{dia}$ de amido e PIEI+1, suplementação infrequente com compostos nitrogenados a cada três dias com quantidade de $660 \mathrm{~g}$ PB e 1320 $\mathrm{g}$ de amido no dia seguinte da suplementação nitrogenada. Computou-se o consumo voluntário do $16^{\circ}$ ao $22^{\circ}$ dia de cada período e as sobras obtidas do $17^{\circ}$ ao $24^{\circ}$ dia. A excreção fecal foi avaliada por intermédio de coletas totais de fezes realizadas do $17^{\circ}$ ao $22^{\circ}$ dia de cada período experimental. Os procedimentos estatísticos foram conduzidos por intermédio do procedimento MIXED do SAS $(?=0,05)$. O consumo de PB e a relação PB:Matéria Orgânica Digerida (MOD) aumentou $(P<0,05)$ com o fornecimento de suplemento. O consumo de matéria seca (CMS) e a matéria seca da forragem (MSF) não foram afetados $(P>0,05)$ pela suplementação. Os coeficientes de digestibilidade da matéria orgânica (MO), fibra em detergente neutro corrigido para cinzas e proteína (FDNcp) e MOD não foram afetados pela suplementação $(P>0,05)$. Conclui-se que a suplementação infrequente de compostos nitrogenados associados ou não a amido em bovinos alimentados com gramíneas tropicais não afeta o consumo e a digestibilidade.

PALAVRAS-CHAVE: bovinos de corte; nitrogênio; amido. 


\title{
INTERAÇÕES ENTRE FORRAGEM E CONDIÇÃO DE INCUBAÇÃO SOBRE A DIGESTIBILIDADE in vitro UTILIZANDO FERMENTADORA ARTIFICIAL
}

\author{
Aline Maria Monteiro Canaan Garcia ${ }^{1}$, Larissa Frota Camacho², Tadeu \\ Eder Silva ${ }^{2}$ Malber Nathan Nobre Palma ${ }^{2}$, Aline Naime Rodrigues ${ }^{3}$, João \\ Vitor Ribeiro Lovatti ${ }^{1}$, Edenio Detmann ${ }^{4}$ \\ ${ }^{1}$ Aluno graduação Universidade Federal de Viçosa; ${ }^{2}$ Doutorando Universidade Federal de Viçosa: \\ ${ }^{3}$ Mestranda Universidade. Federal de Viçosa; ${ }^{4}$ Professor Universidade Federal de Viçosa.
}

A técnica de digestibilidade in vitro com uso de fermentadoras artificiais tem ganhado espaço na análise de alimentos, constituindo técnica simples, de baixo custo e alta capacidade operacional. Contudo, 0 uso de fermentadoras artificiais poderia ocasionar interações entre os alimentos incubados no mesmo jarro de fermentação, influenciando nas estimativas de digestibilidade. Objetivou-se estudar os efeitos da interação entre forragens com diferentes características e condição de incubação, sobre as estimativas de digestibilidade in vitro da matéria seca (DIVMS) e da fibra em detergente neutro (DIVFDN). Foram utilizadas como amostras de forragem cana-de-açúcar, silagem de milho e feno de capim Tifton 85, sendo as duas primeiras secas em estufa $\left(55^{\circ} \mathrm{C}\right)$. Após a secagem, todas as amostras foram processadas em moinho de facas com peneira de $1 \mathrm{~mm}$. Os tratamentos consistiram em duas condições de incubação, forragens incubadas isoladas e incubadas todas juntas. Para os ensaios de digestibilidade foi utilizada uma novilha fistulada no rúmen como doadora de inóculo ruminal e solução tampão de McDougall, sendo esta preparada $24 \mathrm{~h}$ antes de cada incubação e mantida em sala climatizada $\left(39^{\circ} \mathrm{C}\right)$. As amostras foram armazenadas em filter bags de tecido não-tecido e incubadas em fermentadora artificial por 48 horas. Após a incubação os filter bags foram lavados com água destilada quente e pesados para obtenção do resíduo aparentemente não digerido da MS. Em seguida foi realizada a avaliação da digestibilidade in vitro da FDN. Observouse efeito de interação entre alimento e condição de incubação 
$(P<0,05)$ para as estimativas de digestibilidade da MS e da FDN. Para as amostras de cana-de-açúcar as estimativas da DIVMS e DIVFDN foram incrementadas $(P<0,02)$, enquanto para a silagem de milho, ambas as estimativas apresentaram redução $(P<0,01)$ com a incubação em conjunto. As estimativas da DIVMS e DIVFDN do feno de Tifton não apresentaram alterações $(P>0,57)$. Concluise que forragens com diferentes características incubadas em conjunto utilizando fermentadoras artificiais propiciam a interação entre alimentos e condição de incubação, alterando as estimativas de DIVMS e DIVFDN.

PALAVRAS-CHAVE: análise de alimentos; digestibilidade da fibra; sistema in vitro. 


\section{QUAL CAPIM TEM MAIOR DEMANDA DE NITROGÊNIO EM MANUTENÇÃO: MULATO II OU DECUMBENS?}

Aline Muller Motta ${ }^{1}$, Luiz Jardel Müller Motta ${ }^{1}$, Victor Gustavo Valiati Dantas ${ }^{1}$, Joadil Gonçalves de Abreu², Carla Heloisa Avelino Cabral ${ }^{3}$, Carlos Eduardo Avelino Cabral ${ }^{3}$

${ }^{1}$ Aluno graduação da Universidade Federal de Mato Grosso (UFMT); ${ }^{2}$ Professor Associado II da Faculdade de Agronomia e Zootecnia da UFMT; ${ }^{3}$ Professor UFMT.

O lançamento de novos capins é importante para a bovinocultura de corte no Brasil, pois há predomínio na criação de animais em pastejo e existe uma diversidade de condições edafoclimáticas. É importante identificar a exigência nutricional de cada capim lançado no mercado, para que seja possível realizar um planejamento de adubação adequado. O capim mulato II (Urochloa hibrida cv. Mulato II) é um híbrido de três espécies forrageiras (Urochloa ruziziensis, $U$. decumbens e $U$. brizanta) que apresentam distinta exigência em fertilidade. Dessa maneira é necessário conhecer a exigência deste para realização da adubação adequada. O experimento foi realizado em casa de vegetação na Universidade Federal de Mato Grosso, campus Rondonópolis, em delineamento inteiramente casualizado, com dez tratamentos e quatro repetições, arranjados em esquema fatorial $2 \times 5$. Os fatores avaliados foram dois capins (U. decumbens cv. Basilisk e Urochloa hibrida cv. Mulato II) e cinco doses de nitrogênio $(0,100,200,300$ e $400 \mathrm{mg} \mathrm{dm}-3)$. Cada parcela foi constituída de um vaso com capacidade de $5 \mathrm{dm} 3$ contendo cinco plantas. Para implantação foi realizado a calagem, elevando a saturação por bases para $50 \%$, adubação fosfatada, potássica, com micronutrientes e enxofre de acordo com a exigência da forrageira. Quarenta dias após a implantação dos capins, realizouse o corte de uniformização e aplicação dos tratamentos. Foram realizados dois cortes avaliativos, com trinta dias de intervalo. Os dados foram submetidos à análise de regressão linear e quadrática. Em seguida, utilizou-se o teste de identidade de modelos para 
comparar as equações propostas. Em caso de diferença entre modelos, testou-se isoladamente o teste $F$ para interceptos e parâmetros das equações. Os capins Decumbens e Mulato II se diferenciaram em produtividade e valor nutritivo, pois todas as variáveis apresentaram modelos diferentes, exceto a proteína bruta nas lâminas foliares. Os capins apresentaram morfologias distintas em resposta à adubação nitrogenada, pois as equações de porcentagem de colmo+bainha e lâminas foliares apresentaram interceptos e parâmetros diferentes. Quanto ao número de perfilhos, massa seca da parte aérea, lâminas foliares, resíduo, proteína bruta e valor SPAD (Soil Plant Analysis Development), verificaram-se interceptos diferentes e parâmetros iguais, o que demonstra diferença entre as gramíneas em condições de ausência de adubação nitrogenada. Os interceptos do capim Mulato II foram menores que aqueles observados no capim Decumbens, o que demonstra maior restrição do híbrido diante da ausência de adubação, que é a condição de manejo que predomina no Brasil. Assim, em sistemas altamente extensivos, espera-se que em pastos de Mulato II o processo de degradação seja mais rápido e acentuado, comparativamente ao capim Decumbens. Dessa forma, os capins respondem de modo diferente à adubação nitrogenada, de modo o capim Mulato II é mais exigente em nitrogênio que o capim Decumbens.

PALAVRAS-CHAVE: adubação nitrogenada; Brachiaria hibrida; exigência em fertilidade. 


\title{
AVALIAÇÃO DA VARIABILIDADE ENTRE ANIMAIS EM ESTUDOS DE DEGRADAÇÃO IN SITU EM BOVINOS
}

\author{
Amanda de Souza Assunção ${ }^{1}$, Edenio Detmann², João Vitor Ribeiro \\ Lovatti ${ }^{3}$, Giselle Priscila Costa ${ }^{3}$, Ana Carolina Rodrigues ${ }^{3}$, Malber Nathan \\ Nobre Palma ${ }^{4}$, Larissa Frota Camacho Amorim ${ }^{4}$ \\ ${ }^{1}$ Mestrando em Zootecnia, Universidade Federal de Viçosa; ${ }^{2}$ Professor, Universidade Federal de \\ Viçosa; ${ }^{3}$ Graduando em Zootecnia, Universidade Federal de Viçosa; ${ }^{4}$ Doutorando em Zootecnia, \\ Universidade Federal de Viçosa.
}

A digestibilidade constitui a característica mais importante nas avaliações do valor nutritivo das forragens, sendo que para a quantificação dessa variável a técnica in situ é amplamente utilizada. Existem contradições nessa técnica no que diz respeito à interferência de características intrínsecas ao animal sobre degradação do alimento. Evidências apontam que existe influência do animal sobre parâmetros da degradação de alimentos obtidos in situ, o que indicaria que a avaliação do perfil de degradação in situ obtido com um único animal poderia levar a estimativas viesadas. Objetivou-se avaliar a variabilidade entre animais com relação à taxa de degradação $(\mathrm{kd})$ da fração insolúvel potencialmente degradável da MS, PB e FDN e estabelecer o número mínimo de animais para ensaios de degradação ruminal in situ com bovinos para alimentos produzidos em condições tropicais. Foram avaliadas três forragens e quatro concentrados, respectivamente: cana-de-açúcar in natura, silagem de milho, feno de capim Tifton 85, farelo de soja, milho grão, casca de soja e farelo de algodão. Foram utilizadas cinco novilhas Nelore, com peso corporal inicial médio de $328 \pm 9,8 \mathrm{~kg}$, fistuladas no rúmen, alimentadas ad libitum com dieta basal composta por feno de capim Tifton 85 e concentrado comercial, com relação volumoso:concentrado de 80:20 com base na MS. Foram conduzidas sequencialmente três baterias de incubação e em cada bateria todos os alimentos foram incubados em todos os animais. Os resíduos da incubação das amostras de forragem foram analisados quanto aos teores de MS 
e FDN e os resíduos de incubação das amostras de concentrado foram analisados quanto aos teores de MS e PB. Os perfis de degradação foram interpretados por modelos não lineares mistos, nos quais considerou-se a influência aleatória de animais sobre kd. Os modelos foram ajustados considerando-se todos os animais e todas as combinações possíveis dos animais experimentais em grupos de quatro, três e dois animais, buscando-se verificar qual o número mínimo de animais a serem utilizados para ensaios de incubação in situ. Os perfis foram comparados no tocante ao comportamento das estimativas de $\mathrm{kd}$, das variâncias entre animais sobre $k d$ e variância residual, utilizando-se como referência o ajustamento com todos os animais $(n=5)$. As análises estatísticas foram realizadas por intermédio do procedimento NLMIXED do SAS 9.4. A variação no número de animais não afetou drasticamente as estimativas médias das características avaliadas, porém o que se observou foi que com menor número de animais, ampliou-se a dispersão das estimativas, com a observação de valores com grande afastamento das estimativas médias considerando-se todas as possíveis combinações entre animais. A partir dos resultados, conclui-se que a utilização de no mínimo três animais é recomendada pela minimização do risco da influência de efeitos aleatórios extremos de animal sobre a taxa de degradação.

PALAVRAS-CHAVE: bovinos; degradação in situ; alimentos tropicais.

AGRADECIMENTOS: CNPq, INCT-Ciência Animal e FAPEMIG. 


\title{
INFLUÊNCIA DA ENSILAGEM DE GRÃOS REIDRATADOS E DO TEOR DE CONCENTRADO SOBRE O CONSUMO, DIGESTIBILIDADE RUMINAL, INTESTINAL E TOTAL DA MATÉRIA ORGÂNICA EM BOVINOS NELORE
}

\author{
Breno de Castro Silva1, Sebastião de Campos Valadares Filho², Marcos \\ Vinicius Carneiro Pacheco ${ }^{3}$, Letícia Artuzo Godoi ${ }^{3}$, Ana Clara Baião \\ Menezes $^{3}$, Edenio Detmann ${ }^{4}$, Pedro Veiga Rodrigues Paulino ${ }^{5}$ \\ ${ }^{1}$ Estudante de Doutorado em Zootecnia e-mail: breno.castro@ufv.br; ${ }^{2}$ Professor Titular do \\ Departamento de Zootecnia, DZO/UFV; ${ }^{3}$ Estudante de Doutorado em Zootecnia; ${ }^{4}$ Professor \\ Associado do Departamento de Zootecnia, DZO/UFV; ${ }^{5}$ Gerente Global de Tecnologia de Bovinos \\ de Corte da Cargill Nutrição Animal.
}

A pressão da comunidade pelo uso racional dos recursos naturais faz com que seja cada vez maior a busca por planos alimentares e/ou processamento dos grãos que possibilitem o aumento da eficiência de utilização dos nutrientes pelos animais. Porém, faz-se necessário o entendimento da interação entre o alimento e o animal com o intuito de maximizar a eficiência produtiva e reduzir os prejuízos ao meio ambiente. Neste contexto, objetivou-se avaliar o efeito da ensilagem dos grãos de milho ou sorgo reidratados e do teor de concentrado sobre o consumo, digestão ruminal, intestinal e total da matéria orgânica (MO) em bovinos Nelore. Foram utilizados 5 bovinos machos, não castrados, da raça Nelore com idade média de $8 \pm 1$ meses e peso corporal médio de $262 \pm 18 \mathrm{~kg}$, canulados no rúmen, distribuídos em delineamento experimental quadrado latino $5 \times 5$, com arranjo fatorial $2 \times 2+1$. Foram avaliadas cinco dietas experimentais, das quais, quatro foram compostas de $28,44 \%$ de silagem de milho, $60,83 \%$ de grãos de milho moído seco (MMS), sorgo moído seco (SMS), silagem de grãos de milho reidratados (SMR) ou silagem de grãos de sorgo reidratados (SSR) e 10,73\% de suplemento proteico mineral. Avaliou-se ainda, uma dieta com menor teor de concentrado (CTL) composta de $45 \%$ de silagem de milho, $44,27 \%$ de milho moído seco e $10,73 \%$ de suplemento proteico mineral. 
Cada um dos cinco períodos experimentais teve duração de 23 dias, sendo 14 para adaptação e 9 dias de coleta. Do $15^{\circ}$ ao $19^{\circ}$ foi realizada coleta total de fezes. Do $20^{\circ}$ ao $22^{\circ}$ dia foram realizadas oito coletas de digesta omasal com intervalo de 9 horas. $O$ fluxo de MO na digesta omasal foi estimado pelo sistema de indicador duplo. Os dados foram analisados pelo procedimento MIXED do SAS 9.4, sendo considerados $5 \%$ de probabilidade para ocorrência do erro tipo I e $10 \%$ para tendências. Houve tendência de redução $(\mathrm{P}=0,058)$ no consumo de $\mathrm{MO}$ para as dietas à base de silagens de grãos reidratados, quando comparadas às dietas contendo grãos secos. A digestão ruminal da $\mathrm{MO}$ foi menor $(\mathrm{P}<0,05)$ para dietas à base de silagens de grãos reidratados e também para dietas com menor teor de concentrado. Observou-se aumento $(P<0,05)$ da digestão intestinal da $\mathrm{MO}$ para dietas à base de milho em relação a dietas à base de sorgo e também para dietas à base de silagem de grãos reidratados. A digestibilidade aparente total da $\mathrm{MO}$ não foi afetada $(P>0,05)$ pelos fatores avaliados quando expressa em $\mathrm{kg} / \mathrm{dia}$, porém, houve aumento $(P<0,05)$ quando expressa em termos percentuais. Conclui-se que o processo de ensilagem de grãos reidratados promove a redução no consumo e digestão ruminal e aumento da digestão intestinal da $\mathrm{MO}$, não afetando as quantidades totais digeridas.

PALAVRAS-CHAVE: locais de digestão; milho; sorgo.

AGRADECIMENTOS: CNPq, INCT - CA, FAPEMIG e Cargill. 


\title{
INFLUÊNCIA DO TEOR DE CONCENTRADO E ENSILAGEM DE GRÃOS DE MILHO OU DE SORGO REIDRATADOS NAS CONCENTRAÇÕES DE ÁCIDOS GRAXOS VOLÁTEIS E GLICOSE SÉRICA EM BOVINOS NELORE
}

\author{
Bruno Corrêa Lage ${ }^{1}$, Sebastião de Campos Valadares Filho², Breno de \\ Castro Silva3, Marcos Vinicius Carneiro Pacheco ${ }^{3}$, Flávia Adriane de Sales \\ Silva $^{3}$, Herlon Menegueli Alhadas ${ }^{3}$, Érica Garcia Mafort ${ }^{4}$ \\ ${ }^{1}$ Estudante de Graduação em Zootecnia. e-mail: bruno.lage@ufv.br; ${ }^{2}$ Professor Titular do \\ Departamento de Zootecnia, DZO/UFV, Viçosa - MG, Brasil; ${ }^{3}$ Estudante de Doutorado em \\ Zootecnia; ${ }^{4}$ Estudante de Graduação em Medicina Veterinária.
}

O processamento dos grãos e variações nos teores de concentrado em dietas de bovinos são ferramentas nutricionais aplicadas na busca pelo aumento da eficiência de utilização dos nutrientes. Porém, faz-se necessário o entendimento de como tais mudanças na alimentação influenciam os parâmetros ruminais e séricos em bovinos. Sendo assim, objetivou-se avaliar o efeito do teor de concentrado na dieta e da ensilagem dos grãos de milho e sorgo reidratados sobre a concentração de glicose sérica e AGV no líquido ruminal em machos Nelore. Foram utilizados 5 bovinos machos da raça Nelore, não castrados, com idade de $8 \pm 1$ meses e peso corporal de $262 \pm 18 \mathrm{~kg}$, canulados no rúmen, distribuídos em delineamento experimental quadrado latino $5 \times 5$, sendo cinco dietas e cinco períodos, com arranjo fatorial $2 \times 2+1$. Foram utilizadas cinco dietas experimentais, das quais, quatro foram compostas de $28,44 \%$ de silagem de milho, $60,83 \%$ de grãos de milho moído seco (MMS), sorgo moído seco (SMS), silagem de grãos de milho reidratados (SMR) ou silagem de grãos de sorgo reidratados (SSR) e $10,73 \%$ de suplemento proteico mineral. Avaliou-se ainda uma dieta com menor teor de concentrado (CTL) composta de $45 \%$ de silagem de milho, $44,27 \%$ de milho moído seco e $10,73 \%$ de suplemento proteico mineral. Aproximadamente 60 dias antes do início do experimento, procedeu-se à reidratação e ensilagem dos grãos, que tiveram a matéria seca ajustada para 
aproximadamente 65\%. Cada um dos cinco períodos experimentais teve duração de 23 dias, sendo 14 para adaptação e 9 dias de coleta. No $23^{\circ}$ dia foram realizadas coletas de líquido ruminal em três horários: 1 hora antes da alimentação, 2 e 4 horas após o fornecimento das dietas, para avaliação das concentrações de AGV. No mesmo dia e horários, foram realizadas coletas de sangue, para análise das concentrações de glicose sérica. Os dados foram analisados pelo procedimento MIXED do SAS 9.4, sendo considerado $5 \%$ de probabilidade para ocorrência do erro tipo I e $10 \%$ para tendências. Houve efeito $(P<0,05)$ do tipo de grão sobre as concentrações totais de AGV (mmol/dL), sendo maiores valores observados para dietas contendo milho em relação aquelas contendo sorgo. A dieta com maior teor de concentrado e dietas à base de milho apresentaram maiores $(P<0,05)$ proporções molares de propionato e menores $(P<0,05)$ proporções de acetato e relação acetato:propionato. Houve tendência $(P<0,10)$ de aumento da glicose sérica para tipo de grãos, onde os maiores valores foram observados para dietas à base de milho quando comparadas àquelas contendo sorgo. Foi verificado também aumento $(P<0,05)$ nos níveis de glicose para as dietas à base de grãos reidratados, quando comparadas às dietas contendo grãos secos. Conclui-se que as concentrações dos principais $A G V$ no líquido ruminal são afetadas pelo tipo de grão e teor de concentrado na dieta. Além disso, dietas à base de milho e silagem de grãos reidratados aumentam os níveis de glicose sérica.

PALAVRAS-CHAVE: acetato; processamento; propionato.

AGRADECIMENTOS: CNPq, FAPEMIG, INCT - CA e Cargill. 


\title{
EFEITO DA SUPLEMENTAÇÃO DE PROGESTERONA DE LONGA AÇÃO EM VACAS SUBMETIDAS À TRANSFERÊNCIA DE EMBRIÃO
}

\author{
Bruno Silva do Espirito Santo1, Moacir Ferreira Duarte Júnior², Danilo \\ Francisco Campos Pereira ${ }^{3}$, Vinicius Borges Garcia ${ }^{4}$, Luciana Keiko \\ Hatamoto-Zervoudakis ${ }^{5}$, Luis Eduardo Senra e Silva ${ }^{5}$, Ana Maria Bueno \\ Barbosa dos Santos ${ }^{1}$ \\ ${ }^{1}$ Graduação em Medicina Veterinária/Universidade Federal de Mato Grosso, ${ }^{2}$ Doutor em Ciência Animal, \\ ${ }^{3}$ Pró-Embryo Consultoria em Reprodução Animal, ${ }^{4}$ Médico Veterinário Fazenda Ressaca - Cáceres/MT, \\ ${ }^{5}$ Programa de Pós-Graduação em Ciência Animal/Universidade Federal de Mato Grosso.
}

A manutenção da gestação é dependente da secreção de progesterona (P4) secretada pelo corpo lúteo (CL). Altas concentrações após a concepção aumentam a taxa de sobrevivência embrionária, por propiciar um melhor ambiente uterino, e a deficiência de P4 implica na perda gestacional. Por isso, a suplementação de $\mathrm{P} 4$, torna-se uma alternativa para minimizar essas perdas. Com isso, objetivou-se avaliar a ação de uma fonte exógena de P4 de longa ação no dia da transferência de embriões produzidos in vitro na taxa de concepção (TC). Foram utilizadas 292 vacas mestiças, criadas em pasto de capim Brachiaria brizantha cv. Marandú e suplemento mineral. Para sincronização das receptoras foi utilizado o protocolo: dia zero - dispositivo intravaginal de liberação lenta de P4 contendo $1,9 \mathrm{~g}(\mathrm{CIDR} \otimes)$ por 8 dias $+2,0 \mathrm{mg}$ de benzoato de estradiol por via intramuscular (IM) na retirada do dispositivo foi aplicado $0,15 \mathrm{mg}$ de D-Cloprostenol (Croniben $\AA$ ), $300 \mathrm{UI}$ de eCG (Novormon $\AA$ ) e $1 \mathrm{mg}$ de cipionato de estradiol (E.C.P.®) IM. Nove dias após a remoção do CIDR® foi realizada a inovulação dos embriões e as receptoras foram divididas em: grupo controle (GC, n=149 animais, $1 \mathrm{ml}$ de solução placebo, IM) e grupo progesterona (GP4 $\mathrm{n}=143$ animais, $1 \mathrm{ml}$ de P4 (Sincrogest $($ ), IM). O diagnóstico de gestação foi feito através de ultrassonografia transretal 50 dias após a transferência. As taxas de concepção foram calculadas em porcentagem e avaliadas no SAS (PROC Glimmix). A média do escore de condição corporal (ECC) dos animais do GC e GP4 foram de 2,72 e 2,75 
respectivamente. A administração de $\mathrm{P} 4$ injetável no dia da transferência de embrião não influenciou $(P>0,05)$ a taxa de concepção (35,57\%, 53/149 no GC e 45,45\%, 65/143 no GP4). Altas concentrações da P4 entre 3 à 7 dia após a ovulação proporcionam aumento significativo do tamanho do concepto, melhorando a receptividade materna. Embora não tenha sido encontrada diferença significativa, vale ressaltar que dentre os animais trabalhados, $68 \%$ foram de vacas multíparas, com maior probabilidade de estarem ciclando, dessa forma, pode não ter ocorrido o efeito da suplementação devido ao status reprodutivo desses animais. Além disso, os animais passaram por avaliação ultrassonográfica e apenas aqueles com presença de corpo lúteo satisfatório receberam o embrião, associado a isso os animais usados no experimento apresentavam ECC bom e provavelmente por isso, o uso de progesterona exógena não foi eficiente. Diante disso, pode-se concluir que o uso de progesterona injetável nas condições estudadas, não altera a taxa de concepção em vacas submetidas a transferência de embriões produzidos in vitro.

PALAVRAS-CHAVE: interferon-tau; corpo lúteo; concepto. 


\title{
INFLUÊNCIA DOS TEORES DE FIBRA FISICAMENTE EFETIVA PROVENIENTE DE VOLUMOSO EM DIETAS DE GRÃO INTEIRO
}

\author{
Caio William Magalhães Souza ${ }^{1}$, Herlon Maneguelli Alhadas ${ }^{2}$, Nathália \\ Veloso Trópia1, Pauliane Pucetti ${ }^{2}$, Marcos Vinicius Carneiro Pacheco², \\ Breno de Castro Silva ${ }^{2}$, Sebastião de Campos Valadares Filho ${ }^{3}$ \\ ${ }^{1}$ Estudante de Graduação em Zootecnia,DZO/UFV; ${ }^{2}$ Estudante pós de Graduação em \\ Zootecnia,DZO/UFV; ${ }^{3}$ Professor Titular do Departamento de Zootecnia, DZO/UFV, Viçosa - MG.
}

O uso de dietas de alto grão para bovinos de corte, como por exemplo, as dietas sem volumoso, pode resultar em desordens metabólicas, que comprometem o desempenho nutricional dos animais. Sendo assim, objetivou-se com o presente trabalho encontrar um nível de inclusão de fibra fisicamente efetiva (FDNfef) proveniente da cana-de-açúcar em dietas de grão inteiro de milho, que proporcione melhorias no consumo, digestibilidade e nas taxas de ingestão (Ki), de passagem $(\mathrm{Kp})$ e de digestão $(\mathrm{Kd})$ da matéria orgânica (MO). Foram utilizados cinco bovinos Nelore machos não castrados fistulados no rúmem ( $P C=393 \pm 9 \mathrm{Kg}$ ) distribuídos em um quadrado latino $5 \times 5$, os quais receberam as seguintes dietas: controle (CON), sem volumoso e com adição de $850 \mathrm{~g} / \mathrm{Kg}$ de milho grão inteiro e $150 \mathrm{~g} / \mathrm{Kg}$ de suplemento mineral proteico peletizado; e demais dietas com os níveis de 50 (D5), 150 (D15), 250 (D25) e 350 (D35) g/Kg de cana-de-açúcar em substituição ao pellet e/ou ao grão de milho com adição de um suplemento protéico mineral para balanceamento dos nutrientes. O teor de FDNfef proveniente de volumoso foi estimado com o auxílio do conjunto de peneiras Pen State Particle Separator. Para a medição do consumo foram pesadas diariamente o oferecido e as sobras. Foram realizados oito horários de coleta de digesta omasal, a intervalos de nove horas, para a determinação da digestibilidade ruminal, utilizando o sistema de indicador duplo (Co-EDTA e FDNi). A digestibilidade total foi estimada através da coleta spot de fezes em cada um dos horários descritos acima, usando a FDNi como indicador. Foi realizado esvaziamento ruminal antes e três horas após a alimentação em 
dias alternados para cálculo das taxas Ki, Kp e Kd. Foram testados através do $S A S \otimes$ (versão 9.4) os efeitos linear, quadrático e cúbico para os níveis de inclusão de FDNfef, sendo cada um destes comparados com o controle através do teste de Dunnett $(P<0,05)$. Os teores de FDNfef obtidos foram de 20,5, 61,4, 102,4 e 143,3 $\mathrm{g} / \mathrm{Kg}$, para as dietas D5, D15, D25 e D35, respectivamente. O consumo de matéria orgânica apresentou efeito linear decrescente $(P<0,05)$, quando expresso em porcentagem do peso corporal ou quadrático $(P=0,07)$, quando expresso em $\mathrm{Kg} / \mathrm{dia}$, com ponto de otimização na dieta D5. Uma diferença no consumo de $3,78 \mathrm{Kg}$ desta dieta para a CON foi observada. As digestibilidades ruminal e total também tiveram um ponto de otimização em D5, apresentando efeitos linear decrescente ou quadrático. Houve uma diferença de mais de $3 \mathrm{Kg} /$ dia de MO digerida ao longo de todo trato gastrointestinal, quando contrastadas as dietas D5 e CON. As taxas $\mathrm{Ki}, \mathrm{Kp}, \mathrm{Kd}$ também foram otimizadas com o menor nível de inclusão de FDNfef na dieta, corroborando com os dados de consumo e digestibilidade. Sendo assim, recomenda-se a inclusão de $20,47 \mathrm{~g} / \mathrm{Kg}$ de FDNfe de volumoso, correspondendo a $5 \%$ de cana-de-açúcar em dietas de grão de milho fornecido inteiro.

PALAVRAS-CHAVE: cana-de-açúcar; dieta de alto grão; nelore. 


\title{
ESTIMATIVA DO CONSUMO DE VOLUMOSO PELO FORNECIMENTO DE INDICADOR EM COCHO ELETRÔNICO
}

\author{
Camila Andressa Silva de Oliveira ${ }^{1}$, Adailton Camêlo Costa ${ }^{2}$, Sabrina de \\ Paula Baltazar ${ }^{3}$, Juarez Júnior da Silva Paiva ${ }^{3}$, Mauricio Miguel Estrada ${ }^{4}$, \\ Luciana Navajas Rennó ${ }^{5}$, Mario Luiz Chizzotti ${ }^{5}$ \\ ${ }^{1}$ Mestre em Zootecnia - UFV, Viçosa, Brasil; ${ }^{2}$ Mestrando em Zootecnia - UFV, Viçosa, Brasil; \\ ${ }^{3}$ Graduanda em Zootecnia- UFV, Viçosa, Brasil; ${ }^{4}$ Doutorando em Zootecnia- UFV, Viçosa, Brasil; \\ ${ }^{5}$ Professor Adjunto do Departamento de Zootecnia- UFV, Viçosa, Brasil.
}

A maior limitação dos modelos nutricionais para formulação de rações se concentra na inacurácia da predição do consumo de matéria seca, especialmente em pastejo, levando a uma busca contínua de procedimentos para obtenção de estimativas confiáveis. Neste sentido, objetivou-se avaliar a acurácia e a precisão da estimativa de consumo de volumoso mediante o fornecimento do indicador Óxido Crômico (Cr2O3) em cocho eletrônico e coleta total de fezes por 48 horas em bovinos confinados. Foram utilizadas 11 vacas de descarte Nelore, não gestantes e não lactantes, com idade superior a 48 meses e peso vivo médio de $413 \pm 53 \mathrm{~kg}$, alocadas em baias coletivas providas com dois cochos eletrônicos para volumoso, um cocho eletrônico para suplemento e um bebedouro. O estudo foi composto por dois períodos experimentais com vinte e um dias cada, sendo quatorze dias de monitoramento de consumo e sete dias de fornecimento de Cr2O3 misturado ao suplemento. A dieta consistiu de silagem de cana-de-açúcar ad libitum e suplemento múltiplo de consumo autorregulado para $1 \mathrm{~kg} / \mathrm{animal} / \mathrm{dia}$, contendo $10 \mathrm{~g}$ de $\mathrm{Cr} 2 \mathrm{O} 3 \mathrm{por}$ $\mathrm{kg}$ de suplemento nos últimos sete dias do período. Quarenta e oito horas antes do final de cada período experimental foi realizada coleta total de fezes, sendo que cada bolo fecal excretado foi recolhido diretamente do piso e individualmente pesado e amostrado, com registro da quantidade e do horário de defecação. Ao mesmo tempo, o consumo médio diário de suplemento e volumoso foi mensurado eletronicamente nos últimos cinco dias de 
coleta. A partir do consumo individual de suplemento e da concentração de $\mathrm{Cr} 2 \mathrm{O} 3$ nele, foi estimada a matéria seca fecal (MSF) através da concentração do indicador nas fezes. Também foi analisado o teor de fibra em detergente neutro indigestível (FDNi) nos alimentos e fezes, utilizado como indicador interno. A partir do cálculo da MSF excretada, determinou-se a excreção de FDNi total e, descontando a ingestão de FDNi do suplemento, foi calculado o consumo de FDNi oriundo do volumoso. Assim, com base na concentração de FDNi no volumoso, foi estimado o consumo de matéria seca de volumoso. Deste modo, o consumo de volumoso mensurado eletronicamente foi regredido no consumo estimado pelos indicadores, considerando a concentração média diária destes nas fezes coletadas durante 48 horas ininterruptas. Observou-se que o consumo médio de volumoso estimado por meio dos indicadores não diferiu do consumo médio mensurado eletronicamente, entretanto a precisão das estimativas foi moderada $\left(R^{2}<0,30\right)$, não sendo confiável para estimativas de consumo individual, mas adequado para estimar o consumo médio de um grupo de animais. Concluiu-se que o fornecimento de indicadores externos via suplemento de autocontrole de consumo em cocho eletrônico pode ser utilizado para estimar o consumo médio de matéria seca de volumoso em um grupo de bovinos, porém com moderada precisão para estimativas de consumo individual.

PALAVRAS-CHAVE: estimativa de consumo; óxido de cromo; cocho eletrônico.

AGRADECIMENTOS: CNPq. 


\title{
EFFECT OF SUPPLEMENTATION OF GRAZING BEEF HEIFERS AT PRE AND POST-WEANING PERIOD ON METABOLIC PROFILE AND OVARIAN ACTIVITY
}

\author{
Camila de Paula ${ }^{1}$, Román Enrique Maza Ortega ${ }^{2}$, Thiago Ramalho Moreira ${ }^{3}$, \\ Ícaro Artuso Lage ${ }^{3}$, Jefferson Bello dos Santos ${ }^{3}$, Yuri Rodrigues Rezende ${ }^{3}$, \\ Mario Fonseca Paulino ${ }^{4}$ \\ ${ }^{1}$ Mestranda, UFV; ${ }^{2}$ Doutorando, UFV; ${ }^{3}$ Graduando, UFV; ${ }^{4}$ Professor Titular, UFV.
}

Studies have shown different results when is the best time to increase growth and decrease the age to puberty in bovine females. Some authors have reported the occurrence of early puberty with increased rate of gain in early stages of development while others observed a reduction in age at puberty with higher weight gain post weaning. Thus, the supplementation of beef heifers in the preweaning and rearing periods under grazing and assess its carryover effect could contribute to optimizing growth rate and time to sexual maturity of animals. The objective of this study was to evaluate the effects of supplement amounts pre- and post-weaning on metabolic profile and ovarian activity. This experiment was conducted at the Department of Animal Science of the Universidade Federal de Viçosa, Viçosa, Minas Gerais, Brazil, between June and November 2015. Forty Nellore heifers averaging $8.5 \pm 0.06$ months and $248.6 \pm 3.3 \mathrm{~kg}$ body weight (BW) were distributed in a completely randomized design in a $2 \times 2$ factorial scheme with 4 treatments and 10 replicates. The treatments were: 1) $4 \mathrm{~g} / \mathrm{kg}$ of BW of supplement pre-weaning and rearing; 2) $4 \mathrm{~g} / \mathrm{kg}$ of BW of supplement pre-weaning and $6 \mathrm{~g} / \mathrm{kg}$ rearing; 3) $6 \mathrm{~g} / \mathrm{kg}$ of BW pre-weaning and $4 \mathrm{~g} / \mathrm{kg}$ of BW rearing and; 4) $6 \mathrm{~g} / \mathrm{kg}$ of BW pre-waning and rearing. Supplement was composed of corn meal, soybean meal, and mineral mix and, formulated to contain $30 \%$ CP as fed. The duration of the study was 150 days. Animals were allocated to one of four paddocks of 2.5 hectares (one for each treatment), uniformly covered with Brachiaria decumbens Stapf. Blood samples were collected on days 45,90 , and 135 of the experiment to quantify the concentration of insulin, glucose, cholesterol, serum urea nitrogen 
(SUN), albumin, and total proteins. Additionally, every 15 days between 10.5 to 13.0 months of age, blood samples were collected to quantify blood progesterone concentration of heifers. On day 150 of study, transrectal evaluation was performed using ultrasound to measure the diameter of the greatest follicle, number of follicles and corpus luteum presence. Means insulin and glucose concentrations were greater $(P<0.03)$ for heifers that received greater amounts of supplement in the rearing. However, no effects the amounts of supplement were observed $(P<0.15)$ for the other metabolic profile variables evaluated. Follicular number, diameter and progesterone concentration were greater $(P<0.02)$ for heifers that received greater amounts of supplement in the rearing. Higher concentrations of progesterone, follicular diameter, and number of follicles for heifers supplemented with the greatest amounts in the rearing reaffirms the positive effect of nutrition on reproductive function.

PALAVRA CHAVE: nellore; reproduction; progesterone.

AGRADECIMENTOS: UFV, FAPEMIG. 


\title{
EFFECTS OF SUPPLEMENTATION STRATEGIES IN METABOLIC PROFILE ON THE PREWEANING PERIOD OF GRAZING BEEF FEMALE CALVES
}

\author{
Camila de Paula ${ }^{1}$, Román Enrique Maza Ortega ${ }^{2}$, Deilen Paff Sotelo \\ Moreno $^{2}$, Roberta de Souza Amaral ${ }^{3}$, Edson Júnior dos Santos ${ }^{3}$, Anna \\ Flávia Rodrigues da Silva ${ }^{3}$, Mario Fonseca Paulino ${ }^{4}$ \\ ${ }^{1}$ Mestranda, UFV; ${ }^{2}$ Doutorando, UFV; ${ }^{2}$ Doutorando, UFV; ${ }^{3}$ Graduando, UFV; ${ }^{4}$ Professor Titular, UFV.
}

Age at puberty varies depending on numerous factors including body weight, genetics, nutrition, and management. The occurrence of puberty depends on the growth rate and development of the animal to support the endocrine mechanisms that result in first ovulation. Accordingly, several hormones and metabolites have been studied as nutritional signals to reproduction, for example, IGF-I, insulin, leptin, glucose and others. In Brazil, the beef cattle industry is based mainly on the pasture model, which represents more than $90 \%$ of the cattle diet. However, cattle in the pre- and post-weaning periods are characterized by deficient feed in both quality and quantity of forage which causes a slow growth rate and low gains or losses weight of the animals, limiting the continuous growth and leading to a delay in puberty. In this context, nutritional strategies that optimize the body growth and development of animals during the suckling stages and consequently improve its production in the post-weaning. The objective of this study was to evaluate the effects of supplement amounts on metabolic profile of female calves under grazing in the tropics. This experiment was carried out at the Department of Animal Science of the Universidade Federal de Viçosa, Viçosa, Minas Gerais, Brazil, between January and June 2015. Forty female calves (averaging $3.5 \pm 0.06$ months and $127.3 \pm 2.68 \mathrm{~kg}$ ), and their respective dams were distributed in a completely randomized design with two treatments and twenty replicates. The treatments were 1) $4 \mathrm{~g} / \mathrm{kg}$ body weight (BW) of supplement or 2) $6 \mathrm{~g} / \mathrm{kg}$ BW of supplement. Supplement was composed of corn meal, soybean meal, molasses and mineral mix and formulated to contain $30 \%$ crude protein as fed. The experiment 
lasted $150 \mathrm{~d}$. The cow-calf units were allocated in two paddocks of 15 hectares each (one for each treatment), uniformly covered with Brachiaria decumbens Stapf., equipped with drinkers and feeders. The supplement was delivered on creep-feeding system. Cows received mineral mixture ad libitum. On days 45,90 and 135 of study, blood was collected to quantify the concentration of insulin, glucose, cholesterol, serum urea nitrogen (SUN), albumin and total proteins. Blood concentration of insulin, glucose, cholesterol, albumin and total proteins were not affected $(P>0.50)$ by the supplement amounts. Only, mean SUN concentration was greater $(P<0.01)$ for the greatest supplement amount. In addition, a difference was observed in glucose concentration between the collection days, with a downward trend in relation to the first collection. An effect was observed $(P<0.01)$ in albumin concentration among collection days, with the lowest value observed in the second collection. These results indicate that increasing supplement amounts does not improve metabolic status in female calves on creep-feeding system.

PALAVRAS-CHAVE: nutrition; creep-feeding; nellore.

AGRADECIMENTOS: UFV, FAPEMIG. 


\title{
PARÂMETROS GENÉTICOS PARA MOTILIDADE E PERÍMETRO ESCROTAL EM BOVINOS DA RAÇA NELORE
}

\author{
Carla Galvão Fernandes ${ }^{1}$, Ivan Carvalho Filho' ${ }^{2}$, Daniele Botelho Diniz \\ Marques $^{3}$, Túlio Vilar Vilas Boas Oliveira ${ }^{2}$, Layla Cristien de Cassia \\ Miranda Dias ${ }^{4}$, José Domingos Guimarães ${ }^{5}$, Renata Veroneze ${ }^{6}$ \\ ${ }^{1}$ Estudante de Graduação em zootecnia, bolsista FAPEMIG; ${ }^{2}$ Estudante de mestrado; ${ }^{3}$ Estudante \\ de pós-graduação; ${ }^{4}$ Estudante de graduação (UFV); ${ }^{5}$ Professor do departamento de medicina \\ veterinária (DVT/UFV); ${ }^{6}$ Professora do departamento zootecnia (DZO/UFV).
}

A bovinocultura de corte vem buscando maior desempenho reprodutivo em seu rebanho, afim de melhorar sua taxa de desfrute e consequentemente aumentar a lucratividade. Contudo a maioria dos programas de melhoramento focam no desempenho reprodutivo da fêmea e na avaliação do perímetro escrotal sem considerar a correlação desta característica com as demais características relacionadas a fertilidade do macho. Objetivou-se avaliar os parâmetros genéticos para motilidade espermática (ME) e perímetro escrotal (PE). Foram utilizados dados de animais da raça Nelore de 18 aos 36 meses, totalizando 615 animais fenotipados, a matriz de parentesco foi composta por 2611 animais sendo que destes 714 fêmeas foram genotipadas utilizando o Illumina Bovine $70 \mathrm{~K}$ array (70K). Para o cálculo dos parâmetros genéticos, foi utilizada a metodologia Single Step GBLUP proposto por Legarra et al. (2009). Esse método permite a predição dos valores genéticos de indivíduos com e sem genótipo simultaneamente por meio da matriz $\mathrm{H}$. Os componentes de (co) variância foram estimados pelo método da máxima verossimilhança restrita (REML) por intermédio do software AIREMLF90 (Misztal et al., 2002). A estimativa de herdabilidade observada para ME foi de baixa magnitude $(0,08 \pm 0,03)$, o que mostra que essa característica sofre grande efeito do ambiente. A herdabilidade estimada para PE foi de alta magnitude $(0,50 \pm 0,12)$, evidenciando um grande efeito genético aditivo o que permite obter ganho genético alto por meio da seleção. A estimativa de 
correlação genética foi de alta magnitude $(0,99 \pm 0,11)$, revelando que a seleção para o PE irá provocar aumento da ME. Assim a seleção para PE nos programas de melhoramento tem proporcionado seleção indireta para ME uma vez que possui correlação genética alta e favorável com ME. Além disso, o PE tem a vantagem de ser uma característica fácil e barata de medir, necessitando somente de fita métrica.

PALAVRAS-CHAVE: genômica; herdabilidade; fertilidade.

AGRADECIMENTOS: à CAPES, CNPq e FAPEMIG. 


\title{
EFEITO DO NÍVEL DE PROTEÍNA BRUTA NA TERMINAÇÃO NA QUALIDADE DA CARNE DE BOVINOS NELORE OU $F_{1}$ ANGUS X NELORE
}

\author{
Carolina de Oliveira Pacheco ${ }^{1}$; Lyvian Cardoso Alves ${ }^{1}$; Juliana Chaves ${ }^{1}$; \\ Mário Luiz Chizzotti ${ }^{1}$ \\ ${ }^{1}$ Universidade Federal de Viçosa.
}

A proteína é o nutriente de maior custo unitário na nutrição de bovinos e sua inclusão não balanceada em dietas promove aumentos nos custos de produção, o que não é desejado durante a terminação dos mesmos confinados, que consiste em um maior desempenho dos animais, tendo efeito conseguinte na qualidade da carne, nas características das carcaças e na composição química dos tecidos musculares, uma vez que estes podem ser alterados conforme a quantidade e qualidade da proteína bruta na dieta, neste trabalho foram testados 3 níveis de proteína bruta (PB) para saber qual nível traz o melhor desempenho e melhor qualidade da carne. Foram utilizados 30 bovinos, com peso corporal inicial médio de $250 \mathrm{Kg}$, distribuídos ao acaso entres os 3 níveis de proteína, sendo 5 Nelores e $5 \mathrm{~F}_{1}$ Angus $\mathrm{x}$ Nelore consumindo cada nível proteico $(10 \% 12 \%$ ou $14 \%$ de PB com base na MS), alimentados duas vezes ao dia durante 224 dias. Após esse período de confinamento os animais ficaram 16 horas de jejum, foram pesados e logo após levados ao abate. As carcaças foram pesadas para avalição do rendimento de carcaça quente, mensuração de $\mathrm{pH}$ e da temperatura no Longissimus dorsi. Após 24 horas a $0^{\circ} \mathrm{C}$ uma nova pesagem foi realizada para avaliação do rendimento de carcaça fria, mensuração de $\mathrm{pH}$, da temperatura e da espessura de gordura subcutânea, feita a coleta de dados se seguiu para a excisão do Longissimus dorsi, que posteriormente foi dividido em três parcelas das quais uma foi congelada instantaneamente e as outras duas ficaram embaladas a vácuo e refrigeradas $a-4^{\circ} \mathrm{C}$ para avaliação da maturação aos 7 e 14 dias. Observou-se que a espessura de gordura subcutânea foi maior nos animais $\mathrm{F}_{1}$ independente do nível de $\mathrm{PB}$. $\mathrm{O}$ pH final nos tratamentos 
de 12 e $14 \%$ de PB não diferiram entre si porém foram menores que o tratamento com $10 \%$. O peso corporal final não sofreu alteração pelo nível proteico mas bovinos $\mathrm{F}_{1}$ obtiveram uma média maior. A porcentagem de extrato etéreo foi maior nos tratamentos com $14 \%$ de $P B$ e nos animais $F_{1}$, já a quantidade de colágeno solúvel e colágeno total foi maior no tratamento com $12 \%$ de PB. Foi obtida a maior força de cisalhamento no tratamento com $14 \%$ de PB indicando que o maior aporte de aminoácidos reduziu a maciez. Sobre a maturação foi observado que aos 14 dias a força de cisalhamento caiu à medida que os dias aumentaram independente da genética e nível de proteína. É possível concluir que o uso de 10 e $12 \%$ de PB são adequados para assegurar a qualidade da carne.

PALAVRAS-CHAVE: desempenho; confinamento; colágeno. 


\title{
INFLUÊNCIA DA RESTRIÇÃO ALIMENTAR NO DESEMPENHO E QUALIDADE DE CARNE DE BOVINOS NELORE E $F_{1}$ ANGUS X NELORE
}

\author{
Carolina de Oliveira Pacheco1; Lyvian Cardoso Alves'; Juliana \\ Chaves $^{1}$; Mário Luiz Chizzotti ${ }^{1}$ \\ ${ }^{1}$ Universidade Federal de Viçosa.
}

A maciez da carne é principalmente determinada por a alterações post mortem que decorrem de diferenças ante mortem. Os principais fatores ante mortem seriam: genética, maturidade, acabamento, taxa de crescimento e composição do colágeno; os principais fatores post mortem seriam: velocidade de resfriamento, taxa de queda do $\mathrm{pH}, \mathrm{pH}$ final, atividade proteolítica e tempo de maturação. Esse trabalho teve como objetivo avaliar as diferenças entre bovinos Nelore e $F_{1}$ Angus x Nelore com relação ao seu desempenho e qualidade da carne quando submetidos a restrição alimentar, trazendo também o efeito de maturação sobre as diferentes carcaças. Para o mesmo foram utilizados 19 bovinos, não castrados, distribuídos em 4 animais Nelore e 4 animais $F_{1}$ sob alimentação restrita, se alimentando uma vez ao dia com $12 \mathrm{~g}$ de $\mathrm{MS} / \mathrm{Kg}$ de peso corporal; além de 5 animais Nelore e 6 animais $\mathrm{F}_{1}$ sob alimentação ad libitum com $12 \%$ de proteína bruta na base de MS, se alimentando duas vezes ao dia. Ao fim dos 224 dias do confinamento foi feito um jejum de 16 horas, abate, pesagem das carcaças para avaliação do rendimento de carcaça quente, e após 24 horas uma nova pesagem foi feita com intenção de avaliar o rendimento de carcaça fria e posteriormente a excisão do Longissimus Dorsi com a intenção de obter três parcelas de carne, as quais uma foi congelada no instante do corte, e duas embaladas a vácuo, refrigeradas a $-4^{\circ} \mathrm{C}$ para avaliação da maturação por 7 ou 14 dias. Após avaliação do peso corporal quente, peso corporal frio, espessura de gordura subcutânea e teores de colágeno foi possível concluir que animais em consumo ad libitum tiveram um desempenho superior, ou seja, maior rendimento de carcaça 
quente, maior rendimento de carcaça fria, maior espessura de gordura subcutânea e menor teor de colágeno quando comparados aos animais com alimentação restrita, os quais além de obterem menor desempenho tiveram uma maior perda por descongelamento, por conta da menor retenção de água com a contração das miofibrilas gerada pelo encurtamento pelo frio. Com relação a maturação, os animais ad libitum apresentaram valores de solubilidade de colágeno maiores nos dias 1,7 e 14 de maturação na raça Nelore e nos dias 7,14 nos animais $F_{1}$. Em suma, a restrição alimentar ou o menor desempenho de bovinos influencia negativamente a qualidade da carne.

PALAVRAS-CHAVE: maturação; maciez; rendimento. 


\title{
PRODUTIVIDADE DE CAPIM BRAQUIÁRIA FERTIRRIGADO COM EFLUENTE DE SUINOCULTURA
}

\author{
Cíntia Cármen de Faria Meloํㅜ, Danilo Silva Amaral ${ }^{1}$, Luís César Dias \\ Drumond $^{2}$ \\ ${ }^{1}$ Pós-graduando em Produção Vegetal - UFV Campus Rio Paranaíba; ${ }^{2}$ Professor Adjunto UFV - \\ Campus Rio Paranaíba
}

A disposição de efluentes no sistema solo-planta traz muitos benefícios tanto em relação à produção de massa vegetal, por serem ricos em nutrientes e constituir fonte de água, tanto ambientalmente, visto a diminuição do seu potencial poluidor. Esses resíduos são uma opção frente à aquisição de fertilizantes inorgânicos e têm sido muito utilizados na fertirrigação de forrageiras, por apresentarem alta taxa de exportação de nutrientes. Para avaliar a resposta da Brachiaria brizantha cv. Xaraés à aplicação de efluente de suinocultura, foi conduzido um experimento em área de pastagem intensiva no município de Uberlândia-MG. Utilizou-se delineamento em blocos casualizados, com seis tratamentos: T1- 0, T2-500, T3-1000, T4- 1500, T5-2000, T6- $2500 \mathrm{~m}^{3}$ ha $^{-1}$ ano $^{-1}$ do efluente, e três repetições. As unidades experimentais tinham dimensão de $3 \times 3 \mathrm{~m}$, com um metro de bordadura. A aplicação dos tratamentos foi realizada com uma mangueira de uma polegada e o volume calculado em razão do tempo e distribuído uniformemente sobre cada parcela. A vazão foi regulada em 45 litros min $^{-1}$, e os tempos de aplicação foram de 0 , 2, 4, 6, 8 e 10 minutos respectivamente, do tratamento 1 ao 6 . Foram determinadas a altura do relvado pré-pastejo (AR), a taxa de acúmulo de forragem (TAF) e a capacidade de suporte (CS). A coleta de dados foi efetuada em cinco intervalos de 21 dias. Os dados foram testados quanto às condições de homogeneidade das variâncias e normalidade dos resíduos, sucedendo-se a análise de variância. Os efeitos significativos foram avaliados por meio de análise de regressão. Os tratamentos foram significativos para todas as variáveis, sendo observados incrementos com tendência 
linear na produção com o aumento das doses de água residuária. O capim Xaraés apresentou maior produção de matéria seca (MS) na dose mais elevada, uma média de $20 \mathrm{t} \mathrm{ha}^{-1} \mathrm{ano}^{-1}$ enquanto no T1 foram produzidas cerca de $14 \mathrm{t} \mathrm{ha}^{-1} \mathrm{ano}^{-1}$ de MS. A TAF alcançada sem uso de efluente foi de 92 , aumentando para 150 no T4 e $190 \mathrm{~kg} \mathrm{ha}^{-1} \mathrm{dia}^{-1}$ de MS quando foi utilizada a dose de 2500 $\mathrm{m}^{3}$ ha $^{-1}$ ano $^{-1}$. Em relação à CS, o T2 permitiu atingir $5 \mathrm{UA} \mathrm{ha}^{-1}$, enquanto a variável chegou a 8,3 UA ha-1 com a aplicação do T6. Neste tratamento, a altura do relvado teve aumento de $26 \%$ em relação à dose zero de efluente, chegando a $37,5 \mathrm{~cm}$. Conclui-se que o capim Xaraés pode ser indicado para manejo intensivo com utilização de efluente de suinocultura, visto sua resposta em produtividade de forragem, permitindo grande incremento da produção animal.

PALAVRAS-CHAVE: capacidade de suporte; reuso de água; xaraés.

AGRADECIMENTOS: CAPES. 


\title{
INFLUÊNCIA DA CASTRAÇÃO SOBRE AS CARACTERÍSTICAS DE CARCAÇA DE BOVINOS NELORE SUPERPRECOCES ABATIDOS EM DIFERENTES PESOS CORPORAIS
}

\author{
Débora Evelyn de F. Assis' ${ }^{1}$, Luiz Henrique Pereira Silva², Gutierrez José \\ de F. Assis ${ }^{2}$, Mauricio Miguel Estrada ${ }^{3}$, Gustavo B. Carneiro ${ }^{4}$, Germán \\ Dario Ramirez Zamudio ${ }^{5}$, Mario L. Chizzotti ${ }^{6}$ \\ ${ }^{1}$ Estudante de mestrado em Zootecnia Bolsista FAPEMIG UFV/Viçosa- MG; ${ }^{2}$ Estudante de \\ doutorado em Zootecnia Bolsista CNPq UFV/Viçosa- MG; ${ }^{3}$ Estudante de doutorado em Zootecnia \\ UFV/Viçosa- MG; ${ }^{4}$ Estudante de graduação em Zootecnia UFV/Viçosa- MG; ${ }^{5}$ Estudante de \\ doutorado em Zootecnia UFLA/Lavras- MG; ${ }^{6}$ Professor Adjunto do Departamento de Zootecnia \\ UFV/Niçosa- MG.
}

A condição sexual e a maturidade são grandes influenciadores da taxa de deposição dos tecidos corporais, bem como das características de carcaças. O objetivo neste estudo foi avaliar os parâmetros de carcaça de touros jovens e novilhos abatidos em três diferentes pesos corporais. O experimento foi conduzido na Universidade Federal de Viçosa. Utilizaram-se 36 animais, sendo metade foram castrados uma semana antes da desmama. Sendo assim, seis touros e seis novilhos foram abatidos quando o peso corporal médio alcançou os pesos almejados, 280, 380 e $480 \mathrm{~kg}$. Após ao abate, a carcaça foi dividida longitudinalmente, pesadas e suspensas de acordo com o método tenderstretch. Durante o resfriamento, por 24 horas a $4^{\circ} \mathrm{C}$, o $\mathrm{pH}$ e a temperatura da carcaça foram registrados em $0.5,2,4,6,8,10$, $12,14,18,22$ e 24 horas post mortem. Mensurou-se também o comprimento da carcaça, espessura de gordura subcutânea (EGS) e a área de olho de lombo (AOL). O comprimento de sarcômero foi mensurado por difração a laser. Os dados foram analisados em arranjo fatorial $2 \times 3 \mathrm{com}$ duas condições sexuais e três pesos de abate. Os touros tiveram maior peso corporal $(P<0,05)$, peso de carcaça fria, e EGS do que os novilhos. O comprimento da carcaça e AOL foram semelhantes $(P>0,05)$ entre os touros e novilhos. $O$ $\mathrm{pH}$ final e a temperatura mensurados $24 \mathrm{~h}$ post mortem, o $\mathrm{pH}$ aos $18^{\circ} \mathrm{C}$ e a temperatura ao $\mathrm{pH} 6$ foram semelhantes $(\mathrm{P}>0,05)$ para 
carcaças de touros e novilhos. Monitorando o $\mathrm{pH}$ e a temperatura, verificou-se que não houve diferença entre as carcaças de touros e novilhos em qualquer momento post mortem avaliado. O comprimento final do sarcômero não foi diferente entre touros e novilhos ( $\mathrm{P}=0,743)$, com uma média de 1,66 $\mu \mathrm{m}$. Embora o $\mathrm{pH}$ final não tenha sido afetado pelo peso ao abate $(P=0.566)$, o pH da carcaça avaliado em 0,$5 ; 8 ; 12$ e 14 h post mortem foi maior no grupo abatido aos $280 \mathrm{~kg}$, assim como o pH da carcaça aos $18^{\circ} \mathrm{C}$. As temperaturas da carcaça às $24 \mathrm{~h}$, assim como nos demais tempos post mortem, foram maiores $(P<0,01)$ nos bovinos abatidos aos $480 \mathrm{~kg}$, e o comprimento de sarcômero avaliado $24 \mathrm{~h}$ post mortem também foi superior $(P<0,01)$. A temperatura da carcaça ao $\mathrm{pH} 6,0$ foi menor $(\mathrm{P}<0,01)$ nas carcaças de bovinos abatidos aos $280 \mathrm{~kg}$. Touros apresentaram maiores peso de carcaça que novilhos, contudo mesmo comprimento de carcaça, indicando maior massa muscular. $\mathrm{O}$ abate de bovinos leves ocasiona rapida taxa de resfriamento nas carcaças, o que prejudica o declínio do $\mathrm{pH}$ e ocasiona encurtamento de sarcômeros, prejudicando a qualidade da carne.

PALAVRAS-CHAVE: castrado; $\mathrm{pH}$; temperatura.

AGRADECIMENTOS: FAPEMIG, CNPq, CAPES. 


\title{
EFEITO DA CONDIÇÃO SEXUAL, PESO CORPORAL AO ABATE E TEMPO DE MATURAÇÃO SOBRE A MACIEZ DA CARNE DE BOVINOS NELORE SUPERPRECOCES
}

\author{
Débora Evelyn de F. Assis', Luiz Henrique Pereira Silva², Gutierrez José \\ de F. Assis ${ }^{2}$, Mauricio Miguel Estrada', Gustavo B. Carneiro ${ }^{3}$, Juliana \\ Chaves da Silva ${ }^{4}$, Mario L. Chizzotti ${ }^{5}$ \\ ${ }^{1}$ Estudante de mestrado em Zootecnia Bolsista FAPEMIG UFV/Viçosa- MG; ${ }^{2}$ Estudante de \\ doutorado em Zootecnia UFV/Viçosa- MG; ${ }^{3}$ Estudante de graduação em Zootecnia UFV/Viçosa- \\ MG; ${ }^{4}$ Estudante de mestrado em Medicina Veterinária UFV/Viçosa- MG; ${ }^{5}$ Professor Adjunto do \\ Departamento de Zootecnia UFVNiçosa-MG.
}

A condição sexual e a maturidade afetam a hipertrofia muscular dos bovinos e podem influenciar a proteólise post mortem, o que afetaria a maciez da carne. A maciez é considerada uma das características mais importantes da carne, contudo é altamente variável. Objetivou-se avaliar os efeitos da castração e de diferentes pesos ao abate, em três tempos de maturação, sobre os parâmetros de qualidade de carne que influenciam a maciez da carne de bovinos Nelore superprecoces. O experimento foi conduzido nas dependências da Universidade Federal de Viçosa (CEUAP 035/2015), utilizando 36 animais, onde metade foram escolhidos de maneira aleatória e castrados uma semana antes da desmama. Sendo assim, seis touros e seis novilhos foram abatidos quando o peso corporal médio alcançou os pontos finais préestabelecidos de 280,380 e $480 \mathrm{~kg}$. Após ao abate e evisceração, a carcaça foi dividida em duas meias carcaças, que foram resfriadas em câmara fria a $4^{\circ} \mathrm{C}$ por 24 horas. Uma amostra do músculo Longissimus na região entre a $6^{\mathrm{a}}$ e $9^{\mathrm{a}}$ costelas foi coletada para análise da carne, fracionada em três porções iguais, e embaladas à vácuo, sendo uma imediatamente congelada $\mathrm{a}-18^{\circ} \mathrm{C}$ (1 dia post-mortem), e as outras maturadas a $4^{\circ} \mathrm{C}$ por 7 ou 14 dias. Também foram retiradas amostras de carne decorridos os diferentes tempos de maturação. Os parâmetros analisados foram maciez, mensurada através da força de cisalhamento, indice de fragmentaçao miofibrilar (IFM) e o conteúdo de desmina intacta por 
western blot. Os dados foram analisados em esquema fatorial $2 \mathrm{x}$ 3 com duas condições sexuais e três pesos de abate. A força de cisalhamento obtida 1 dia post-mortem foi menor aos $480 \mathrm{~kg}$ de peso corporal $(P=0,02)$. No entanto, a força de cisalhamento da carne maturada por 7 ou 14 não foi afetada pelos pesos de abate $(P>0,05)$. Embora o IFM em 1 e 7 não tenha diferido entre os pesos de abate, houve uma tendência $(P<0,10)$ para maior IFM aos 14 dias de maturação nos bovinos abatidos com $280 \mathrm{~kg}$ de peso corporal. A desmina intacta diminuiu com a maturação, porém não houve efeito do peso de abate. A castração não afeta a força de cisalhamento nem o IFM da carne não maturada de bovinos, entretanto com o aumento do tempo de maturação, bovinos castrados apresentaram carne mais macia, sugerindo maior proteólise post-mortem.

PALAVRAS-CHAVE: bovinos; castrados; novilhos.

AGRADECIMENTOS: FAPEMIG, CNPq, CAPES. 


\section{PRODUCTIVE PERFORMANCE, NUTRIENTS INTAKE AND DIGESTIBILITY OF GRAZING BEEF HEIFERS RECEIVING INCREASING LEVELS OF PROTEIN SUPLEMENT AT PERIPARTUM AND POSTPARTUM PERIODS}

\section{Deilen Paff Sotelo Moreno', Thiago Ramalho Moreira, Román Maza Ortega, David Contreras Marquez, Felipe Henrique de Moura, Vinícius Augusto Vieira Pereira, Mário Fonseca Paulino ${ }^{1}$ Universidade Federal de Viçosa.}

The low perfomance of pregnant beef heifers is usually due to low energy intake, protein and limited body reserves, in addition to the growth of the foetus in the last third of gestation, which increases their nutritional requirements, as well as the intensity of negative energy balance postpartum. Some studies have shown that different levels of protein supplementation have a positive effect on forage dry matter intake, digestibility, body weight (BW) and body conditions score (BCS). Thus, prepartum and postpartum protein supplementation for beef heifers, fed low-quality tropical forages may improve their forage intake and digestibility, nutrient concentrations in the rumen, crude protein (CP) intake, availability of dietary energy, BCS, metabolic status and animal performance. Therefore, the objective of this study was to evaluate the effect of increasing levels of peripartum and postpartum protein supplementation on nutrient intake, digestibility and productive performance of Nellore heifers on tropical pasture. The experiment was carried out at the Beef Cattle Section of Universidade Federal de Viçosa, Brazil, May to November, which is the dry and dry-rainy season transition. Twenty-eight Nellore heifers with initial average $5.4 \pm 0.50$ months of gestation, $3.1 \pm 0.74$ years old, $459.7 \pm 6.8 \mathrm{~kg}$ of BW and $5.8 \pm 0.10$ of BCS, kept in four 7 -ha paddocks formed by Brachiaria decumbens Stapf. provided with covered drinkers and troughs were used in a completely randomized design with 4 treatments and 7 replicates. The treatments consisted of increasing 
levels of protein supplement: 0.0 (Control $=\mathrm{CON}), 0.4(\mathrm{LOW}), 0.8$ (MEDIUM) and 1.2 (HIGH) kg/animal.day of protein supplement containing $25 \% \mathrm{CP}$. All the animals received a mineral mixture ad libitum. The experiment lasted 180 days, and weight and BCS of heifers were measured at the start, at calving and the end of the experiment. Similarly, the calves were weighed at birth and the end of the experiment. The BCS was evaluated by 4 raters using the 1 to 9 scale as recommended by the NRC (1996). A 9-day digestibility trial was conducted beginning at day 40 of the experiment to evaluate the nutritional characteristics of the diet of the heifers. The supplementation level increased the intake of all evaluated nutrients, digestibility of organic matter, neutral detergent fibre corrected for ash and protein, as well as higher average daily gain prepartum and body weight of calves at birth $(P<0.05)$. Protein supplement at the levels evaluated did not affect body condition score $(P>0.05)$. It was concluded that the supply of up to $1.2 \mathrm{~kg} / \mathrm{day}$ of protein supplement for grazing heifers optimizes forage intake and average daily gain before calving, and increases the body weight of calves at birth.

PALAVRAS-CHAVE: beef cattle; forage; primiparous.

AGRADECIMENTOS: UFV, FAPEMIG. 


\title{
METABOLIC STATUS OF GRAZING BEEF HEIFERS RECEIVING INCREASING LEVELS OF PROTEIN SUPPLEMENT AT PERIPARTUM AND POSTPARTUM PERIODS
}

\author{
Deilen Paff Sotelo Moreno ${ }^{1}$, Thiago Ramalho Moreira, Román Maza Ortega, \\ David Contreras Marquez, Jéssika Almeida Bitencourt, Júlia de Abreu \\ Lopes, Mário Fonseca Paulino \\ ${ }^{1}$ Doutorando em Zootecnia, Universidade Federal de Viçosa.
}

\begin{abstract}
Pregnant beef heifers have high requirements, and their development depends on several factors, including nutritional factors and gestation time. The transition late gestation to the start of lactation is associated with mobilization of body reserves, increased blood non-esterified fatty acids (NEFA) and $\beta$ hydroxybutyrate (BHB) and decreased glucose concentrations. Further, these cows have additional nutrient requirements to continue their growth, in addition to being under the stress calving. As a result, their calving interval is extended, which is a major constraint to improving reproductive efficiency. Therefore, the objective of this study was to evaluate the effect of increasing levels of prepartum and postpartum protein supplementation on reproductive performance and metabolic status of pregnant Nellore heifers on tropical pasture. The experiment was carried out at the Beef Cattle Section of Universidade Federal de Viçosa, Brazil, May to November, which is the dry and dry-rainy season transition. Twenty-eight Nellore heifers with initial average $5.4 \pm 0.50$ months of gestation, $3.1 \pm 0.74$ years old, $459.7 \pm 6.8 \mathrm{~kg}$ of body weight and $5.8 \pm 0.10$ of body conditions score, kept in four 7-ha paddocks formed by Brachiaria decumbens Stapf. provided with covered drinkers and troughs were used in a completely randomized design with 4 treatments and 7 replicates. The treatments consisted of increasing levels of protein supplement: 0.0 (Control $=\mathrm{CON}), 0.4$ (LOW), 0.8 (MEDIUM) and $1.2(\mathrm{HIGH}) \mathrm{kg} /$ animal.day of protein supplement containing $25 \%$ crude protein. All the animals received a mineral mixture ad libitum. The experiment lasted 180 days,
\end{abstract}


during which blood samples were collected as a function of days in relation to calving for quantification of concentrations of blood metabolites at 15 days before expected calving date (?15), and 30 $(+30)$ and $60(+60)$ days postpartum for urea, NEFA and BHB levels. In addition, blood samples were collected $30(+30), 45(+45)$, $60(+60)$ and $75(+75)$ days postpartum to measure total proteins, albumin, globulins, glucose, triglycerides, and progesterone levels. An interaction effect among treatment $x$ days in relation to calving occurred for concentrations of serum urea nitrogen, total proteins, albumin and globulins $(P<0.05)$. Supplementation did not affect glucose, triglyceride, NEFA, BHB or progesterone levels $(P>0.05)$. However, there was an effect $(P<0.05)$ as a function of days in relation to calving on triglyceride, NEFA and progesterone. It was concluded that increasing protein supplement amounts for grazing heifers improves the indicators of the protein status.

PALAVRAS-CHAVE: beef cattle; forage; metabolismo.

AGRADECIMENTOS: UFV, FAPEMIG. 


\title{
DESEMPENHO PRODUTIVO E ECONÔMICO DE DOIS GRUPOS GENÉTICOS DE BOVINOS TERMINADOS EM CONFINAMENTO
}

\author{
Drielly Coelho Marcondes ${ }^{1}$, Laissa Araujo Guimarães ${ }^{1}$, Severino Delmar \\ Junqueira Villela ${ }^{1}$, Marcos Vendrame Esposito ${ }^{1}$, Charles Paranhos \\ Oliveira ${ }^{1}$, Débora Virgínia Ribeiro ${ }^{1}$ \\ ${ }^{1}$ Universidade Federal dos Vales do Jequitinhonha e Mucuri - UFVJM.
}

Os confinamentos representam atualmente uma tecnologia na cadeia produtiva da carne considerando seu rápido giro de produção. O estudo foi realizado a partir de dados obtidos do confinamento Nossa Senhora Aparecida, localizado no município de Martinópolis, São Paulo, no ano de 2016. Objetivou-se avaliar o desempenho produtivo e econômico de dois grupos (tratamentos) genéticos de bovinos, Nelore e Cruzados ( $1 / 2$ Nelore $\times 1 / 2$ Red Angus) em sistema de terminação em confinamento por um período de 93 dias, totalizando 1028 animais, sendo 608 Cruzados e 420 Nelores, divididos em 10 repetições. Os animais tinham média de 18 meses de idade, peso médio inicial de $422 \mathrm{~kg}$ e final de $566,5 \mathrm{~kg}$, ambos receberam a mesma dieta. O delineamento utilizado foi em inteiramente casualizado (DIC), sendo as variáveis de desempenho produtivo analisadas pelo Software Sisvar 5.6. Os índices de desempenho produtivo avaliados foram o consumo de matéria seca (CMS), ganho médio de peso diário (GMD), rendimento de carcaça $(\mathrm{RC})$, quilos de matéria seca por arroba produzida (kg de MS/@) e peso de carcaça (PCa). Os indicadores econômicos foram avaliados pelas médias de custo diário total (CD) por animal, margem bruta (MB), margem liquida (ML), lucro(L) e taxa de retorno financeiro (TR). Os animais Cruzados obtiveram maior GMD $(1,64 \mathrm{~kg} / \mathrm{d}, \mathrm{P}<0,0001)$, bem como $\mathrm{PCa}(333,97 \mathrm{~kg}, \mathrm{P}=$ $0.0001), \operatorname{RC}(55,56 \%, P=0.0002)$, CMS (12,87 kg/d, $P=0.0001)$, enquanto os animais Nelore apresentaram GMD de 1,48 kg/d, PCF de $292,88 \mathrm{~kg}, \mathrm{RC}$ de $55,00 \%$, e CMS de 10,71 Kg/d. Apesar do CMS superior dos animais Cruzados, o kg de MS/@ foi semelhante entre Cruzados e Nelores (158,96 e 159,59 kg de MS/ @ produzida, 
respectivamente). O satisfatório resultado produtivo, corrobora para uma provável influência da heterose propiciada pelos cruzamentos entre Bos tauros indicus (Nelore) e Bos taurus taurus (Red Angus). Na avaliação econômica, os Cruzados apresentaram CD superior ao dos Nelores (R $\$ 11,97$ e $R \$$ 10,42, respectivamente). Considerando que os gastos com custos fixos e custo de oportunidade somaram juntos o valor de $R \$ 1,00 /$ dia fixado para cada animal, o custo com alimentação pode ser explicado como o maior influenciador do CD para Cruzados. A alimentação representou $90,97 \%$ dos custos da atividade desconsiderando o preço de aquisição dos animais. Comparado a estudos semelhantes que chegaram à faixa de $94,15 \%$ e $85 \%$ o resultado está dentro da média. As médias de $M L, M B$ e $L$ dos Cruzados $(R \$$ 215,$34 ; R \$ 146,38$ e $R \$ 129,14$, respectivamente) foram superiores à dos Nelores ( $R \$ 194,26 ; R \$ 114,26 ; R \$ 94,26$, respectivamente). A TR foi de 3,50\% para Cruzados e 2,97\% para Nelores. Pode-se observar, portanto que o desempenho produtivo e econômico dos cruzados (Nelore $\times$ Red Angus) foi superior ao do grupo dos animais Nelore, o que torna rentável a implantação dessa tecnologia genética nos confinamentos. Entretanto, ambos os grupos apresentaram desempenho satisfatório, viabilizando assim a atividade.

PALAVRAS-CHAVE: desempenho; cruzado; econômico.

AGRADECIMENTOS: UFVJM e Fazenda Nossa Senhora Aparecida Martinópolis-SP. 


\title{
QUALIDADE DA CARNE DE BOVINOS NELORE ALIMENTADOS COM SORGO OU MILHO, SECO OU REIDRATADO
}

\author{
Fabiano Andrade Ferreira1', Germán Darío Ramírez Zamudio², Rizielly \\ Saraiva Reis Vilela ${ }^{3}$, Maurício Miguel Estrada ${ }^{4}$, Marcos Vinicius Carneiro \\ Pacheco $^{4}$, Breno de Castro Silva ${ }^{4}$, Mário Luiz Chizzotti ${ }^{5}$ \\ ${ }^{1}$ Mestre em zootecnia - UFV; ${ }^{2}$ Estudante de doutorado em zootecnia - UFLA; ${ }^{3}$ Estudante de \\ mestrado em zootecnia - UFV; ${ }^{4}$ Estudante de doutorado em zootecnia - UFV; ${ }^{5}$ Professor do \\ Departamento de Zootecnia - UFV.
}

Atualmente, o milho é o ingrediente mais utilizado nas dietas de terminação nos confinamentos, devido a sua alta densidade energética, que é necessária para a terminação das carcaças e que reflete numa melhor qualidade da carne. No entanto, o custo do milho é altamente variável e o uso de outros grãos alternativos como o sorgo, ou técnicas de processamento como a reidratação, podem ser estratégias interessantes para reduzir o custo de produção. O objetivo deste trabalho foi avaliar o efeito do tipo de cereal (milho ou sorgo) e a técnica de processamento (reidratação) sobre as características qualitativas da carne de tourinhos Nelore terminados em confinamento. Foram utilizados 24 machos Nelore, não castrados, com idade 8 meses e peso médio inicial de $270 \pm 53$ $\mathrm{kg}$, mantidos em baias coletivas por um período experimental de 140 dias, alimentados com dietas com relação volumoso:concentrado de 30:70 na MS, utilizando silagem de milho como volumoso. Foi utilizado delineamento inteiramente casualizado, em arranjo fatorial $2 \times 2$, constituído por dois cereais (milho ou sorgo) e o uso ou não de processamento dos grãos (grão secos ou reidratados e ensilados), com 6 animais por tratamento. Não houve diferenças relacionadas ao tipo de grão ou ao processamento, assim como não foi encontrada interação entre esses fatores $(P>0,05)$, sobre $\mathrm{opH}$ e a temperatura final da carcaça e as características qualitativas da carne: como coloração, força de cisalhamento, comprimento de sarcômero, perdas de água e composição centesimal. Contudo, houve maior intensidade de 
amarelo $\left(b^{*}\right)$ na gordura subcutânea dos animais provenientes das dietas à base de milho $(P=0,038)$. Este resultado pode ser decorrente do teor mais elevado de caroteno e xantofila no milho em comparação com o sorgo, conferindo maior pigmentação no produto. A cor seja na carne ou na gordura, influencia a decisão de compra do consumidor, e cores mais intensas na gordura são relacionadas a animais velhos. Deste modo, pode-se concluir que a utilização de sorgo ao invés de milho nas dietas de confinamento favorece uma coloração mais clara da gordura na carcaça, sem alterar as características qualitativas da carne.

PALAVRAS-CHAVE: betacarotenos; confinamento; reidratação.

AGRADECIMENTOS: CNPq, FAPEMIG, CAPES, FUNARBE. 


\title{
EFFECTS OF INFREQUENT SUPPLEMENTATION WITH NITROGEN AND STARCH ON RUMEN FIBER DEGRADATION AND AMMONIA IN CATTLE FED HIGH-QUALITY TROPICAL GRASS
}

\author{
Giselle Priscila Costa ${ }^{1}$, Edenio Detmann ${ }^{2}$, William Lima Santiago dos \\ Reis $^{3}$, João Vitor Ribeiro Lovatti ${ }^{4}$, Malber Nathan Nobre Palma ${ }^{3}$, Amanda \\ de Souza Assunção ${ }^{3}$, Aline Maria Monteiro Canaan Garcia ${ }^{4}$ \\ ${ }^{1}$ Estudante de Mestrado DZO-UFV e-mail: giselle.costa@ufv.br; ${ }^{2}$ Professor Titular do Departamento \\ de Zootecnia, DZO/UFV, Viçosa-MG, Brasil. e-mail: detmann@ufv.br; ${ }^{3}$ Estudante de Doutorado \\ DZO-UFV; ${ }^{4}$ Estudante de Graduação DZO-UFV.
}

The objective was to evaluate the effects of daily and every three days supplementation with nitrogen $(N)$ or $N$ and starch on rumen fiber degradation and rumen ammonia $N$ (RAN) concentration in cattle fed a high-quality tropical grass (Cynodon sp. hay, $8.0 \%$ crude protein, CP). Five cannulated Nellore heifers (299 $\pm 7,5 \mathrm{~kg}$ body weight) were used in a $5 \times 5$ Latin square design. The experiment consisted of five experimental periods, which lasted 27 $\mathrm{d}$ each. The treatments were: control (CONT); daily supplementation with $200 \mathrm{~g}$ of CP (P/D); daily supplementation with $200 \mathrm{~g}$ of $\mathrm{CP}$ and $400 \mathrm{~g}$ of starch (PS/D); every three days supplementation with $600 \mathrm{~g}$ of $\mathrm{CP}$ (P/3D); and every three days supplementation with $600 \mathrm{~g}$ of CP and $1200 \mathrm{~g}$ of starch (PS/3D). The $\mathrm{N}$ supplement consisted of a mixture of soybean meal $(740 \mathrm{~g} / \mathrm{kg}$ as fed) and urea and ammonium sulfate $(9: 1,260 \mathrm{~g} / \mathrm{kg}$ as fed). The evaluations were performed d 22 to $d 24$ of each experimental period, which encompassed one supplementation cycle for infrequent supplementation. Samples of rumen fluid were taken at $6: 00,12: 00,18: 00$, and $24: 00$ of each day and analyzed with regard RAN. The values were interpreted as average daily RAN concentration. For in situ evaluation of potentially degradable neutral detergent fiber (pdNDF) degradation rate, samples of the forage were incubated in the rumen using nylon bags for 6,12 and $24 \mathrm{~h}$ within each day of the supplementation cycle. Statistical analyses were performed using the MIXED procedure of SAS $9.4(?=0.05)$. On 
average, degradation rate of pdNDF was not affected (P?0.26) by the treatments. However, there was $(P<0.02)$ an interaction between day of the supplementation cycle and treatments. The treatments CONT, P/D and PS/D presented stable fiber degradation throughout the three-day supplementation cycle. Nevertheless, for $\mathrm{PS} / 3 \mathrm{D}$, there was an impairment to fiber digestion on the first day of the supplementation cycle, day in which these animals had access to supplements, followed by a recuperation of fiber digestion rate in the following two days, when they were not supplemented. For P/3D, in situ fiber digestion rate was greater on day 1 and then gradually dropped in the day 2 and day 3 . On average, supplements increased $(P<0.01)$ RAN 4,2 to $8,7 \mathrm{mg} / \mathrm{dL}$. Among supplemented animals, infrequent supplementation increased $(P<0.04)$ RAN when compared to daily supplementation. An interaction $(P<0.01)$ between treatments and days of the supplementation cycle pointed out that RAN levels were constant over days for CONT, P/D and $P S / D$, but for infrequent supplemented animals RAN was greater on day 1 and then decreased in the two following days. In general, decreasing the supplementation frequency does not affect fiber degradation in the rumen. Ammonia concentration in the rumen is improved by supplementation, but becomes variable among days when infrequent supplementation is provided to the animals.

PALAVRAS-CHAVE: degradation rate; rumen ammonia nitrogen; supplementation frequency.

AGRADECIMENTOS: CNPq, FAPEMIG e INCT-CA. 


\title{
USO DE CÂMERA DE INFRAVERMELHO NA CLASSIFICAÇÃO E TIPIFICAÇÃO DE CARCAÇAS BOVINAS
}

\author{
Gutierrez J. de F. Assis ${ }^{1}$, André Luis Carvalho Mendes², Débora Evelyn de \\ F. Assis ${ }^{3}$, Gustavo Borges Carneiro ${ }^{4}$, Augusto Matos Corrêa ${ }^{3}$, Luiz \\ Henrique Pereira Silva ${ }^{5}$, Mario Luiz Chizzotti ${ }^{6}$ \\ ${ }^{1}$ Estudante de doutorado em Zootecnia, UFV/Viçosa-MG, bolsista CNPq, gutierrez.assis@ufv.br;

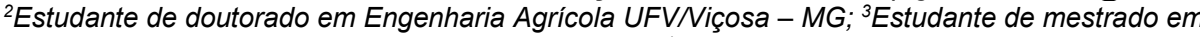 \\ Zootecnia, UFV/Viçosa - MG, Bolsista FAPEMIG; ${ }^{4}$ Estudante de graduação em Zootecnia, \\ UFV/Viçosa - MG; ${ }^{5}$ Estudante de doutorado em Zootecnia, UFV/Viçosa - MG; ${ }^{6}$ Professor Adjunto \\ do Departamento de Zootecnia, UFV/Viçosa - MG, bolsista PQ/CNPq.
}

A classificação e tipificação de carcaças permite aos frigoríficos inferirem sobre a qualidade e quantidade de carne que será produzida. No Brasil, estes processos são subjetivos, diante disso, objetivou-se predizer a composição física e química de carcaças bovinas através da análise de imagens de câmeras infravermelhas. $O$ experimento foi conduzido no Laboratório de Animais do Departamento de Zootecnia da Universidade Federal de Viçosa. Foram utilizados trinta e cinco touros Nelore, com idade média de $14 \pm 0,3$ meses e peso médio de $437 \pm 47 \mathrm{~kg}$. Os animais foram submetidos a jejum de sólidos, insensibilizados e abatidos. A carcaça de cada animal foi dividida longitudinalmente e resfriada em câmara fria a $4^{\circ} \mathrm{C}$ por 24 horas. As carcaças resfriadas foram pesadas, sendo mensurado o comprimento de carcaça, área de olho de lombo (AOL) e espessura de gordura subcutânea (EGS). Em seguida, a seção entre a $9^{\mathrm{a}}$ e $11^{\mathrm{a}}$ costelas foi retirada para estimação indireta da composição química e física da carcaça, em $\mathrm{kg}$. Um sensor sincronizado com o software MATLAB (The MathWorks Inc., Natick, Massachusetts, EUA) foi usado para capturar imagens nas meias carcaças da esquerda. O sensor foi posicionado a uma altura de 1,50 metros em relação ao solo e a uma distância de 3,80 metros da carcaça. Uma imagem de cada carcaça foi escolhida para obter os parâmetros biométricos a serem analisados (área, volume, comprimento). Todos os procedimentos estatísticos foram realizados utilizando o software SAS 9.0 
(Statistical Analysis System Institute, Inc.). O LASSO (Least Absolute Shrinkage and Selection Operator) foi utilizado para selecionar as variáveis biométricas mais relevantes para predizer a composição física e química e posteriormente, o procedimento REG foi utilizado para calcular o valor $P$ das variáveis selecionadas no GLMSELECT. As equações desenvolvidas apresentaram coeficientes de determinação $\left(r^{2}\right)$ semelhantes ao das equações geradas pelos parâmetros tradicionais, no entanto as equações utilizando os dados biométricos apresentam menores erros de predição. Considerando apenas dados bidimensionais (2D), as predições de músculo, gordura, extrato etéreo e proteína bruta a partir e imagens foram significativas $(P<0.05)$ e apresentaram $r^{2}$ de $0,97,0,56,0,87$ e 0,93 , respectivamente. Utilizando dados tridimensionais (3D), associados aos $2 \mathrm{D}$, as predições de músculo, gordura, extrato etéreo e proteína bruta na carcaça apresentaram $\mathrm{r}^{2}$ de 0,$96 ; 0,84 ; 0,70$ e 0,91 , respectivamente. As mesmas predições a partir de AOL e EGS apresentaram $r^{2}$ de 0,96; 0,54; 0,59 e 0.92 , respectivamente. $O$ uso de imagens para classificação e avaliação de carcaças mostrou-se técnica promissora, mas são necessários mais estudos para aumentar a precisão dessa técnica. Os parâmetros biométricos em $2 \mathrm{D}+3 \mathrm{D}$ produziram a melhor estimativa do tecido muscular e a gordura nas carcaças, uma vez que avaliam uma maior proporção corporal em relação à parâmetros tradicionais (AOL e EGS) que avaliam apenas uma região específica.

PALAVRAS-CHAVE: biometria; precisão; predição.

AGRADECIMENTOS: CNPq, CAPES e FAPEMIG. 


\title{
CORTES PRIMÁRIOS E SECUNDÁRIOS DA CARCAÇA DE BOVINOS DA RAÇA NELORE CLASSIFICADOS PARA DIVERGENTES CLASSES DE CONSUMO ALIMENTAR RESIDUAL (CAR)
}

\author{
Heloisa de Almeida Fidelis ${ }^{1}$, Sarah Figueiredo Martins Bonilha ${ }^{2}$, Maria \\ Eugênia Zerlotti Mercadante ${ }^{2}$, Joslaine Noely dos Santos Gonçalves \\ Cyrillo $^{2}$, Wignez Henrique ${ }^{3}$, Hirasilva Borba ${ }^{4}$ \\ ${ }^{1}$ Faculdade de Ciências Agrárias e Veterinárias - Unesp campus Jaboticabal, Jaboticabal/SP \\ ${ }^{2}$ Centro APTA Bovinos de Corte - Instituto de Zootecnia, Sertãozinho/SP; ${ }^{3}$ Centro APTA - Polo \\ Regional Centro Norte, São José do Rio Preto/SP; ${ }^{4}$ Faculdade de Ciências Agrárias e Veterinárias - \\ Unesp campus Jaboticabal, Jaboticabal/SP.
}

Este trabalho foi realizado com o objetivo de identificar possíveis diferenças nos cortes primários e secundários da carcaça de bovinos machos da raça Nelore pertencentes a três diferentes classes de consumo alimentar residual (CAR), após o período de terminação em confinamento. Foram avaliados 27 animais em baias individuais, sendo nove de cada classe de CAR (baixo, médio e alto), com médias iniciais de peso corporal de $430 \pm 44 \mathrm{~kg}$ e idade de $709 \pm 24$ dias. O período experimental teve duração de 98 dias, sendo os animais abatidos quando atingiram média de $550 \mathrm{~kg}$ de peso corporal. A dieta foi formulada com silagem de milho, feno de braquiária, milho grão moído, farelo de soja e suplemento mineral, na proporção 35:65 de volumoso:concentrado, permitindo ganho médio diário de $1,880 \mathrm{~kg}$. Os animais foram divididos em 9 blocos de acordo com os pesos e a classe de CAR (o mais pesado de cada classe de CAR - Baixo, Médio e Alto - para o mais leve de cada classe). Portanto, o delineamento experimental foi em blocos, analisados pelo procedimento MIXED do SAS e médias comparadas pelo PDIFF ao nível de $5 \%$ de significância. A variação encontrada para o valor de CAR foi de 2,386 kg/dia (média de $1,183 \pm 0,442$ para baixo, 0,178 $\pm 0,299$ para médio e $1,203 \pm 0,457$ para alto CAR), sendo significativa $\left(<0,0001^{*}\right)$ devido a própria diferença no consumo entre as classes. Não foram encontradas diferenças significativas entre as classes de CAR para as variáveis relacionadas ao peso corporal (peso ao abate de $555 \pm 43,9 \mathrm{~kg}$, 
$568 \pm 57,2 \mathrm{~kg}$ e $550 \pm 63,7 \mathrm{~kg}$; para baixo, médio e alto CAR, respectivamente). Não houve diferença significativa entre as classes de CAR para os pesos de carcaças quente e resfriada (325 $\pm 28,7$ e $319 \pm 26,6 \mathrm{~kg}$ para baixo; $332 \pm 32,9$ e $325 \pm 32,2 \mathrm{~kg}$ para médio; $322 \pm 45,7$ e $315 \pm 44,7 \mathrm{~kg}$ para alto CAR), e cortes primários da carcaça (traseiro: $76,4 \pm 7,67,77,2 \pm 8,63$ e $75,4 \pm 10,6$; dianteiro: $68,5 \pm 5,18,69,0 \pm 6,75$ e $67,8 \pm 9,74$; ponta de agulha: $18,0 \pm 1,63$; $18,9 \pm 2,49$ e $17,8 \pm 2,96$; valores para baixo, médio e alto CAR, respectivamente). Sendo assim, a semelhança entre as classes de CAR na porção comestível (total dos cortes secundários para alto, médio e baixo CAR, respectivamente, no traseiro: $51,5 \pm 0,698 \mathrm{~kg}$, $51,4 \pm 0,630 \mathrm{~kg}$ e $51,7 \pm 0,821 \mathrm{~kg}$; e no dianteiro: $49,1 \pm 0,806 \mathrm{~kg}$, $49,2 \pm 1,09 \mathrm{~kg}$ e $48,9 \pm 1,52 \mathrm{~kg})$, ossos $(13,2 \pm 1,57$ e 11,3 $\pm 2,45$ para baixo; $13,1 \pm 1,71$ e $11,4 \pm 1,64$ para médio; $13,3 \pm 1,73$ e 10,9 $\pm 2,31$ para alto CAR; valores em $\mathrm{kg}$ do traseiro e dianteiro, respectivamente) e aparas totais da carcaça $(11,7 \pm 1,14$ e $8,46 \pm 1,06$ para baixo; $12,6 \pm 1,52$ e $8,75 \pm 1,42$ para médio; $11,2 \pm 1,34$ e 7,82 $\pm 1,35$ para alto CAR; valores em $\mathrm{kg}$ do traseiro e dianteiro, respectivamente) também já era esperada. Os animais mais eficientes (baixo CAR), mesmo consumindo menos, apresentaram cortes de carcaça e cárneos comerciais semelhantes àqueles que consumiram mais (médio e alto CAR), ou seja, o menor consumo de alimentos por animais machos da raça Nelore selecionados para CAR não prejudica a produção de carne.

PALAVRAS-CHAVE: bovinocultura de corte; confinamento; eficiência alimentar.

AGRADECIMENTOS: Fapesp, CNPq, Instituto de Zootecnia. 


\title{
PERDAS ECONÔMICAS POR CONDENAÇÃO TOTAL DE CARCAÇAS DE BOVINOS EM FRIGORÍFICOS LOCALIZADOS NO ESTADO DE MATO GROSSO ENTRE 2007 E 2016
}

\author{
${ }^{1}$ Henrique Castrillon Leiva Rolim, ${ }^{2}$ Diego Pierotti Procópio \\ ${ }^{1}$ Discente do curso de Zootecnia da Universidade Federal de Mato Grosso (UFMT); ${ }^{2}$ Professor do \\ Departamento de Zootecnia e Extensão Rural (DZER) da Universidade Federal de Mato Grosso (UFMT)
}

No ano de 2016, o estado de Mato Grosso foi o que possuiu o maior registro de rebanho efetivo de bovinos dentre as unidades federativas brasileiras, com um total de 30,29 milhões de cabeças $(13,9 \%$ do total nacional) e também o que mais realizou abates, com um total de 4,69 milhões de animais (13,9\% do total nacional). No período de 2007 a 2016, no estado de Mato Grosso foram abatidos 45,39 milhões de bovinos, dos quais, 610,84 mil carcaças foram descartadas por uma série de causas que implicam na condenação total nos frigoríficos. Nesse contexto, objetivou-se determinar as perdas econômicas originárias da condenação total de carcaças de bovinos em frigoríficos localizados no estado de Mato Grosso para o período de 2007 a 2016. Para o alcance do objetivo proposto, as informações sobre os abates e a quantidade de carcaças descartadas por condenação total em Mato Grosso foram obtidas na base de dados do Sistema de Inspeção Federal (SIF), o preço médio anual da arroba do boi gordo foi obtida na base de dados do Instituto Mato-Grossense de Economia Agropecuária (IMEA) e o Índice Geral de Preços (IGP-DI) para a conversão dos valores nominais na base de dados da Fundação Getúlio Vargas (FGV). A determinação da perda econômica foi realizada para cada ano do período de 2007 a 2016, por meio da multiplicação da quantidade de carcaças descartadas (com rendimento médio de 480 quilos) pelo preço médio anual da arroba do boi gordo. Posteriormente, os valores monetários da série analisada foram atualizados para o ano de 2016 através da utilização do IGP-DI. Os valores alcançados das perdas econômicas de carcaças descartadas por meio da condenação 
total para o estado de Mato Grosso em 2007 foram de R $\$$ 123.863.280,22, em 2008 de $R \$ 136.405 .038,08$, em 2009 de $\mathrm{R} \$ 136.405 .038,08$, em 2010 de $\mathrm{R} \$ 116.262 .099,68$, em 2011 de $\mathrm{R} \$ 126.980 .427,02$, em 2012 de $\mathrm{R} \$ 120.075 .896,27$, em 2013 de $\mathrm{R} \$ 113.811 .188,34$, em 2014 de $\mathrm{R} \$ 94.772 .472,38$, em 2015 de $\mathrm{R} \$ 46.492 .587,54$ e em 2016 de $\mathrm{R} \$ 132.169 .774,24$. Dessa forma, o valor total da perda econômica foi de $R \$ 1.130 .537 .878,73$ no período de 2007 a 2016. Com exceção do ano de 2007, a contaminação foi principal causa para a condenação total das carcaças nos frigoríficos mato-grossenses no período analisado, com um total de 211,16 mil casos registrados (representando $34,5 \%$ do total de carcaças condenadas totalmente de 2007 a 2016). Esse fator é decorrente principalmente de falhas em atividades operacionais realizadas sobre o animal e a carcaça durante o processo produtivo no frigorífico. Recomenda-se a utilização de ferramentas administrativas que visem à melhoria contínua do processo produtivo dos frigoríficos mato-grossenses, com o intuito de reduzir a ocorrência de descartes de carcaças por meio da condenação total. Esse tipo de estratégia é de extrema importância quanto ao aumento da competitividade da cadeia produtiva de carne bovina do estado de Mato Grosso.

PALAVRAS-CHAVE: abates; pecuária de corte; processo produtivo. 


\title{
CONCENTRAÇÕES DE ÁCIDOS ORGÂNICOS E AMÔNIA RUMINAL EM DIETAS CONTENDO DIFERENTES TEORES DE FIBRA FISICAMENTE EFETIVA PROVENIENTE DE VOLUMOSO
}

\author{
Herlon M. Alhadas ${ }^{1}$, Nathália Veloso Trópia ${ }^{2}$, Pauliane Pucetti ${ }^{3}$, Marcos \\ Vinícios C. Pacheco ${ }^{1}$, Ana Clara Baião Menezes ${ }^{1}$, Letícia Arthuso Godoi ${ }^{1}$, \\ Sebastião de Campos Valadares Filho ${ }^{4}$ \\ ${ }^{1}$ Doutorando em Zootecnia, Universidade Federal de Viçosa; ${ }^{2}$ Graduanda em Zootecnia, \\ Universidade Federal de Viçosa, ${ }^{3}$ Mestranda em Zootecnia, Universidade Federal de Viçosa, \\ ${ }^{4}$ Professor Titular DZO/UFV.
}

As concentrações de ácidos orgânicos e de amônia ruminal são função de uma combinação de vários fatores, e por este motivo, sua eficiência de uso para comparação entre tratamentos vem sendo questionada. Logo, objetivou-se com o presente estudo avaliar as modificações nas concentrações e pool de ácidos orgânicos e amônia ruminal promovidas pela inclusão de fibra fisicamente efetiva (FDNfef) proveniente de volumoso em dietas de grão de milho inteiro. Foram utilizados cinco bovinos Nelore machos não castrados fistulados no rúmen $(P C=393 \pm 9 \mathrm{~kg})$ em delineamento tipo quadrado latino $5 \times 5$. As dietas utilizadas foram: controle, sem adição de volumoso e com $850 \mathrm{~g} / \mathrm{Kg}$ de milho grão inteiro e $150 \mathrm{~g} / \mathrm{Kg}$ de uma ração comercial peletizada; e dietas contendo 50, 150, 250 e $350 \mathrm{~g} / \mathrm{Kg}$ de inclusão de cana-de-açúcar, sem a presença do pellet e com a adição de um suplemento proteíco mineral para balanceamento dos nutrientes. O teor de FDNfef foi avaliado através do conjunto de peneiras Pen State Particle Separator. Foram realizados, por período, oito horários de coleta de líquido ruminal em intervalos de 9 horas, para estimativa das concentrações dos ácidos orgânicos (lactato, propionato, acetato, butirato e valerato) e NH3. Para o cálculo do pool de cada metabólito e quantificação do líquido ruminal, foram realizados, por período, dois dias de esvaziamento ruminal (antes e 3 horas após a alimentação). A concentração obtida foi corrigida pela quantidade de líquido para se estimar o pool dos intermediários. Foram 
testados através do $S A S \otimes$ (versão 9.4) os efeitos linear, quadrático e cúbico para os níveis de inclusão de FDNfef, os quais foram contrastados com o controle através do teste de Dunnett $(P<0,05)$. Os níveis de FDNfef obtidos foram de 20,5, 61,4, 102,4 e 143,3 $\mathrm{g} / \mathrm{kg}$, respectivamente, em ordem crescente de inclusão de volumoso. Em relação aos ácidos orgânicos, o mesmo padrão de resposta só foi verificado para o propionato, sendo este linear crescente tanto na concentração $(P<0,05)$ quanto no pool $(P<$ $0,05)$. Já para o acetato foi verificado um aumento linear somente no seu pool $(P=0,09)$, não ocorrendo efeito em sua concentração $(P>0,05)$. Consequentemente, a relação acetato:propionato só foi significativa quando se considerou o pool total, havendo um aumento linear $(P<0,05)$ para este índice. Também foi observada uma diferença em relação à concentração de butirato $(P=0,07)$, que respondeu de forma linear decrescente ao aumento de FDNfef na dieta. Todavia, a concentração e pool de $\mathrm{NH} 3$ seguiram o mesmo padrão, respondendo de forma linear crescente $(P<0,05)$ aos níveis de FDNfef. Uma diferença de até 9 litros de líquido ruminal foi observada para uma mesma concentração, sendo que esta variável aumentou de forma linear em relação aos níveis de FDNfef $(P<0,05)$. Logo, a concentração de ácidos orgânicos pode não ser um bom parâmetro para avaliação de dietas, tendo a concentração de amônia melhor relação com seu pool total.

PALAVRAS-CHAVE: fermentação ruminal; cana-de-açúcar; milho grão inteiro.

AGRADECIMENTOS: CNPq, CAPES, INCT-CA, FAPEMIG. 


\title{
METABOLIC AND HORMONAL RESPONSES ON PERIPARTUM OF GRAZING BEEF CATTLE SUPPLEMENTED ON PRE-PARTUM
}

\author{
Hudson Caio Martins ${ }^{1}$, Samira Silveira Moreira1, Júlia Avansi Marques², \\ Bruno Inácio Correa Oliveira ${ }^{3}$, Isabela de Paula Cidrine ${ }^{1}$, Matheus Fellipe \\ de Lana Ferreira ${ }^{1}$, Luciana Navajas Rennó ${ }^{1}$ \\ ${ }^{1}$ UFV; ${ }^{2} F M V Z-U S P ;{ }^{3} F A I T$.
}

Nutritional status at calving is the main factor affecting time to pregnancy. Metabolic parameters that relate nutritional status to physiological processes within grazing animals, mainly Zebu, are not fully understood. This study evaluated the effects of 60-day prepartum energetic-protein supplementation on metabolic and hormonal responses on peripartum of grazing beef cattle. Thirtyeight Nellore multiparous cows averaging $230 \pm 10$ days of gestation were used. Two treatments were evaluated: control, without supplementation and daily supplementation ( $30 \%$ of CP) with $1.5 \mathrm{~kg}$ during the 60 days before expected calving. The experiment was conducted in a completely randomized design. Blood samples were collected before supplementation at 30 days pre-partum, at calving, 15,30 and 45 days post-partum to quantify insulin-like growth factor (IGF-1), insulin, total triiodothyronine (T3), total thyroxine (T4) by chemiluminescence and glucose by calorimetric enzymatic method. The ANOVA for were performed considering $\alpha=0.10$ and repeated measures over time on PROC MIXED in SAS 9.4. There was no effect of supplementation on glucose, insulin and IGF-1 concentrations $(P>0.10)$. However, the concentration of these variables changed significantly $(P<0.10)$ along the days relative to calving. For glucose, higher serum concentrations were observed at calving (day $0-80,37 \mathrm{mg} / \mathrm{dL}$ ), decreased at 15 days and then stabilized at baseline $(P<0.10)$. At calving, cows are under stressful conditions, thus glucocorticoids act stimulating glycogen catabolism in order to minimize the stress during calving. Decreased glucose concentrations after calving were probably caused by reduced dry matter intake, and also to the 
higher energy demand for milk production, using glucose to produce lactose. During the experiment, insulin and IGF-1 levels behavior were similar and also not influence by supplementation $(P>0.10)$. The higher values for both hormones were during calving day, possibly due to the increase of blood glucose, and its decrease during early lactation is part of the homeorhetic changes to support galactopiesis. Thereafter, IGF-1 concentrations were restored after 30 days post-partum, and insulin at 45 days. On the other hand, both T3 and T4 presented interaction between supplementation and days relative to calving $(P<0.10)$, concentrations were different at day -30 . Ruminants during food restriction adapt lowering the maintenance requirements by decreasing basal metabolism rate, which can explain the reduction of both total T3 and T4 on prepartum for non-supplemented animals compared to supplemented animals. We conclude that supplementation had no effect $(P>0.10)$ towards serum concentration of glucose and hormones. Concentration of those variables changed significantly $(P<0.10)$ along the days relative to calving.

PALAVRAS-CHAVE: physiology; gestation; nelore.

AGRADECIMENTOS: CNPq e CAPES. 


\title{
QUAL É O MÁXIMO DE NITROGÊNIO QUE MODIFICA A ÁREA DE OCUPAÇÃO DO CAPIM MARANDU?
}

\author{
Jenifer Santos de Mattos ${ }^{1}$, Pedro Emanuel da Costa Lourenço², Kyron \\ Cabral Sales ${ }^{3}$, João Bosco de Campos Filho ${ }^{4}$, Lívia Vieira de Barros ${ }^{5}$, \\ Joadil Gonçalves de Abreu ${ }^{6}$, Carlos Eduardo Avelino Cabral ${ }^{7}$

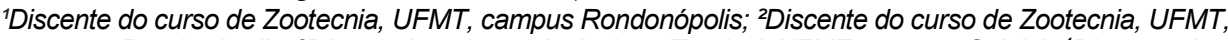

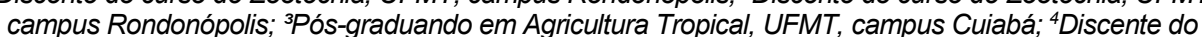 \\ curso de Agronomia, UFMT, campus Cuiabá; ${ }^{5}$ Professor do DZER, UFMT, campus Cuiabá; ${ }^{6}$ Professor \\ do DZER, UFMT, campus Cuiabá; 'PProfessor do ICAT, UFMT, campus Rondonópolis
}

A bovinocultura de corte, no Brasil, ocorre predominantemente em sistemas de pastejo. Com intuito de aumentar a taxa de lotação, estratégias como a adoção de lotação rotativa vinculada a adubação nitrogenada vêm sendo utilizadas com maior frequência nas propriedades. No entanto, para assegurar a eficiência deste método de colheita de forragem, é necessário prioritariamente dimensionar a área de ocupação, que diz respeito ao quanto de área de pasto é demandada diariamente para alimentação de cada animal ( $\left.\mathrm{m}^{2} \cup \mathrm{A}-1 \mathrm{dia}-1\right)$. Assim, objetivouse quantificar a influência da adubação nitrogenada na área de ocupação do capim Marandu (Brachiaria brizantha cv. Marandu). O experimento foi realizado na fazenda experimental da Universidade Federal de Mato Grosso, campus Cuiabá, localizada no município de Santo Antônio do Leverger, no período de novembro de 2015 a abril de 2016 (águas 2015/2016) e de novembro 2016 a abril de 2017 (águas 2016/2017). O delineamento utilizado foi inteiramente casualizado, com cinco tratamentos e sete repetições. Os tratamentos consistiram em doses de nitrogênio após cada corte do capim Marandu: 0, 25, 50, 75 e $100 \mathrm{~kg}$ ha-1, na forma de sulfato de amônio. As alturas de desfolhação e de resíduo adotadas foram de 40 e $20 \mathrm{~cm}$, respectivamente. Após cada colheita de forragem, realizava-se a adubação conforme os tratamentos mencionados. Para a estimativa da área de ocupação adotou-se o consumo diário de matéria seca em $2,5 \%$ do peso vivo, e as eficiências de colheita de $50 \%$ e $75 \%$ (como não houve pastejo no experimento o termo "eficiência de pastejo" foi substituído por "eficiência de colheita"). 
Os dados foram submetidos ao teste de regressão linear, quadrática e response-linear-plateau $(P=0,10)$. Em ambas as eficiências de colheita, a área de ocupação foi descrita por modelo quadrático $(P<0,10)$, contudo também explicado por responselinear-plateau $(P<0,10)$, de modo que não houve efeito dos anos. Para a eficiência de colheita de $50 \%$, em ausência de adubação nitrogenada estimou-se uma área de ocupação de $190 \mathrm{~m}^{2}$ UA-1 dia-1 e, a partir da dose de nitrogênio de $52 \mathrm{~kg}$ ha -1 corte-1, estabilizou-se em uma área de ocupação de $100 \mathrm{~m}^{2}$ UA-1 dia-1. Por outro lado, quando se utilizou uma eficiência de colheita de $75 \%$, em ausência de adubação nitrogenada estima-se uma área

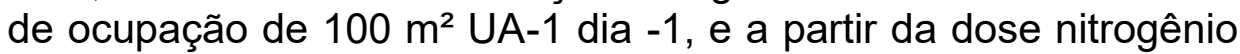
de 52 kg ha-1 corte-1, estabilizou-se em uma área de ocupação de $54 \mathrm{~m}^{2}$ UA-1 dia-1. A área de ocupação mencionada comumente na

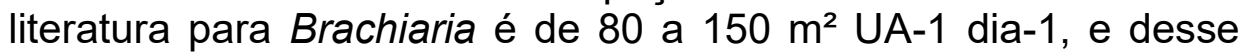
modo, percebe-se que estes valores estão associados a sistemas que não utilizam nitrogênio na adubação de manutenção. Desta forma, a adubação nitrogenada diminui a área de ocupação e promove aumento da taxa de lotação em sistemas de bovinocultura de corte, admitindo-se em lotação rotativa doses de nitrogênio máxima de aproximadamente $50 \mathrm{~kg}$ ha-1 por ciclo de pastejo.

PALAVRAS-CHAVE: adubação de manutenção; braquiarão; lotação rotativa.

AGRADECIMENTOS: CNPq. 


\title{
UTILIZAÇÃO DE DIFERENTES FONTES DE GEMA DE OVO NO MEIO DE CRIOPRESERVAÇÃO SEMINAL DE BOVINOS
}

\author{
Jéssica Ligoski Cabral ${ }^{1}$, Tathiana Ferguson Motheo ${ }^{2}$, Luciana Keiko \\ Hatamoto-Zervoudakis ${ }^{3}$, Pedro Paulo Tsuneda ${ }^{4}$, Rafael Moraes de Assis ${ }^{1}$, \\ Marlon Eduardo dos Santos Rodrigues ${ }^{1}$, Gilmar Ferreira Rodrigues ${ }^{1}$ \\ ${ }^{1}$ Discente do Curso de Medicina Veterinária Universidade Federal de Mato Grosso, Cuiabá, MT, \\ Brasil; '2Docente no programa de Pós Graduação em Ciência Animal (PPGCA) - Universidade \\ Federal de Mato Grosso, Cuiabá, MT, Brasil; ${ }^{3}$ Docente no programa de Pós Graduação em Ciência \\ Animal (PPGCA) e do Curso de Medicina Veterinária - Universidade Federal de Mato Grosso, \\ Cuiabá, MT, Brasil; " ${ }^{4}$ Doutorando pelo programa de Pós Graduação em Ciência Animal (PPGCA) - \\ Universidade Federal de Mato Grosso, Cuiabá, MT, Brasil.
}

A gema de ovo é um dos crioprotetores extracelulares mais utilizados nos meios de criopreservação seminal. Esta atua como filme protetor sobre as membranas biológicas devido à presença de lipoproteínas de baixa densidade e alto peso molecular em sua composição. Usualmente, a gema de ovo de galinha (Gallus domesticus) é a mais utilizada em meios de criopreservação. Dessa forma, o objetivo do presente estudo foi testar fontes alternativas de gema de ovo ao meio diluidor e avaliar quais delas promovem melhor efeito protetivo sobre a membrana plasmática de espermatozoides bovinos durante o processo de criopreservação. Foram utilizados quatro touros da raça Nelore (Bos taurus indicus) hígidos, em idade reprodutiva e com fertilidade comprovada. O sêmen foi coletado por meio de eletroejaculação e submetido às análises imediatas de volume, cor, odor, turbilhonamento, motilidade e vigor espermáticos e concentração espermática. Após avaliação, cada ejaculado foi dividido em quatro alíquotas as quais

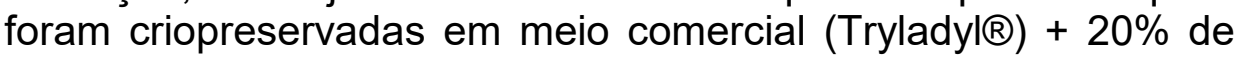
gema de ovo + água bidestilada (proporção 3:1:1, respectivamente), sendo a fonte de gema variável entre os tratamentos. Dessa forma, os tratamentos foram divididos em: GB: gema de ovo de galinha comercial; GC: gema de ovo de galinha caipira; CO gema de ovo de codorna e PT: gema de ovo de pata. Para análise das amostras pós descongelamento, o sêmen foi descongelado em banho maria a $37^{\circ} \mathrm{C}$ por 30 segundos e 
submetido às avaliações de motilidade e vigor espermáticos e à integridade e funcionalidade da membrana plasmática por meio da coloração de eosina-nigrosina (EOS) e pelo teste de expansão hiposmótico (HOST). O sêmen fresco apresentou valores médios de $70 \%$ (0-100\%) de motilidade, 3 (0 a 5) de vigor, 3 (0 a 5) de turbilhonameto e concentração espermática de $70 \times 10^{6}$ espermatozoides $/ \mathrm{mL}$. Após descongelamento não foram encontradas diferenças significativas para as variáveis de motilidade e vigor espermáticos, apresentando estes valores médios de $27,5 \%$ e 1,5 para GC, $27,5 \%$ e 2 para CO, $40 \%$ e 2 para GB e $40 \%$ e 2,5 para PT. Ao avaliar a integridade da membrana plasmática, por meio da coloração de EOS, foram constatadas porcentagens médias de espermatozoides com a membrana íntegra de 55,75\% (GC), 64\% (CO), 54,25 (GB) e 58,5\% (PT) $(\mathrm{P}>0,05)$. Já ao avaliar a funcionalidade e integridade desta mesma membrana por meio do HOST, foram observados $34 \%$ (GC), $42,5 \%$ (CO), $46 \%$ (GB) e 52,5\%(PT) de espermatozoides com cauda enrolada $(P>0,05)$. Com base nos resultados apresentados, pôdese concluir que independentemente da fonte de gema de ovo utilizada, o efeito protetivo sobre a membrana plasmática de espermatozoides bovinos é o mesmo. Entretanto, acredita-se que a utilização de maior número amostras sejam necessárias para comprovação de tais resultados.

PALAVRAS-CHAVE: membrana plasmática; espermatozoide; crioprotetor. 


\title{
AVALIAÇÃO DA SUPLEMENTAÇÃO MINERAL INJETÁVEL (SUPLENUT®, BIOGÉNESIS BAGÓ) NA MELHORIA DO DESEMPENHO EM BEZERROS E BEZERRAS DA RAÇA NELORE
}

\author{
João Paulo Lollato ${ }^{1}$, Milton Maturana Filho ${ }^{3}$, Reuel Luís Gonçalves ${ }^{2}$, \\ Vinícius Tadano Marques ${ }^{4}$, Guillermo A. Mattioli ${ }^{5}$, Juan M. Rodríguez \\ Pérsico $^{6}$, Ed Hoffmann Madureira ${ }^{7}$ \\ ${ }^{1}$ Biogénesis-Bagó, Curitiba-PR, Brasil - e-mail: JoaoPaulo.Lollato@biogenesisbago.com; \\ ${ }^{2}$ Biogénesis-Bagó, Curitiba-PR, Brasil; ${ }^{3}$ MF VetPlan Consultoria Agropecuária, Águas da Prata - \\ $S P$, Brasil; ${ }^{4}$ Médico Veterinário autônomo, Umuarama- $P R$, Brasil ${ }^{5}$ Universidad Nacional de La \\ Plata, Buenos Aires Argentina; ${ }^{6}$ Biogénesis Bagó, Garin Buenos Aires, Argentina; ${ }^{7}$ Departamento \\ de Reprodução animal FMVZ/ USP, Pirassununga-SP, Brasil.
}

A suplementação estratégica de minerais durante o período pré desmame tem sido associada a melhoria do desempenho e do desenvolvimento ponderal em bezerros de corte. A carência de Zinco e Cobre, pode atrasar o desenvolvimento e consequentemente um atraso no programa genético e/ou comercial das propriedades. O Objetivo desse estudo foi verificar a eficiência da utilização da suplementação mineral injetável (SUPLENUT®, Biogénesis Bagó) aos 60 dias de vida em bezerros e bezerras da raça nelore, na melhoria do ganho de peso até os 150 dias de vida. O experimento foi conduzido na Fazenda Santa Virginia da CIA Mate Laranjeira, na cidade de Ponta Porã- MS. Os grupos experimentais foram G1) Suplementação, que recebeu 1 dose de SUPLENUT® aos 60 dias de vida (Machos, $N=130$ e fêmeas $n=120$ ) e; $G 2$ ) controle (placebo, Machos, $N=130$ e fêmeas $n=140$ ), totalizando 520 animais no estudo. Desta forma, machos $(n=260)$ e femeas $(n=260)$ foram distribuídos aleatoriamente entre os grupos experimentais. A composição do produto (SUPLENUT®) é de 1,50 $\mathrm{g}$ de edetato dissódico de cobre-zinco e de 5,00 $\mathrm{g}$ de edetato dissódico de zinco solução a cada $100 \mathrm{~mL}$ de veículo q.s.p. A dose aplicada nos animais foi de $1 \mathrm{~mL}$ para cada $50 \mathrm{~kg}$ de peso vivo, sendo que o peso médio dos animais no início do experimento era de $101,15 \mathrm{~kg}$. A avaliação de peso foi realizada aos dias $60 \pm 7$, $105 \pm 7$ e $150 \pm 7$ de vida. As vacas com bezerros ficaram todas no 
mesmo lote, assim como as vacas com bezerras. Foi tomado o cuidado de utilizar animais nascidos no mesmo mês dentro dos lotes. Os dados obtidos foram submetidos à análise de variância e normalidade dos resíduos e posteriormente pelo teste PROC MIXED para, utilizando-se o programa Statistical Analyses System (SAS, 9.3) adotando-se nível de significância de 5\%. Houve efeito da suplementação injetável no peso, independente do sexo dos animais entre 105 e 150 dias $(G 1=100,1$ vs $G 2=98,4)$ e consequentemente no ganho de peso durante o experimento $(\mathrm{G} 1=186,4 \mathrm{~kg}$ vs $\mathrm{G} 2=181,2 \mathrm{~kg})$. O efeito da suplementação injetável colaborou com o ganho total de peso nos bezerros (G1=195,6 vs $G 2=192,3)$. Nas femeas, a suplementação injetável, melhorou o ganho de peso total (G1=175,8 kg vs G2=167,6 kg) e também o peso aos 150 dias de vida $(\mathrm{G} 1=276,9 \mathrm{~kg}$ vs $\mathrm{G} 2=270,5$ $\mathrm{kg}$ ). Portanto, a suplementação estratégica com SUPLENUT® (Biogénesis Bagó) aos 60 dias de vida, colaborou com a melhoria do desempenho de bezerros e bezerras lactentes da raça Nelore.

PALAVRAS-CHAVE: bezerros; Suplementação injetável; Nelore. 


\section{COMPARAÇÃO DE DOIS SUPLEMENTOS MINERAIS E VITAMÍNICOS INJETÁVEIS, NO DESEMPENHO DE FÊMEAS NELORE EM CONFINAMENTO}

João Paulo Lollato', Milton Maturana Filho² , Reuel Luiz Gonçalves', Bruno Di Rienzo', Guillermo A. Mattioli ${ }^{3}$, Juan M. Rodríguez Pérsico ${ }^{4}$, Ed Hoffmann Madureira ${ }^{5}$, Lucas Vaz $^{6}$

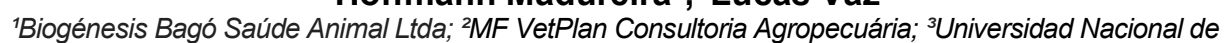
La Plata; ${ }^{4}$ Biogénesis Bagó, Garin Buenos Aires, Argentina; ${ }^{5}$ Departamento de Reprodução animal FMVZ/ USP, Pirassununga-SP; ${ }^{6}$ Médico Veterinário autônomo, Planalto-SP, Brasil.

A suplementação estratégica de vitaminas, minerais e aminoácidos injetáveis, durante o período de confinamento podem auxiliar no aumento da atividade de enzimas antioxidativas e consequentemente melhorar a adaptabilidade e o desempenho de bovinos em confinamento. O Objetivo desse estudo foi comparar dois suplementos injetáveis utilizados em entrada de confinamento (Kit Adaptador MIN e VIT, Biogénesis Bagó e; Aminofort@, Vitafort) na melhoria do ganho de peso em novilhas Nelore. O experimento foi conduzido na Fazenda Califórnia, na cidade de Planalto-SP. Os grupos experimentais foram G1) Kit Adaptador ( $N=103$ ) e; G2) Aminofort $(\mathrm{N}=103)$, totalizando 206 animais distribuídos aleatoriamente. A suplementação injetável foi realizada na entrada do confinamento e outra dose 30 dias após, na realização da primeira pesagem. As doses de cada um dos produtos foram realizadas de acordo com a recomendação. A composição do KIT ADAPTADOR é de: 5.950.000 UI de vitamina A; 5.000 UI de vitamina $\mathrm{E}, 1 \mathrm{~g}$ de edetato de Cobre, $4 \mathrm{~g}$ de edetato de zinco, $1 \mathrm{~g}$ de edetato de manganês e $0,5 \mathrm{~g}$ de selênio na forma de selenito de sódio para cada $100 \mathrm{~mL}$ de excipientes q.s.p. A composição do Aminofort $\circledast$ é de: 420 mg L-Ácido Glutâmico, $1 \mathrm{~g}$ L-Lisina, Cloridrato, $210 \mathrm{mg}$ Acetil Metionina, $60 \mathrm{mg}$ L - Triptofano, $210 \mathrm{mg}$ de $\mathrm{L}$ - Histidina Cloridrato, $5 \mathrm{~g}$ de Hidrolisados de Órgãos e Glândulas, 16 mg de Sódio, 3 mg de Cobalto, 42 mg Magnésio, 15 $\mathrm{mg}$ de Cobre, $15 \mathrm{mg}$ de Manganês, $8 \mathrm{mg}$ de Zinco, $10 \mathrm{mg}$ de Ferro Dextrano, 500 mg de Vitamina B1 (Cloridrato de Tiamina), 500 mg 
de Vitamina B6 (Cloridrato de Piridoxina) e 2,2 g de Niacina (Ácido Nicotínico) para cada $100 \mathrm{~mL}$ de excipientes q.s.p. A segunda avaliação de peso foi realizada aos dias 30 dias após entrar no confinamento e também na saída para o abate. Os ganhos em energia metabolizável foram calculados de acordo com o NRC (2000). Os dados obtidos foram submetidos à análise de variância e normalidade dos resíduos e posteriormente pelo teste PROC MIXED para, utilizando-se o programa Statistical Analyses System (SAS, 9.3) adotando-se nível de significância de $5 \%$. Não houve diferença de peso entre os grupos na primeira pesagem, no entanto, os animais do $\mathrm{G} 1$, tiveram maior peso $(p<0,05)$ ao final do confinamento $(\mathrm{G} 1=379,4 \pm 3,8 \mathrm{~kg}$ vs $\mathrm{G} 2368 \pm 2,7 \mathrm{~kg})$, devido a um maior ganho de peso na segunda etapa do estudo ( $G 1=48,6 \pm$ $2,7 \mathrm{~kg}$ vs $41,1 \pm 3,1 \mathrm{~kg}$ ) para $\mathrm{G} 1$ e $\mathrm{G} 2$, respectivamente $(\mathrm{p}<0,05)$, o que está relacionado a um efeito das maiores quantidades de vitaminas e microminerais do suplemento Kit Adaptador, que pode ter diminuído as condições de estresse oxidativo, principalmente por aumentar a atividade de metaloenzimas, como a superóxido dismutase, que são dependentes de cobre e zinco para sua melhor atividade em mamíferos. Portanto, a suplementação estratégica com Kit Adaptador® (Biogénesis Bagó) colaborou com a melhoria do desempenho de novilhas em confinamento e foi superior ao desempenho de suplementos injetáveis com minerais e aminoácidos.

PALAVRAS-CHAVE: confinamento; novilhas; suplementação injetável. 


\title{
EFFECTS OF DAILY OR EVERY THREE DAYS PROTEIN OR PROTEIN AND STARCH SUPPLEMENTATION ON INTAKE AND DIGESTIBILITY OF NELLORE HEIFERS FED MEDIUM-QUALITY TROPICAL GRASS
}

\author{
João Vitor Ribeiro Lovatti ${ }^{1}$, William Lima Santiago dos Reis ${ }^{2}$, Malber \\ Nathan Nobre Palma ${ }^{2}$, Giselle Priscila Costa ${ }^{3}$, Aline Maria Monteiro \\ Canaan Garcia ${ }^{1}$, Aline Naime Rodrigues ${ }^{3}$, Edenio Detmann ${ }^{4}$ \\ ${ }^{1}$ Aluno graduação Universidade Federal de Viçosa; ${ }^{2}$ Doutorando Universidade Federal de Viçosa; \\ ${ }^{3}$ Mestranda Universidade Federal de Viçosa; ${ }^{4}$ Professor Universidade Federal de Viçosa.
}

The objective was to evaluate the effects of daily or every three days supplementation with protein or protein and starch on intake and digestibility in Nellore heifers fed a high-quality tropical grass. Five rumen cannulated Nellore heifers (299 $\pm 7.5 \mathrm{~kg}$ of BW) were used in a $5 \times 5$ Latin square design. Treatments were: control, non-supplemented (CONT); $200 \mathrm{~g}$ of CP (Crude Protein) daily (P/D); $200 \mathrm{~g}$ of CP and $400 \mathrm{~g}$ of starch daily (PS/D); $600 \mathrm{~g}$ of CP every three days (P/3D); $600 \mathrm{~g}$ of CP and $1200 \mathrm{~g}$ of starch every three days (PS/3D). The basal diet consisted of a high-quality Tifton hay (Cynodon sp; 8\% CP;75\% NDF (Neutral Detergent Fiber)), fed ad libitum twice daily at $06 \mathrm{~h}$ and $18 \mathrm{~h}$. The experiment consisted of five experimental periods, which lasted 27 days each, 15 days of adaptation to the treatments and 12 days for sample collections. Voluntary forage and digestible OM (Organic Matter) intake were quantified day 16 to 22 (covering 2 supplementation cycles). Statistical analyses were performed using the MIXED procedure of SAS 9.4. Treatments effects were interpreted according to a $2 \times 2$ +1 factorial arrangement (two frequencies, daily versus every 3 days; starch supplementation, with or without; and a control treatment). Significances were declared at $\mathrm{P}<0.05$. Overall, supplementation increased $(\mathrm{P}<0.02)$ intake of $\mathrm{CP}$ and digested $\mathrm{OM}$ (DOM), and the ratio of CP intake to DOM intake (CP:DOM). Treatments with supplementation at every $3 \mathrm{~d}$ (P/3D and PS/3D) had lower forage intake, which consequently decreased OM, NDF 
and DOM intake. Starch supplementation (PS/D and PS/3D) increased DOM intake ( $\mathrm{kg} / \mathrm{d}$ ) and decreased CP:DOM and NDF intake $(\mathrm{g} / \mathrm{kg}$ BW). The interaction between supplementation and starch addition did not affect $(P>0.61)$ intake. Intake was affected $(P<0.01)$ by interaction between treatments and sampling days. On the first day of the supplementation cycle, treatments with infrequent supplementation (P/3D and PS/3D) had lower forage intake $(P<0.01)$, without differences among treatments $(P ? 0.23)$ on days 2 and 3 of the supplementation cycle. Supplementation increased $(P<0.01)$ total digestibility of $\mathrm{OM}, \mathrm{CP}$, and diet DOM content, whereas NDF digestibility was not affected $(P>0.93)$ by treatments.

PALAVRAS-CHAVE: daily supplementation; infrequent supplementation; protein supplementation.

AGRADECIMENTOS: CNPq, Fapemig, INCT - Ciência Animal. 


\title{
NUTRITIONAL AND METABOLIC EVALUATION IN NELLORE COWS SUPPLEMENTED DURING PERI AND/OR POSTPARTUM KEEPING IN TROPICAL PASTURE
}

\author{
João Vitor Ribeiro Lovatti, Claudia Batista Sampaio, Aline Souza Trece, \\ Felipe Henrique de Moura, Thiago Ramalho Moreira,Edson Junior dos \\ Santos, Edenio Detmann \\ Universidade Federal de Viçosa - Animal Science Department
}

The aim of this study was to evaluate the effects of supplementation at peri and/or postpartum period on nutritional and metabolic responses in Nellore cows keeping in tropical pasture (Brachiaria decumbens). Forty-five pregnant cows with an average body weight (BW) of $543 \pm 130 \mathrm{~kg}$ and $200 \pm 30$ days of gestation were housed in 8 paddocks with full access to water and mineral mix. Treatments evaluated during peripartum were: control (mineral $\mathrm{mix})$ and supplemented $(0.2 \%$ of BW in supplement with $43.5 \%$ of crude protein, CP). After parturition, 4 supplementation strategies were evaluated: control (mineral mix peri and postpartum), SN (supplemented only at peripartum), NS (supplemented only at portpartum), and SS (supplemented peri and portpartum). The study was analyzed using PROC MIXED in SAS 9.4 (SAS Inst., Cary, NC) assuming a completely randomized design with 2 treatments at peripartum and 4 treatments at postpartum. Treatment, animal and paddock were considered as a fixed effect whereas treatment within paddock was considered random in both periods of evaluation. In peripartum period, there was no effect $(P$ $>0.10$ ) of supplementation on the values of performance characteristics and on ADGconc (average daily gain of conceptus) and BWbirth. Similarly, at peripartum, no significant differences $(P$ $>0.10$ ) on the intake in percentage and $\mathrm{g} / \mathrm{kg}$ of BW parameters was observed. Yet, compared with control, supplementation did not $(\mathrm{P}>$ 0,10 ) affect the digestibility of OM and NDFap, but, a significant difference $(P<0.10)$ was observed in $C P / O M$ digestibly ratio and $\mathrm{CP}$ digestibility at peripartum. The supplementation at peripartim 
affected $(P<0.10)$ plasma ureic nitrogen $(P U N)$, but not $(P>0.10)$ the concentrations of BHB, NEFA, glucose, albumin, total proteins, IGF-1, leptin and insulin. No significant effects was observed $(P>0.10)$ for the performance parameters in postpartum period, just for calf ADG, were significant effect $(P<0.10)$ of maternal postpartum supplementation. There was no significant difference $(P>0.10)$ for intake and digestibility in the postpartum period. No significant differences $(P>0.10)$ in treatment and sampling time were observed on blood levels of BHB, total proteins and albumin. The effect of sampling time $(P<0.10)$ for glucose, leptin, cholesterol and progesterone was verified. Significant effects $(P<0.10)$ of postpartum supplementation were observed for NEFA, PUN, and cholesterol. There was an interaction effect between pre and postpartum treatment $(P<0.10)$ for blood levels of NEFA, IGF-1, insulin and PUN indicating that animals not supplemented in peripartum were influenced more by supplementation at postpartum. Overall, independent of the supplementation period, animals with BSC above 5 at gestation, and supplemented have better metabolic status after parturition, and probably ovarian activity early that not supplemented.

PALAVRAS-CHAVE: metabolism; protein; reproduction.

AGRADECIMENTOS: CNPq. 


\title{
SOLUBILIDADE E TIPOS DE COLÁGENOS NA CARNE DE BOVINOS NELORE INTEIROS E CASTRADOS EM DIFERENTES IDADES
}

\author{
Juliana Chaves da Silva ${ }^{1}$, Polyana Galvão Bernardes Coelho ${ }^{2}$, Luiz Pereira \\ Silva $^{3}$, Mauricio Miguel Estrada ${ }^{3}$, Débora Evelyn de Freitas Assis ${ }^{4}$, Mario \\ Luiz Chizzotti ${ }^{5}$, Maria Verônica de Souza ${ }^{6}$ \\ ${ }^{1}$ Estudante de mestrado em Medicina Veterinária DVT/UFV Viçosa-MG; ${ }^{2}$ Médica Veterinária \\ DVT/UFV Viçosa-MG; ${ }^{3}$ Estudante de doutorado em Zootecnia DZO/UFV Viçosa-MG; ${ }^{4}$ Estudante de \\ mestrado em Zootecnia DZO/UFV Viçosa-MG; ${ }^{5}$ Professor Adjunto do Departamento de Zootecnia \\ UFV/Niçosa-MG; ${ }^{6}$ Professora Titular do Departamento de Medicina Veterinária UFVNiçosa-MG
}

A maciez está entre os principais atributos para a valorização da carne pelo consumidor, sendo afetada por diversos fatores, entre eles a presença de tecido conjuntivo e a composição do colágeno. $O$ colágeno recém-sintetizado contém ligações cruzadas divalentes, que são solúveis ao calor e tornam-se trivalentes e estáveis ao calor com o aumento da idade, enquanto que a maciez da carne diminui com a redução da solubilidade do colágeno. A coloração Picrosirius Red detecta o padrão de birrefrigência das fibras colágenas quando submetidas à microscopia de luz polarizada. As fibras do tipo I (COL I) são mais espessas e intensamente birrefrigentes com tonalidade variando do vermelho ao amarelo, enquanto as fibras do tipo III (COL III), são mais delgadas e menos birrefrigentes, e emitem coloração esverdeada. O objetivo desse estudo foi avaliar os tipos e a solubilidade do colágeno intramuscular na carne de bovinos Nelore castrados e inteiros, abatidos com diferentes idades $(8,11$ e 14 meses). As amostras para histologia foram incluídas em parafina $e$ cortadas a $5 \mu \mathrm{m}$ e coradas com Picrosirius Red. Dez imagens de cada amostra, com aumento de 40X, foram analisadas no Software Image J, com o plug-in Threshold Colour, utilizando Matiz 0-42 para COL I e Matiz 43-120 para COL III, com saturação de 0-255, e brilho 1-225. A solubilidade do colágeno diferiu $(p=0,0299)$ entre as classes sexuais, evidenciando maior solubilidade em animais inteiros. Houve efeito da idade dos animais no tipo de colágeno, sendo que os animais com 11 meses apresentaram maiores 
valores de COL I $(p=0,0004)$. Houve interação $(p=0,0254)$ entre idade e sexo para o $\mathrm{COL}$ III e para a percentagem de COL I $(p=0,0194)$, onde touros abatidos aos 14 meses apresentaram menor proporção de COL I. Nosso estudo não evidenciou efeito da idade dos animais na solubilidade do colágeno, provavelmente devido a reduzida idade ao abate dos animais (menor que 14 meses). A maior solubilidade do colágeno e menor proporção de $\mathrm{COL}$ I nos touros provavelmente está associada à maior hipertrofia e deposição muscular nos animais inteiros, devido a necessidade de remodelagem da matriz extracelular para o crescimento da fibra muscular.

PALAVRAS-CHAVE: matriz extracelular; picrosirius red; touros

AGRADECIMENTOS: CNPq, CAPES e FAPEMIG. 


\title{
GRUPO GENÉTICO E PONTO ÓTIMO DE ABATE COMO VARIÁVEIS DO RESULTADO ECONÔMICO EM OPERAÇÕES DE CONFINAMENTO
}

\author{
Kárito Augusto Pereira ${ }^{1}$, Fernando de Paula Leonel${ }^{2}$, Janderson Damaceno \\ dos Reis ${ }^{3}$, Severino Delmar Junqueira Villela ${ }^{1}$, Renata Vaz Ribeiro ${ }^{4}$ \\ ${ }^{1}$ Universidade Federal dos Vales dos Jequitinhonha e Mucuri (UFVJM); ${ }^{2}$ Universidade Federal de São \\ João Del Rei (UFSJ); ${ }^{3}$ Universidade Federal de Viçosa (UFV); ${ }^{4}$ Universidade Federal de Goiás (UFG).
}

Objetivou-se identificar o tempo ideal de abate a partir do peso em arrobas e da margem bruta de dois grupos genéticos de bovinos confinados, visando a maximização do resultado econômico. Utilizaram-se bovinos machos (castrados e inteiros) compostos por dois grupos genéticos: anelorados e cruzamento industrial (Cl), alocados em uma serie temporal de 2014 a 2016, resultando em 23.348 animais distribuídos em 285 lotes. Para tal analise mensuraram-se os dias de confinamento com os pesos em arroba mínimo, médio e máximo correlacionando com a margem bruta como resultado econômico que foi advinda a partir do valor da arroba no mês que os animais foram abatidos. A abordagem metodológica caracteriza-se como exploratória descritiva, com a adoção de técnicas quantitativas. Os indicadores foram comparados por meio de planilhas no Excel versão 2010 e analisados a nível de $5 \%$ de significância pela estatística descritiva. Fazendo-se possível mensurar que o ponto ótimo de abate em função do peso em arrobas visando a maximização da margem bruta foi expresso com maior representatividade pelos animais anelorados quando abatidos com 24,06 \pm 1,62 arrobas aos 105 dias de confinamento, resultando em $\mathrm{R} \$ 305,94$ de margem bruta. Já o grupo do $\mathrm{Cl}$, obtive margem bruta máxima de $\mathrm{R} \$ 76,90$ por animal aos 168 dias de confinamento sendo abatidos com 21,75 \pm 1,21 arrobas. Fato que pode ser explicado devido ao maior preço de aquisição desse grupo, interferindo consideravelmente no resultado econômico, uma vez que também permaneceram por mais tempo confinados e exibiram menor ganho de peso em arrobas que o grupo dos anelorados. Visto que, tais diferenças nos 
dias de permanência tornam-se imprescindíveis na lucratividade do sistema. Desse modo, quando analisado o peso mínimo em arroba observou-se que os grupos genéticos apresentaram acentuada redução da margem bruta, sobretudo para o $\mathrm{Cl}$ com $\mathrm{R} \$-1.624,03$ de prejuízo abatidos com 16,82 $\pm 1,21$ arrobas, seguido pelos anelorados com margem bruta mínima negativa na ordem de $R \$$ $1.564,81$ de prejuízo abatidos com 15,05 arrobas, onde permaneceram até dez dias confinados. Entretanto, nos dois grupos genéticos quando se elevou o peso em arrobas no momento do abate o prejuízo reduziu e a margem bruta foi maximizada com tendência linear crescente $(R 2=0,9782$ para anelorados e R2 $=0,9765$ para $\mathrm{Cl}$ ), pois se investiu mais com adição de mais arrobas nos animais que já se encontravam confinados, reduzindo a necessidade de troca com a compra do boi de reposição. É notória à necessidade de elucidar que o ponto ótimo de abate nunca será uma unidade de tempo determinada, pois tem relação direta com a genética, custo da dieta, preço do boi magro de reposição, além do preço da arroba. Sendo uma condição individual e estratégica de negócio de cada operação, afim de propiciar maior assertividade na tomada de decisão. Conclui-se que os animais anelorados apresentaram melhor desempenho econômico quando abatido com 24,06 arrobas aos 105 dias de confinamento.

PALAVRAS-CHAVE: anelorado; arroba; margem bruta. 


\title{
RENDIMENTO DE CARCAÇA DE QUATRO GRUPOS GENÉTICOS DE BOVINOS TERMINADOS EM SISTEMA DE CONFINAMENTO
}

\author{
Kárito Augusto Pereira ${ }^{1}$, Fernando de Paula Leonel ${ }^{2}$, Janderson \\ Damaceno dos Reis ${ }^{3}$, Severino Delmar Junqueira Villela ${ }^{1}$, Angelo Herbet \\ Moreira Arcanjo ${ }^{1}$, Bruno Grossi Costa Homem ${ }^{4}$ \\ ${ }^{1}$ Universidade Federal dos Vales dos Jequitinhonha e Mucuri (UFVJM); ${ }^{2}$ Universidade Federal de \\ São João Del Rei (UFSJ); ${ }^{3}$ Universidade Federal de Viçosa (UFV); ${ }^{4}$ Universidade Federal de \\ Lavras (UFLA).
}

Objetivou-se mensurar o rendimento de carcaça entre quatro grupos genéticos de bovinos terminados em sistemas de confinamento. Utilizaram-se bovinos machos (castrados e inteiros) compostos por quatro grupos genéticos: Nelores, anelorados, mestiços (sem raça definida) e cruzamento industrial $(\mathrm{Cl})$, alocados em uma serie temporal de 2014 a 2016, resultando em 59.710 animais distribuídos em 709 lotes, onde foi fornecida a mesma dieta para todos os grupos genéticos. Na formação do peso de abate em arrobas considerou-se o rendimento de carcaça $(\mathrm{RC})$ real de cada animal obtido no frigorifico a partir da seguinte formula: $\mathrm{RC}=$ peso da carcaça quente/peso vivo final $x 100$. Já para a análise dos dados utilizou-se do programa estatístico SAS System, a nível de $1 \%$ de significância pelo teste de Tukey. A partir dos resultados obtidos, foi possível inferir que $o$ indicador produtivo de desempenho constituído pelo rendimento de carcaça apresentou convergência nos resultados, com efeito do grupo genético, em função da fisiologia dos animais. Os animais de origem Nelore $(57,00 \pm 0.02)$ apresentaram os mais elevados índices de rendimentos de carcaças ao nível de $1 \%$ de significância $(P<0,01)$ quando relacionado com os demais, seguido pelos animais anelorados $(56,26 \pm 0.02)$ e $\mathrm{Cl}(56,43 \pm 0.02)$ em que não houve diferenças estatísticas entre estes dois grupos, e por último com pior desempenho os de origem mestiços $(54,79 \pm 0.02)$. Aliado ao fato que os animais de $\mathrm{Cl}$ entraram com peso inferior $(360,39 \pm$ $41,06 \mathrm{~kg}$ ), mas ganharam mais peso durante o período confinado 
(aproximadamente $210,52 \mathrm{~kg}$ ), enquanto os animais dos demais grupos iniciaram o confinamento com pesos superiores $(387,46 \pm$ $48,47 \mathrm{~kg}, 400,90 \pm 50,98 \mathrm{~kg}$ e $377,39 \pm 56,18 \mathrm{~kg}$ ), e tiveram desempenho de ganho de $177,61 \mathrm{~kg}, 166,41 \mathrm{~kg}$ e 160,18 $\mathrm{kg}$ para Nelores, anelorados e mestiços, respectivamente. Tais ganhos observados no grupo de $\mathrm{Cl}$ podem ser justificados pois os animais que entraram mais leves podem ser mais jovens, apresentando maior potencial de ganho de peso. Já os que apresentaram maiores pesos de entrada podem ser animais que estavam próximos ao período de deposição de gordura na carcaça, como é observado nos animais mestiços, já que este grupo genético apresentou o menor índice de rendimento de carcaça perante os demais durante todo o período avaliado. O desempenho biológico dos animais anelorados resultou no mesmo rendimento de carcaça do $\mathrm{Cl}$ durante o período analisado em resultado da heterose entre Bos taurus indicus e seus cruzamentos especifico para a produção de carne. Todavia, os mestiços e seus cruzamentos são destinados a produção de leite. Reafirmando que o cruzamento é uma ferramenta imprescindível na pecuária de corte a fim de propiciar maiores índices de rendimento de carcaça e de receita, uma vez que o confinador recebe por quilo de carcaça produzida. Concluindo que o grupo constituído por mestiços obtive o pior RC dentre os demais, quando confinados.

PALAVRAS-CHAVE: ganho de peso; mestiço; nelore. 


\title{
UTILIZAÇÃO DE CASCA DE SOJA EM SUPLEMENTO MÚLTIPLO PARA NOVILHOS NELORE RECRIADOS À PASTO NO PERÍODO DE TRANSIÇÃO SECA-ÁGUAS
}

\author{
Leandro Soares Martins ${ }^{1}$, Flávio Augusto Portela Santos², Lainer Sousa e \\ Leite $^{3}$, Ériton Egídio Lisboa Valente ${ }^{4}$ \\ ${ }^{1}$ Pesquisador do Centro de Pesquisa Nutripura, Pedra Preta, MT; ${ }^{2}$ Professor titular do \\ Departamento de Zootecnia da Universidade de São Paulo, Piracicaba, SP; ${ }^{3}$ Diretor do Centro de \\ Pesquisa Nutripura, Pedra Preta, MT; ${ }^{4}$ Professor adjunto do Departamento de Zootecnia da \\ Universidade Estadual do Oeste do Paraná, Toledo, PR.
}

No presente estudo objetivou-se comparar o uso de suplementos isoprotéicos compostos por milho e farelo de soja ou por casca de soja, sobre o desempenho de novilhos Nelore em sistema de pastejo, assim como comparar economicamente a utilização dos dois suplementos. O experimento foi conduzido no Centro de Pesquisa Nutripura (Mato Grosso, Brasil) no período de transição seca-águas entre os dias 1 de Setembro a 11 de Novembro de 2017, compreendendo 71 dias de experimento, numa área total de pastagem de 63 ha, dividida em 12 piquetes. Foram utilizados um total de 240 novilhos zebuínos não castrados, predominantemente da raça Nelore, com peso inicial de $289 \pm 0,9$ $\mathrm{kg}$. O delineamento utilizado foi $\mathrm{o}$ em Blocos Completos Casualizados, utilizando como critério de blocagem as diferentes plantas forrageiras presentes na área experimental, que conta com quatro piquetes formados por Brachiaria Híbrida - Capim Mulato II (Convert); quatro piquetes formados por Brachiaria brizantha (cv. Marandu) e quatro piquetes formados por Brachiaria humidicola. Os tratamentos testados foram: Casca - suplemento composto por casca de soja, uréia e núcleo mineral e Farelo - suplemento composto por farelo de soja, milho moído, uréia e núcleo mineral. Os 12 lotes de 20 animais foram considerados como as repetições. Os dados econômicos foram calculados com base nos preços praticados em Rondonópolis, MT, durante a execução do estudo. Os novilhos consumiram em média $1,33 \%$ do peso corporal em suplemento (4,3 kg/animal/dia de suplemento). Os animais provenientes dos diferentes tratamentos não apresentaram 
diferenças significativas para peso corporal final $(P>0,05)$ e nem para ganho médio diário de peso $(0,947$ e $0,970 \mathrm{~kg} / \mathrm{dia}$ para os tratamentos Casca e Farelo, respectivamente). Os animais provenientes do tratamento Farelo apresentaram uma menor conversão alimentar do suplemento $(P<0,05)$ em relação aos animais do tratamento Casca (4,59 e 4,43 de conversão alimentar do suplemento para os animais dos tratamentos Casca e Farelo, respectivamente). Ao avaliar alguns dados econômicos, levando em consideração os valores praticados no estado de MT, na região de Rondonópolis, foi constatado que o custo dos suplemento foi de $\mathrm{R} \$ 0,43$ e $\mathrm{R} \$ 0,64$ para os suplementos dos tratamentos Casca e Farelo, respectivamente, o que resultou em um custo da arroba produzida (considerando apenas o suplemento e um rendimento de carcaça de $50 \%$ para os animais utilizados) de $\mathrm{R} \$ 56,42$ para os animais do tratamento Casca e $\mathrm{R} \$ 82,57$ para os animais do tratamento Farelo. A margem bruta por animal considerando apenas o desembolso com a suplementação, foi de $\mathrm{R} \$ 182,17 \mathrm{e}$ $\mathrm{R} \$ 124,43$ para os novilhos dos tratamentos Casca e Farelo, respectivamente. A utilização da casca de soja em alternativa à combinação de milho moído com farelo de soja em suplementos para novilhos de corte em pastejo não altera o ganho de peso e eleva a margem bruta.

PALAVRAS-CHAVE: coproduto; pastejo; suplementação.

AGRADECIMENTOS: Centro de Pesquisa Nutripura. 


\title{
GRÃO ÚMIDO DE MILHO EM SUBSTITUIÇÃO AO GRÃO SECO DE MILHO MOÍDO INFLUENCIANDO O DESEMPENHO DE ANIMAIS TERMINADOS EM CONFINAMENTO À PASTO
}

\author{
Leandro Soares Martins ${ }^{1}$, Flávio Augusto Portela Santos ${ }^{2}$, Lainer Sousa e \\ Leite $^{3}$, Ériton Egídio Lisboa Valente ${ }^{4}$ \\ ${ }^{1}$ Pesquisador do Centro de Pesquisa Nutripura, Pedra Preta, MT, Brasil; ${ }^{2}$ Professor titular do \\ Departamento de Zootecnia da Universidade de São Paulo, Piracicaba, SP, Brasil; ${ }^{3}$ Diretor do \\ Centro de Pesquisa Nutripura, Pedra Preta, MT, Brasil; ${ }^{4}$ Professor adjunto do Departamento de \\ Zootecnia da Universidade Estadual do Oeste do Paraná, Toledo, PR, Brasil.
}

O presente estudo foi realizado com o objetivo de comparar a utilização do grão úmido de milho com a utilização do grão de milho seco moído, sobre o desempenho de bovinos machos inteiros na fase de terminação, em sistema de confinamento à pasto. O estudo foi conduzido no Centro de Pesquisa Nutripura, no município de Pedra Preta, MT entre os meses de Setembro e Dezembro de 2017. Foram utilizados 459 novilhos inteiros, com peso corporal inicial médio de $437 \pm 2,1 \mathrm{~kg}$, distribuídos em uma área dividida em 12 piquetes de 2,7 ha, formada pelas forrageiras Panicum maximum (cv. Mombaça) ou Brachiaria humidicola. Cada piquete tinha $20 \mathrm{~m}$ lineares de cocho com acesso apenas por um lado e bebedouro compartilhado entre dois piquetes vizinhos. $\mathrm{O}$ delineamento utilizado foi o em Blocos Completos Casualizados, adotando como critério de blocagem as diferentes origens (3 fazendas) dos animais. Os tratamentos testados foram: Grão Úmido: dieta contendo $570 \mathrm{~g} / \mathrm{kg}$ de grão úmido de milho e Grão Seco: dieta contendo $570 \mathrm{~g} / \mathrm{kg}$ de grão seco moído de milho. Cada tratamento contava com seis repetições (lotes de novilhos). 0 fornecimento das dietas foi realizado duas vezes ao dia, aproximadamente $09: 00 \mathrm{~h}$ e as 15:00h com utilização de dois vagões forrageiros de mistura total, com balança acoplada. As medidas de consumo não levam em conta a fração derivada do pasto. Os novilhos que receberam o tratamento Grão Úmido apresentaram consumo de matéria seca (CMS) médio de 9,252 kg, 
que foi significativamente menor $(P=0,001)$ do que o CMS de $10,637 \mathrm{~kg}$ apresentado pelos animais que receberam o tratamento Grão Seco. O mesmo resultado foi observado ao comparar o CMS em percentagem do peso corporal (PC) dos animais dos diferentes tratamentos $(2,19$ e $1,95 \%$ do PC para os animais dos tratamentos Grão Seco e Grão Úmido, respectivamente). O ganho médio diário de peso e peso final dos animais foram de 1,350 e $513 \mathrm{~kg}$ e 1,288 e $506 \mathrm{~kg}$, para os tratamentos Grão Seco e Grão Úmido, respectivamente, não apresentando diferença significativa entre eles $(P>0,05)$. Não foram observadas diferenças entre os tratamentos para eficiência alimentar $(0,154$ e 0,157 para os animais dos tratamentos Grão Seco e Grão Úmido, respectivamente). Os novilhos que receberam o tratamento Grão Úmido apresentaram maior $(P=0,011)$ rendimento de carcaça $(56,9)$ que os novilhos que receberam Grão Seco $(56,2)$. Foi concluído que a utilização de grão úmido de milho na dieta de bovinos em sistema de confinamento à pasto proporciona maior rendimento de carcaça, diminuição do consumo, sem alterar o ganho de peso e eficiência alimentar, quando comparado com a utilização de grão seco de milho na mesma proporção.

PALAVRAS-CHAVE: concentrado energético; consumo; terminação.

AGRADECIMENTOS: Equipe - Centro de Pesquisa Nutripura. 


\title{
CONSUMO E DIGESTIBILIDADE DO AMIDO EM DIETAS CONTENDO MILHO EM DIFERENTES GRANULOMETRIAS OU GRÃO DE SORGO MOÍDO EM BOVINOS NELORE
}

\author{
Letícia Artuzo Godoi ${ }^{1}$, Sebastião de Campos Valadares Filho ${ }^{2}$, Breno de \\ Castro Silva ${ }^{3}$, Flávia Adriane de Sales Silva ${ }^{3}$, Herlon Meneguelli Alhadas ${ }^{3}$, \\ Edenio Detmann ${ }^{4}$, Luciana Navajas Rennó ${ }^{4}$ \\ ${ }^{1}$ Estudante de Doutorado - leticia.godoi@ufv.com; ${ }^{2}$ Professor Titular; ${ }^{3}$ Estudante de Doutorado; \\ ${ }^{4}$ Professor Associado do Departamento de Zootecnia, DZO/UFV.
}

O amido corresponde a principal fonte de energia em sistemas intensivos de produção, o que torna de grande importância o seu máximo aproveitamento. Assim, devido às características físicas dos grãos de milho e sorgo, principalmente os utilizados no Brasil, faz-se necessário a realização de algum tipo de processamento, de forma a melhorar a eficiência de utilização dos nutrientes pelos microrganismos ruminais e pelo trato digestório total. Objetivou-se avaliar a digestão ruminal e intestinal de amido em bovinos alimentados com dietas contendo milho em diferentes granulometrias ou grão de sorgo moído. Foram utilizados cinco bovinos machos não castrados da raça Nelore, fistulados no rúmen e no íleo, com peso médio inicial de $348 \pm 39,3 \mathrm{~kg}$ e idade média de $20 \pm 1$ meses, distribuídos em delineamento experimental quadrado latino $5 \times 5$, sendo cinco dietas e cinco períodos. As dietas experimentais foram: $85 \%$ de grão de milho inteiro e $15 \%$ de pellet (MI); as demais foram compostas de $30 \%$ de silagem de milho, 10\% de suplemento proteico e $60 \%$ de milho quebrado (MQ); ou moído grosso (MG); ou moído fino (MF) ou sorgo moído fino (SF). O fluxo de amido omasal e ileal foi estimado utilizando o sistema de indicador duplo, sendo utilizados a fibra insolúvel em detergente neutro indigestível (FDNi) como indicador da fase sólida e o CoEDTA para fase líquida e de pequenas partículas. Todas as médias foram comparadas utilizando-se o teste Fisher, considerando $5 \%$ como nível crítico de probabilidade. Os consumos de amido, expressos em $\mathrm{kg} / \mathrm{dia}$ ou em $\mathrm{g} / \mathrm{kg}$ de $\mathrm{PC}$, foram menores $(P<0,05)$ 
para a dieta contendo milho inteiro e não diferiram $(P>0,05)$ entre as demais dietas. Para as quantidades digeridas ( $\mathrm{kg} / \mathrm{dia})$, no rúmen e intestino grosso não houve efeito $(P>0,05)$ do processamento $e$ tipo de cereal. Já, no intestino delgado, foram menores $(P<0,05)$ para a dieta do grão inteiro em relação às demais dietas. Houve tendência de menores $(P<0,10)$ quantidades digeridas totais de amido para a dieta do milho inteiro em relação às dietas contendo milho quebrado e milho moído fino e não foi verificada diferença $(P>0,05)$ entre as dietas com milho e sorgo no mesmo processamento. Conclui-se que a granulometria da dieta, exceto quando o milho é fornecido inteiro, não altera os consumos e digestibilidade aparente total do amido. No entanto, granulometrias menores resultam em maiores coeficientes de digestibilidade do amido.

PALAVRAS-CHAVE: bovinos; digestibilidade; processamento de grãos.

AGRADECIMENTOS: CNPq, FAPEMIG, INCT-CA. 


\title{
EFEITO DO MILHO EM DIFERENTES GRANULOMETRIAS OU GRÃO DE SORGO MOÍDO SOBRE O PH RUMINAL EM BOVINOS NELORE
}

\author{
Letícia Artuzo Godoi ${ }^{1}$, Sebastião de Campos Valadares Filho², Diego \\ Zanetti ${ }^{3}$, Marcos Vinicius Carneiro Pacheco ${ }^{4}$, Ana Clara Baião Menezes ${ }^{4}$, \\ Mario Luiz Chizzotti ${ }^{5}$, Pedro Veiga Rodrigues Paulino ${ }^{6}$ \\ ${ }^{1}$ Estudante de Doutorado - leticia.godoi@ufv.com; ${ }^{2}$ Professor Titular; ${ }^{3}$ Professor IFSULDEMINAS; \\ ${ }^{4}$ Estudante de Doutorado; ${ }^{5}$ Professor Associado do Departamento de Zootecnia, DZO/UFV; \\ ${ }^{6}$ Gerente Global de Tecnologia de Bovinos de Corte da Cargill Nutrição Animal.
}

Quando dietas com elevada quantidade de carboidratos solúveis são fornecidas aos animais, geralmente ocorre aumento na produção de ácidos graxos voláteis (AGV). Contudo, se a taxa de produção excede a taxa de remoção, haverá acúmulo dos mesmos no ambiente ruminal, redução do $\mathrm{pH}$ da digesta e consequentemente o aparecimento da acidose, que pode ser de natureza aguda, com uma depressão do $\mathrm{pH}$ no rúmen abaixo de $\mathrm{pH} 5,2$ ou subaguda, com $\mathrm{pH}$ ruminal, variando de 5,5 a 5,8. Objetivou-se avaliar o pH ruminal e a concentração de AGV em bovinos alimentados com dietas contendo milho em diferentes granulometrias ou grão de sorgo moído. Foram utilizados cinco bovinos machos não castrados da raça Nelore, fistulados no rúmen e no íleo, com peso médio inicial de $348 \pm 39,3 \mathrm{~kg}$ e idade média de $20 \pm 1$ meses, distribuídos em delineamento experimental quadrado latino $5 \times 5$, sendo cinco dietas e cinco períodos. As dietas experimentais foram: $85 \%$ de grão de milho inteiro e $15 \%$ de pellet (MI); as demais foram compostas de $30 \%$ de silagem de milho, 10\% de suplemento proteico e $60 \%$ de milho quebrado (MQ); ou moído grosso (MG); ou moído fino (MF) ou sorgo moído fino (SF). Os cinco períodos tiveram duração de 21 dias cada, sendo 15 para adaptação e 6 dias de coleta. Do $16^{\circ}$ ao $18^{\circ}$ foi mensurado o $\mathrm{pH}$ ruminal a cada 15 minutos utilizando-se um bolus. Do $19^{\circ}$ ao $21^{\circ}$ foram realizadas oito coletas de digesta ruminal com intervalo de 9 horas para estimar a concentração de AGV. Para o pH foram estimadas médias de quadrados mínimos para cada dieta em cada 
tempo de avaliação. Os valores foram plotados em gráficos de dispersão por dieta e os gráficos foram avaliados por integração numérica no tocante à área total $(\mathrm{pH} \times \mathrm{h})$ localizada abaixo ou acima de patamares teóricos para interpretação do efeito total das dietas ao longo de um período de 24 horas. Estes dados foram comparados descritivamente. Quanto aos AGV, as médias foram comparadas utilizando-se o teste Fisher, considerando $5 \%$ como nível crítico de probabilidade. Apenas na dieta em que o milho foi fornecido inteiro, verificou-se pH ruminal abaixo de 5,2, durante todo o dia, o que indica elevada incidência de acidose aguda. Para as dietas em que o milho foi fornecido moído grosso ou fino e para a dieta à base de sorgo moído fino, o pH manteve-se entre 5,2 e 5,8 a maior parte do dia, indicando a presença de acidose subaguda. Apenas para a dieta de milho quebrado, obteve-se pH ruminal ao longo de todo o dia acima de 5,8. Não houve efeito da granulometria sobre as concentrações de ácidos graxos voláteis (AGV, mmol/dL), porém o fornecimento do grão de milho inteiro reduziu as proporções molares de acetato e ampliou as proporções molares de propionato quando comparado às demais dietas. Conclui-se que a granulometria dos grãos pode alterar as proporções molares dos AGV, o que favorece a redução do $\mathrm{pH}$ ruminal e a incidência de acidose.

PALAVRAS-CHAVE: ácidos graxos voláteis; nelore; $\mathrm{pH}$ ruminal.

AGRADECIMENTOS: CNPq, FAPEMIG, INCT-CA. 


\section{RELAÇÃO PROTEÍNA E ENERGIA NA DIETA DE NOVILHAS NO PERÍODO DE TRANSIÇÃO ÁGUAS-SECA}

Letícia Brito Alves ${ }^{1}$, Deborah França Pires ${ }^{1}$, Jackelliny Melo de Barros Rosa $^{1}$, Milene Rodrigues Dias', Alyce Raiana Monteiro dos Santos ${ }^{2}$, Carlos Eduardo Avelino $\mathrm{Cabral}^{3}$, Carla Heloisa Avelino Cabral ${ }^{3}$

${ }^{1}$ Discente do curso de Zootecnia, UFMT, campus Rondonópolis; ${ }^{2}$ Discente do Programa de Pósgraduação em Agricultura Tropical, UFMT, campus Cuiabá; ${ }^{3}$ Professor do ICAT, UFMT, campus Rondonópolis.

Sabe-se que apesar do pasto constituir a base da alimentação dos ruminantes no Brasil, as gramíneas não são capazes de suprir todas as exigências nutricionais do animal, pois o desbalanço na relação proteína-energia interfere no desempenho animal. Uma alternativa para minimizar o desequilíbrio entre os nutrientes encontra-se na inserção de suplemento na dieta, e por isso, objetivou-se identificar o efeito da suplementação proteica e energética sobre o desempenho de novilhas em pastejo na transição águas-seca. $\mathrm{O}$ experimento foi realizado em Rondonópolis, Mato Grosso, em uma área de 7 hectares, formada por pastagem com Brachiaria brizantha cv. Marandu, em sistema com lotação contínua. O período experimental ocorreu na transição águas-seca (11 de março de 2015 a 31 de maio de 2015). Os tratamentos consistiram em suplemento mineral (tratamento controle) e três suplementos múltiplos, formulados para atender $300 \mathrm{~g}$ dia-1 de PB fornecidos nas quantidades diárias de 0,5, 1,0 e $1,5 \mathrm{~kg}$ animal-1. Os suplementos proteicos foram denominados de baixo, médio e alto consumo, respectivamente. Foram utilizadas 40 novilhas mestiças com predominância de sangue zebuíno com idade e peso médio inicial de 14 meses e $182 \pm 1,13 \mathrm{~kg}$. O delineamento experimental foi o inteiramente casualizado, com quatro tratamentos e dez repetições. Os dados foram processados por meio da análise de variância e foram feitas comparações por meio de contraste (animais suplementados $x$ não suplementados) e por meio do teste Tukey $(p=0,05)$. A relação proteína-energia influenciou o desempenho dos animais, visto que houve maior 
desempenho dos animais suplementados (GMD $=675 \mathrm{~g} / \mathrm{animal}$ ) comparativamente aos animais do grupo controle (GMD $=467$ $\mathrm{g} / \mathrm{dia}$ ). Quanto aos animais suplementados, aqueles alimentados com suplemento de médio (PB: $27,70 \%$ ) e alto consumo (PB: $18,20 \%$ ) obtiveram maior ganho médio diário que os demais, demonstrando em pastos com teor de PB entre 11,50 a 12,30\% existe a demanda de suplementos com menor relação proteínaenergia. Por outro lado, o consumo de suplemento de médio e alto consumo proporcionou redução no consumo de pasto, o que pode aumentar o custo de produção, pois o pasto é a alternativa de menor custo de produção. É válido ressaltar que altas quantidades de energia na dieta causa um desbalanço metabólico, aumentando a produção de calor, o que diminui o consumo e o tempo de pastejo. Quanto à digestibilidade, não houve diferença entre os tratamentos na digestibilidade de FDN, o que demonstra que não houve restrição na digestão da fibra consumida. $\mathrm{Na}$ transição águassecas, o fornecimento suplementar de proteína e energia otimiza o desempenho animal, de modo que o suplemento de médio consumo (relação proteína-energia intermediária) favorece o desempenho animal e ao mesmo tempo resultarem maior lucro comparativamente aos demais tratamentos.

PALAVRAS-CHAVE: suplementação a pasto; recria; efeito substitutivo.

AGRADECIMENTOS: CNPq. 


\title{
PRINCIPAIS IMPACTOS E CAUSAS DAS CONDENAÇÕES DE VÍSCERAS VERMELHAS COMESTÍVEIS, PERTENCENTES A BOVINOS DE CORTE, ABATIDOS EM UM MATADOURO FRIGORIFICO SOB INSPEÇÃO ESTADUAL, LOCALIZADO NO NORDESTE BAIANO
}

\author{
Luane Etienne Barreto1, Pedro Alexandre Gomes Leite ${ }^{1}$, Thiago Araújo \\ Boulhosa ${ }^{2}$, Bruno Souza Malta ${ }^{1}$ \\ ${ }^{1}$ Universidade Estadual de Santa Cruz; ${ }^{2}$ Frigorifico Regional de Alagoinhas LTDA.
}

O Brasil atualmente é considerado um dos maiores produtores e exportadores de carne bovina do mundo, prática essa que ocupa uma posição de destaque na economia nacional, e responde pela geração de emprego e renda à milhões de brasileiros. Diante disso, a fim de evitar perda econômica e proliferação de zoonoses, a melhoria da qualidade sanitária, o conhecimento e identificação de patologias ou contaminações de vísceras e carcaças nos locais de abate, fez-se necessário. $O$ presente trabalho teve como objetivo quantificar as patologias que mais acometeram as vísceras vermelhas dos bovinos de corte no ano de 2017, e discorrer sobre as principais causas de suas condenações. Realizado em um matadouro frigorífico, sob inspeção estadual, atualmente inserido no SISBI, localizado na região de Alagoinhas, Bahia, o local executa abate de bovinos, suínos, caprinos e ovinos vindos de todo o estado. Foram abatidos, obedecendo as regras de inspeção ante e post mortem preconizadas pelo Serviço de Inspeção Federal, do MAPA, pelas normas do RIISPOA, no período de Janeiro a Dezembro de 2017, um total de 57.106 bovinos. Na inspeção post mortem todas as vísceras foram analisadas de acordo com o fluxograma da linha de inspeção abrangendo a Linha D; Linha E; Linha F, e Linha G, a fim de constatar quaisquer anormalidades nas vísceras, sendo essas classificadas como condenadas. Durante o período analisado foram caracterizadas impróprias para o consumo, pelo serviço de 
inspeção estadual $n^{\circ} 626,48.534$ vísceras vermelhas. Do total, 10.771 vísceras $(22,2 \%)$ foram rejeitadas devido à presença de pneumonia, seguido de $6.202(12,8 \%)$ vísceras com enfisema pulmonar, $4.771(9,8 \%)$ por bronquite, $4.512(9,3 \%)$ devido a nefrite, e $4.049(8,3 \%)$ por consequência de aspiração de sangue. Das condenações realizadas no período de estudo, 28.299 vísceras representavam afecções pulmonares, o que simboliza mais da metade $(58,3 \%)$ dos fatos considerados impróprios para o consumo. As enfermidades do trato respiratório, devido sua alta morbidade e mortalidade, geram consequências na vida do animal, prejudicando seu ganho de peso, atrasando sua vida reprodutiva, além de resultar em altas perdas econômicas dos rebanhos principalmente para o proprietário do lote, devido a condenação das vísceras ou até a carcaça em sua totalidade, dependendo da patologia. Como visto, a pneumonia é a patologia com o maior número de condenações, se define como uma doença multifatorial, mas que ocorre, principalmente, devido ao ambiente, ou pela presença de patógenos no local. Fato este que pode ser evitado através de disseminação de informações aos proprietários da região sobre as consequências do manejo inadequado, mostrando o que pode ser feito para evitar a prevalência dessas afecções, e principalmente, ligando isso ao prejuízo econômico pessoal, visto que, em geral, cada quilo não sai a menos de $R \$ 1,00$ quando se trata da venda das vísceras comestíveis.

PALAVRAS-CHAVE: bovinos de corte; afecções pulmonares; prejuízo econômico. 


\section{O CAPIM MULATO II ASSEMELHA-SE AO CAPIM MARANDU EM RESPOSTA A ADUBAÇÃO NITROGENADA?}

Luiz Jardel Müller Motta ${ }^{1}$, Pedro Emanuel da Costa Lourenço', Lucas Gimenes Mota ${ }^{1}$, Cleiton Barbosa Apolônio Ola ${ }^{1}$, Joadil Gonçalves de Abreu $^{1}$, Carla Heloisa Avelino Cabral ${ }^{1}$, Carlos Eduardo Avelino Cabral ${ }^{1}$ ${ }^{1}$ Universidade Federal de Mato Grosso - Campus Universitário de Rondonópolis (UFMT-CUR).

Os bovinos de corte, no Brasil, são alimentados basicamente em pastagens, o que demanda uma diversidade de forrageiras para atender a variabilidade de condições do país. Visto isso, o capim Mulato II (Urochloa hibrida cv. Mulato II) é um híbrido de três espécies forrageiras (Urochloa ruziziensis, $U$. decumbens e $U$. brizantha) com distintas exigências em fertilidade. Assim, identificando-se a semelhança da resposta à adubação do capim Mulato II com os capins progenitores, será possível realizar adubação adequada, sem que ocorra deficiência de nutrientes ou desperdício de fertilizante. Dessa forma, por meio de teste de identidade de modelos, comparou-se a resposta dos capins Mulato II e Marandu (Brachiaria brizantha cv. Marandu) quanto à adubação nitrogenada. O experimento foi realizado em casa de vegetação na Universidade Federal de Mato Grosso, campus Rondonópolis, em delineamento inteiramente casualizado, com dez tratamentos e quatro repetições, arranjados em esquema fatorial $2 \times 5$. Os tratamentos consistiram em dois capins (Marandu e Mulato II) e cinco doses diferentes de nitrogênio $(0,100,200,300$ e $400 \mathrm{mg}$ $\mathrm{dm}^{3}{ }^{3}$. Realizou-se a implantação dos capins e quarenta dias após a semeadura realizou-se o corte de uniformização e a aplicação dos tratamentos. Foram realizadas duas avaliações de rebrota do capim, espaçados em trinta dias. Os resultados foram submetidos à análise de regressão linear e quadrática e, em caso significativo, adotou-se o teste $\mathrm{F}$ para comparação de modelos. Em casos de modelos distintos, realizou-se o teste $\mathrm{F}$ para comparação de interceptos e parâmetros das equações propostas. Em todos os testes, adotou-se $5 \%$ de probabilidade de erro. Todas as variáveis, 
de ambos os capins, foram descritas por modelo quadrático em resposta à adubação nitrogenada. Os capins Marandu e Mulato II assemelharam em produtividade e valor nutritivo, pois houve modelos comuns para a massa seca de lâminas foliares, colmo+bainha, parte aérea, resíduo, raízes, proteína bruta nas lâminas foliares e na parte aérea, perfilhamento, número de folhas e valor SPAD, que é um índice que apresenta boa correlação com teor de clorofila e nitrogênio na planta. Por outro lado, houve diferença na morfologia dos capins, pois a porcentagem de colmo+bainha e porcentagem de lâminas foliares foram descritas por equações diferentes, contudo, com interceptos iguais. Assim, percebeu-se que a morfologia dos capins é semelhante em ausência de adubação, contudo a adubação nitrogenada proporciona incrementos distintos em porcentagem de lâmina foliar e colmo+bainha. Uma vez que os capins são semelhantes, o uso do Mulato II sem a adubação devida irá favorecer a degradação dos pastos, pois o Marandu é um capim expressivo e uma das causas da sua degradação é a deficiência de nutrientes. Por fim, quanto a adubação nitrogenada ocorre respostas semelhantes entre o capim Mulato II e o Marandu, de modo que pode-se admitir a mesma exigência de nitrogênio.

PALAVRAS-CHAVE: mulato II; teste de identidade de modelos; urochloa hibrida.

AGRADECIMENTOS: CNPq, Universidade Federal de Mato Grosso - Campus Universitário de Rondonópolis (UFMT-CUR) 


\title{
EFEITO DOS TEORES DE FIBRA FISICAMENTE EFETIVA PROVENIENTE DE VOLUMOSO EM DIETAS DE GRÃO DE MILHO INTEIRO SOBRE A EFICIÊNCIA DE USO DA PROTEÍNA E DA ENERGIA EM BOVINOS DE CORTE
}

\author{
Nathália V. Trópia ${ }^{1}$, Herlon M. Alhadas ${ }^{2}$, Caio William M. Souza ${ }^{3}$, Pauliane \\ Pucetti ${ }^{2}$, Lethiane Rocha², Flávia A. Sales ${ }^{2}$, Sebastião de Campos \\ Valadares Filho ${ }^{4}$

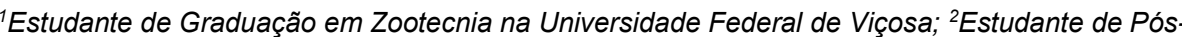 \\ graduação em Zootecnia na Universidade Federal de Viçosa; ${ }^{3}$ Estudante de Graduação em \\ Zootecnia na Universidade Federal de Viçosa; ${ }^{4}$ Professor Titular do Departamento de Zootecnia da \\ Universidade Federal de Viçosa.
}

A proteína é um nutriente que está envolvido em uma série de reações químicas no metabolismo animal, tendo a síntese microbiana importante contribuição no suprimento deste composto. Dessa forma, objetivou-se com o presente trabalho encontrar um nível de inclusão de fibra fisicamente efetiva (FDNfef) proveniente de volumoso em dietas de grão de milho inteiro que permita a otimização do uso da proteína bruta (PB) e dos nutrientes digestíveis totais (NDT), bem como da síntese de proteína microbiana (PBmic), além de se encontrar a contribuição das bactérias associadas à fase líquida (BAL) e das bactérias associadas à fase sólida (BAP) no pool bacteriano ruminal. Foram utilizados cinco bovinos Nelore machos não castrados fistulados no rúmen $(P C=393 \pm 9 \mathrm{Kg}$ ) distribuídos em um quadrado latino $5 \times 5$, os quais receberam as seguintes dietas: controle (CON), com milho grão inteiro $(850 \mathrm{~g} / \mathrm{Kg})$ e um núcleo mineral proteico peletizado (150 $\mathrm{g} / \mathrm{Kg}$ ); e dietas com níveis crescentes de cana-de-açúcar: $50 \mathrm{~g} / \mathrm{Kg}$ (D5), $150 \mathrm{~g} / \mathrm{Kg}$ (D15), $250 \mathrm{~g} / \mathrm{Kg}$ (D25) e $350 \mathrm{~g} / \mathrm{Kg}$ (D35)), sem adição de pellet e com a inclusão de um suplemento mineral proteico para balanceamento dos nutrientes. As dietas foram calculadas de modo que fossem isoprotéicas (125 g/Kg de PB). O cálculo da FDNfef foi realizado com o auxílio das peneiras Pen State Particle Sepatator. Foram realizados oito horários de coleta 
de digesta omasal, a intervalos de nove horas, afim de se estimar a digestibilidade ruminal e se obter amostras para isolamento das BAL e das BAP. Para determinação da digestibilidade total, e estimativa do consumo de NDT, foram realizadas coletas spot de fezes nos mesmos horários descritos acima. Já a estimativa da contribuição das BAL e das BAP ruminal no pool bacteriano total foi realizada através do esvaziamento do rúmen antes e três horas após a alimentação em dias alternados. Foram testados para os níveis de inclusão de FDNfef, no programa SAS (versão 9.4), os efeitos linear, quadrático e cúbico, sendo também contrastados com o controle através do teste de Dunnett $(P=0,05)$. Os teores de FDNfef obtidos foram de 20,5, 61,4, 102,4 e 143,3 g/Kg, para as dietas D5, D15, D25 e D35, respectivamente. Com a inclusão de apenas $20,5 \mathrm{~g} / \mathrm{Kg}$ de FDNfef proveniente de volumoso foi possível se otimizar o consumo de PB e NDT, bem como as digestibilidades totais da $\mathrm{PB}$, que responderam de forma quadrática ou linear decrescente. Consequentemente, a síntese de PBmic apresentou um efeito quadrático $(P=0,06)$ com ponto de otimização em D5, não havendo diferença na eficiência microbiana $(P>0,05)$. $A$ contribuição das BAL no pool total foi superior à das BAP, apresentando uma reação média de 80:20. Logo, com uma inclusão de $20,5 \mathrm{~g} / \mathrm{Kg}$ de FDNfef proveniente de volumoso em dietas de grão de milho inteiro é possível se otimizar o uso da proteína e da energia, e a contribuição das BAL no pool total de microrganismos ruminais mostrou-se em torno de quatro vezes superior à das BAP.

PALAVRAS-CHAVE: grão de milho inteiro; digestibilidade ruminal; proteína microbiana.

AGRADECIMENTOS: CNPq, Fapemig, INCT de Ciência animal. 


\title{
ANÁLISE DAS PERDAS ECONÔMICAS ORIUNDAS DA CONDENAÇÃO TOTAL DE CARCAÇAS DE BOVINOS ABATIDOS NO ESTADO DE SÃO PAULO
}

\author{
Pâmela Gracioli Vilas Boas', Weyber Ferreira de Souza', Aline de Almeida \\ Pedroso1, Marcos Paulo Freitas da Silva1, Diego Pierotti Procópio ${ }^{2}$ \\ ${ }^{1}$ Graduando em Medicina Veterinária, Faculdade de Medicina Veterinária, Universidade Federal de \\ Mato Grosso - UFMT; ${ }^{2}$ Professor do Departamento de Zootecnia e Extensão Rural, Faculdade de \\ Agronomia e Zootecnia - UFMT.
}

O estado de São Paulo em 2016 ocupava a posição de oitava unidade federativa dentre as que possuíam o maior rebanho efetivo do país, com um total 11,03 milhões de cabeças (equivalente a $5 \%$ do total nacional). Apesar da posição de destaque no cenário nacional, problemas com a qualidade sanitária das carcaças e questões relacionadas à segurança alimentar, agravam em perdas para o setor de bovinocultura de corte paulista por meio do descarte de carcaças que não se enquadram ao perfil desejado pelo mercado. Dessa forma, objetivou-se neste estudo quantificar as perdas econômicas originárias da condenação total de carcaças de bovinos em frigoríficos localizados, no estado de São Paulo no período de 2006 a 2016. O estudo foi realizado através do levantamento de informações sobre abates dos animais, por meio do preço de mercado da arroba do boi gordo em São Paulo e do Índice Geral de Preços (IGP-DI) para a atualização dos valores nominais, que foram obtidos nas bases de dados do Sistema de Inspeção Federal (SIF), do Centro de Estudos Avançados em Economia Aplicada (CEPEA) e da Fundação Getúlio Vargas (FGV), respectivamente. A quantificação da perda econômica foi realizada para cada ano da série analisada, por meio da multiplicação da quantidade de carcaças descartadas, com rendimento médio de 480 quilos, pelo valor médio anual pago pela arroba do boi gordo. Por fim, os valores foram atualizados para o ano de 2016 por meio da utilização do IGP-DI. No período de 2006 a 2016, no estado de São Paulo foi condenado um total de $1.743 .473(4,95 \%)$ carcaças de um montante de 35.188 .742 
bovinos abatidos. As perdas econômicas calculadas a partir do descarte de carcaças de bovinos por condenação total de cada ano da série analisada foram de em 2006 ( $R \$ 309.967 .366,73), 2007$ $\begin{array}{llll}(\mathrm{R} \$ 233.844 .353,28), & 2008 & (\mathrm{R} \$ 275.376 .776,27), & 2009\end{array}$ $\begin{array}{llll}(\mathrm{R} \$ 319.701 .248,24), & 2010 \quad(\mathrm{R} \$ 312.094 .920,61), & 2011\end{array}$ $\begin{array}{llll}(\mathrm{R} \$ 326.522 .618,75), & 2012 & (\mathrm{R} \$ 286.006 .610,71), & 2013\end{array}$ $\begin{array}{lll}(R \$ 370.414 .862,59), & 2014 \quad(R \$ 461.236 .504,64), & 2015\end{array}$ $(R \$ 444.514 .868,11)$ e 2016 ( $R \$ 321.559 .230,72)$, o que em conjunto equivale ao montante de $\mathrm{R} \$ 3.661 .239 .360,00$ para o estado de São Paulo. Verificou-se que para que os produtos cárneos continuem competitivos e incorporado ao mercado mundial, é necessário a responsabilização com fundamentos nas boas práticas de produção, como mecanismo de prevenção e controle de enfermidades nos rebanhos, com gestão eficiente do processo produtivo tanto em propriedades rurais quanto em frigoríficos, seguindo procedimentos e práticas bem definidas que permitam a obtenção de carcaças de qualidade no setor de bovinocultura de corte paulista e também do país. Ressalta-se a importância da utilização desses tipos de estratégias pelos agentes econômicos que compõem a cadeia produtiva de carne bovina, com o objetivo de redução de perdas e desperdícios, já que demanda mundial por alimentos é crescente e se tornando exigente quanto à qualidade do produto.

PALAVRAS-CHAVE: frigorífico; prejuízo; bovinocultura de corte.

AGRADECIMENTOS: UFMT. 


\title{
VARIAÇÃO DO PH RUMINAL AO LONGO DO DIA, CONSUMO E DIGESTIBILIDADE RUMINAL DA FDNCP EM RESPOSTA AO TEOR DE CONCENTRADO E AO USO DE SILAGEM DE GRÃOS REIDRATADOS EM DIETAS DE MACHOS NELORE
}

\author{
Pauliane Pucetti ${ }^{1}$, Sebastião de Campos Valadares Filho ${ }^{2}$, Breno de Castro \\ Silva ${ }^{3}$, Nathalia Veloso Trópia ${ }^{4}$, Caio William Magalhães ${ }^{4}$, Erica Garcia \\ Mafort ${ }^{5}$, Luciana Navajas Rennó 6 \\ ${ }^{1}$ Estudante de Mestrado em Zootecnia; ${ }^{2}$ Professor Titular do Departamento de Zootecnia, \\ DZO/UFV, Viçosa; ${ }^{3}$ Estudante de Doutorado em Zootecnia; ${ }^{4}$ Estudante de Graduação em \\ Zootecnia; ${ }^{5}$ Estudante de Graduação em Medicina Veterinária; ${ }^{6}$ Professora Adjunto do \\ Departamento de Zootecnia, DZO/UFV, Viçosa.
}

O aumento do teor de concentrado nas dietas de bovinos em confinamento e a utilização de diferentes métodos de processamento dos grãos podem estar diretamente relacionados ao aumento na eficiência produtiva dos animais. Porém, o aumento nas quantidades de carboidratos rapidamente fermentáveis no rúmen pode acarretar em desordens metabólicas e prejudicar a digestão ruminal da fibra. Objetivou-se avaliar o efeito do teor de concentrado e da ensilagem dos grãos de milho e sorgo reidratados sobre o $\mathrm{pH}$ ruminal, consumo e a digestão ruminal da fibra insolúvel em detergente neutro corrigida para cinzas e proteína (FDNcp). Foram utilizados 5 bovinos machos, não castrados, da raça Nelore com idade média de $8 \pm 1$ meses e peso corporal médio de $262 \pm 18$ $\mathrm{kg}$, canulados no rúmen, distribuídos em delineamento experimental quadrado latino $5 \times 5$, com arranjo fatorial $2 \times 2+1$. Foram avaliadas cinco dietas experimentais, das quais, quatro foram compostas de $28,44 \%$ de silagem de milho, $60,83 \%$ de grãos de milho moído seco (MMS), sorgo moído seco (SMS), silagem de grãos de milho reidratados (SMR) ou silagem de grãos de sorgo reidratados (SSR) e $10,73 \%$ de suplemento proteico mineral. Avaliou-se ainda, uma dieta com menor teor de concentrado (CTL) composta de $45 \%$ de silagem de milho, $44,27 \%$ de milho moído seco e $10,73 \%$ de suplemento proteico mineral. Cada um dos cinco 
períodos experimentais teve duração de 23 dias, sendo 14 para adaptação e 9 dias de coleta. Do $15^{\circ}$ ao $19^{\circ}$ dia realizou-se a mensuração do $\mathrm{pH}$ ruminal a cada 15 minutos com a utilização de um bolus ruminal. Do $20^{\circ}$ ao $22^{\circ}$ dia foram realizadas oito coletas de digesta omasal com intervalo de 9 horas. O fluxo de FDNcp na digesta omasal foi estimado pelo sistema de indicador duplo. Para o $\mathrm{pH}$, foram estimadas médias para cada dieta em cada tempo de avaliação, sendo os valores encontrados plotados em gráficos de dispersão por dieta e posteriormente avaliados por integração numérica no tocante à área total $(\mathrm{pH} \times \mathrm{h})$ localizada acima ou abaixo de patamares teóricos $(5,2$ e 5,8) ao longo de um período de 24 horas. Os dados referentes ao consumo e digestibilidade ruminal foram analisados pelo procedimento MIXED do SAS 9.4, sendo considerados $5 \%$ de probabilidade para ocorrência do erro tipo I. Os valores de $\mathrm{pH}$ ao longo do dia variaram pouco, oscilando entre 5,8 e 6,8 para as dietas no geral, com exceção da dieta SMR onde notou-se predominância de valores de pH abaixo de 5,8. Observouse redução $(P<0,05)$ no consumo de FDNcp para as dietas com menor teor de concentrado. Houve redução $(P<0,05)$ do consumo e digestibilidade ruminal da FDNcp para as dietas à base de silagens de grãos reidratados. Tais resultados podem estar relacionados à possível ocorrência de acidose subaguada para a dieta SMR, o que influenciou o efeito de processamento neste estudo. Conclui-se que a redução no $\mathrm{pH}$ ruminal de dietas à base de silagem de grãos reidratados afeta o consumo e digestão ruminal da FDNcp.

PALAVRAS-CHAVE: acidose; milho; sorgo.

AGRADECIMENTOS: FAPEMIG, CNPq, INCT Ciência Animal, Cargil Nutrição Animal. 


\title{
ESTIMATIVAS DE PARÂMETROS GENÉTICOS PARA AS CARACTERÍSTICAS REPRODUTIVAS: DIAS PARA O PRIMEIRO PARTO E IDADE AO PRIMEIRO PARTO, EM NOVILHAS NELORE
}

\author{
Pedro Vital Brasil Ramos ${ }^{1}$, Túlio Vilar Vilas Boas Oliveira', Fábio Luiz \\ Buranelo Toral ${ }^{2}$, Luisa Crivelli Alvarenga ${ }^{3}$, Talita Estáfani Zunino Santana ${ }^{1}$, \\ Renata Veroneze ${ }^{4}$, Fabyano Fonseca e Silva ${ }^{4}$ \\ ${ }^{1}$ Mestrando(a) do Programa de Pós Graduação em Zootecnia, UFV, Viçosa- MG, Bolsista do \\ CNPq/CAPES; ${ }^{2}$ Escola de Veterinária- UFMG, Belo Horizonte- MG. Departamento de Zootecnia; \\ ${ }^{3}$ Graduanda em Medicina Veterinária, Universidade Federal Fluminense-UFF, Niterói- $R J$; \\ ${ }^{4}$ Universidade Federal de Viçosa- UFV, Viçosa-MG. Departamento de Zootecnia.
}

O desempenho reprodutivo é de extrema importância e estritamente relacionado com o desempenho econômico da bovinocultura de corte. Dentre as características avaliadas que indicam eficiência reprodutiva, se encontram idade ao primeiro parto (IPP) e dias para o primeiro parto (DPP), que embora seja menos estudada, avalia a capacidade reprodutiva da fêmea. Esta característica é representada pelo intervalo, em dias, entre o primeiro dia da estação de monta em que a fêmea foi exposta ao reprodutor e a data de seu parto subsequente. Neste contexto, objetivou-se estimar parâmetros genéticos para as características IPP e DPP em novilhas Nelore. Os dados foram fornecidos pela Fazenda Mundo Novo, localizada no município de Uberaba-MG. Foram utilizadas informações de 1273 novilhas sob sistema de criação extensivo. Os animais entraram em estação de monta, com duração em torno de 120 dias, com média de 24,16 meses. O período de observação das características foi de 1999 a 2012. Inicialmente foi realizada análise de consistência dos dados, exclusão de outliers e análise descritiva. Em seguida, foram estimados os componentes de variância assumindo modelo animal por meio de análises bicarcterísticas conduzidas no software AIREMLF90. As características DPP e IPP obtiveram média de 340,7 e 1077,2 dias, respectivamente. A herdabilidade estimada para IPP foi de 0,10 e indica pequena variância genética, sugerindo que a seleção direta para esta característica deve apresentar 
pequenas taxas de ganho genético anual. Porém, devido à importância econômica da característica, a seleção realizada por longo período poderá resultar em impacto econômico positivo. No entanto, a estação de monta restrita pode ter contribuído para a baixa herdabilidade. Em situações em que as fêmeas permanecem em reprodução o ano todo, a variância genética para IPP talvez seja maior por não haver limitação de período. Outro motivo que pode justificar a baixa herdabilidade é o manejo reprodutivo, pois esses animais foram expostos à reprodução em idade préestabelecida, em torno de 24 meses de idade, sendo que poderiam ter condições de se reproduzir mais cedo e expressar maior potencial. Para a característica DPP, a herdabilidade foi 0,17 , indicando possuir maior variância genética quando comparada a IPP, o que justifica sua escolha como critério de seleção. A correlação genética entre as duas características foi de 0,87 e indica a possibilidade de obtenção de resposta correlacionada positiva e favorável na diminuição da IPP utilizando DPP como critério de seleção. Entretanto, como esta característica também apresenta baixa herdabilidade, a resposta deve ocorrer de forma lenta. De forma geral, conclui-se que a seleção realizada com base nas características de reprodução IPP e DPP pode ocasionar melhora na eficiência reprodutiva das fêmeas. As características apresentaram alta correlação genética, no entanto, a DPP apresentou maior herdabilidade, e portanto pode ser indicada como critério de seleção.

PALAVRAS-CHAVE: correlação genética; fertilidade; gado de corte.

AGRADECIMENTOS: UFV, CNPq. 


\title{
ESTIMAÇÃO DE PARÂMETROS GENÉTICOS PARA PESO AO SOBREANO EM BOVINOS DA RAÇA NELORE
}

\author{
Renata Cruz e Sousa1, Herta de Oliveira Monteiro Ribeiro², Thais Ferreira dos \\ Santos ${ }^{1}$, Gilberto Romeiro de Oliveira Menezes ${ }^{3}$, Felipe Gomes da Silva ${ }^{4}$ \\ ${ }^{1}$ Discente de Graduação em Zootecnia na UFMT; ${ }^{2}$ Discente de Mestrado em Ciência Animal na \\ UFMT; ${ }^{3}$ Doutor, pesquisador da Embrapa Gado de Corte; ${ }^{4}$ Doutor, professor na UFMT.
}

A crescente demanda de alimentos que acompanha o aumento populacional exige que o mercado fornecedor também esteja evoluindo de forma a atender essas necessidades. Dentro desse contexto se encaixa o melhoramento genético animal, que viabiliza a seleção de animais que apresentam características favoráveis a essa produção, de forma a repassar informações genéticas que colaborem com o rebanho futuramente. E assim, o estudo dos parâmetros genéticos de características faz-se importante, pois a partir deles é possível predizer quanto será transmitido para a prole, e apontar se é benéfico ou não escolher um animal por determinada individualidade, como por exemplo, peso ao sobreano. Nesse estudo, utilizou-se um banco de dados fornecido pela Embrapa Gado de Corte, contendo informações de animais da raça Nelore, provenientes da região Centro-Oeste, com nascimento entre os anos de 2001 e 2014. Para a edição do banco de dados fez-se uso do software SAS University Edition, além disso, o mesmo foi empregado na remoção de outliers e no teste de correlação. Após restrições, restaram 12.867 registros de peso ao sobreano, com valores de $200 \mathrm{~kg}$ a $500 \mathrm{~kg}$. Visando realizar a avaliação genética desses animais e seus componentes de variância, foi empregado o software WOMBAT, versão de 2017. Esses animais foram avaliados em um grupo de efeitos fixos previamente testados no SAS, que apresentaram interação entre sexo do animal e mês da pesagem, assim como entre sexo do animal, propriedade da pesagem, ano da pesagem e regime alimentar ao qual o animal estava sujeito. Como resultado, ao avaliar os valores de peso ao sobreano, obteve-se como variância 
fenotípica o valor de $582,85 \mathrm{~kg}^{2}$ e de variância genética aditiva de $133,18 \mathrm{~kg}^{2}$. Tendo em vista que a variância fenotípica é a soma da variância genética com a variância ambiental, é possível perceber que o meio em que o animal está incluído tem uma grande influência sobre a expressão de suas características. Isto é, além dos efeitos fixos como regime alimentar, existem efeitos aleatórios ambientais não passíveis de correção, como por exemplo, presença de endo e ectoparasitas ou maior exposição a chuva ou sol. O que somado à carga genética, irá definir o desempenho dos animais. Ademais, obteve-se variância residual de $449,67 \mathrm{~kg}^{2}$ e a herdabilidade da característica foi de 0,23 , considerada média, o que indica que poderia ser favorável a utilização dessa característica em programas de melhoramento genético. Concluise que todos os valores obtidos são condizentes aos encontrados na literatura, e que há necessidade de avaliar a correlação genética com outras características, de maneira a aprimorar os resultados e, dessa forma, possibilitar uma melhor seleção de animais.

PALAVRAS-CHAVE: bovino de corte; herdabilidade; melhoramento genético.

AGRADECIMENTOS: Embrapa Gado de Corte. 


\section{CINÉTICA ESPERMÁTICA E ATIVIDADE CITOQUÍMICA MITOCONDRIAL DO SÊMEN DESCONGELADO DE BOVINOS PANTANEIROS APÓS SUPLEMENTAÇÃO COM ÁCIDO ASCÓRBICO AO MEIO DE CRIOPRESERVAÇÃO}

\footnotetext{
Taiane dos Santos Schmidt ${ }^{1}$, Luciana Keiko Hatamoto -Zervoudakis ${ }^{2}$, Tathiana Ferguson Motheo ${ }^{2}$, Pedro Paulo Tsuneda ${ }^{3}$, Marlon Eduardo dos Santos Rodrigues ${ }^{1}$, Jéssica Ligoski Cabral ${ }^{1}$, Bruno Silva do Espirito Santo ${ }^{1}$ ${ }^{1}$ Aluno de graduação em Medicina Veterinária - UFMT; ${ }^{2}$ Professor do Programa de pós-graduação em ciência animal (PPGCA) - UFMT; ${ }^{3}$ Doutorando no Programa de pós-graduação em ciência animal (PPGCA) - UFMT.
}

Os bovinos de raça Pantaneira (Bos taurus taurus) descendem de raças de bovinos oriundos da Península Ibérica, trazidos ao Brasil durante sua colonização. Devido a interação e permanência no ecossistema do Pantanal, ao longo dos séculos, estes animais sofreram adaptações que resultaram na aquisição de características de rusticidade e resistência. Atualmente, é uma raça ameaçada de extinção e deste modo, o uso de biotécnicas reprodutivas, como a criopreservação seminal, são imprescindíveis para o resgate, preservação e expansão da raça. O presente estudo teve como objetivo avaliar se a suplementação do meio de criopreservação seminal com vitamina C (ácido ascórbico) promove melhorias na qualidade espermática do sêmen de bovinos pantaneiros após o descongelamento. Amostras seminais de 6 touros da raça Pantaneira foram coletadas por meio de eletroejaculação e em seguida submetidas às análises imediatas de volume, cor, aspecto, motilidade, vigor, concentração e morfologia espermáticas. Ato contínuo, estas foram divididas em duas alíquotas, as quais foram diluídas em meio diluidor comercial (Tryladyl®) acrescido de $20 \%$ de gema de ovo e água bidestilada (proporção 3:1:1, respectivamente), com ou sem adição de ácido ascórbico. Dessa forma, foram formados dois grupos experimentais: Controle (C) - meio base sem suplementação e TAmeio base suplementado com $3 \mathrm{mM}$ de ácido ascórbico. O sêmen 
foi envasado em palhetas de $0,5 \mathrm{~mL}$ e posteriormente submetido à protocolo de congelamento com curva de equilíbrio de 4 horas. As amostras congeladas foram armazenadas em botijões criogênicos até o processamento. As palhetas foram descongeladas a $37^{\circ} \mathrm{C}$ por 30 segundos e submetidas às análises do sistema computadorizado de análise de sêmen (CASA). Analisaram-se as variáveis: motilidade (MOT), motilidade progressiva (MOTP), velocidade média de trajetória (VAP), amplitude de deslocamento lateral da cabeça (ALH) e linearidade (LIN). Ainda, foi avaliada a atividade citoquímica mitocondrial (DAB) dos espermatozoides. Não houve diferença significativa do tratamento suplementado com ácido ascórbico (TA) comparado ao controle, sobre as variáveis MOT, MOTP, VAP, ALH, LIN e atividade citoquímica mitocondrial. Portanto, a suplementação do meio de criopreservação seminal com a suplementação de vitamina C utilizada não apresentou benefícios sobre a cinética espermática e atividade citoquímica mitocondrial dos espermatozoides. Entretanto, também não foram observadas alterações deletérias sobre as mesmas variáveis, fazendo-se necessário o estudo de diferentes concentrações de ácido ascórbico a serem acrescidas ao meio diluidor que promovam melhorias no processo de criopreservação seminal de bovinos da raça Pantaneira.

PALAVRAS-CHAVE: espermatozoides; antioxidantes; vitamina C. 


\section{EFEITOS FIXOS E ALEATÓRIOS QUE INFLUENCIAM O PESO A DESMAMA DE BOVINOS DE CORTE}

\footnotetext{
Thais Ferreira dos Santos ${ }^{1}$, Herta de Oliveira Monteiro Ribeiro², Renata Cruz e Sousa ${ }^{1}$, Gilberto Romeiro de Oliveira Menezes ${ }^{3}$, Dr. Felipe Gomes da Silva ${ }^{4}$ ${ }^{1}$ Discente de graduação em Zootecnia na UFMT; ${ }^{2}$ Discente de Mestrado em Ciência Animal na UFMT; ${ }^{3}$ Pesquisador da Embrapa Gado de Corte; ${ }^{4}$ Professor da UFMT
}

As características de crescimento de bovinos de corte são importantes para melhor eficiência econômica do rebanho. O peso de desmama é um atributo a ser avaliado para a seleção e melhoramento genético. Para obter avaliação genética dos animais, foram verificados quais efeitos fixos e possíveis interações a serem agrupadas. Também realizou-se a avaliação e comparação dos efeitos aleatórios a fim de se obter o melhor modelo (parte fixa e aleatória). O banco de dados utilizado nesse estudo foi fornecido pela Embrapa Gado de Corte (Campo Grande, MS), que após restrições continha informações de 13.292 animais da raça Nelore, advindos região Centro-Oeste, com nascimento entre os anos de 2001 e 2014. O software SAS University Edition foi utilizado para edição do banco de dados, verificação de outliers, análise descritiva, e teste dos efeitos fixos. Foram impostas restrições baseadas em histogramas de idade ao parto e peso dos animais, considerando um intervalo de $148 \mathrm{~kg}$ a $320 \mathrm{~kg}$. Com o intuito de comparar as combinações de efeitos fixos resultantes das análises de variância, além das avaliações genéticas e estimações de componentes de variância foi utilizado o software WOMBAT, versão de 2017. Para analisar a parte aleatória utilizaram-se os critérios: Logaritmo da Função Verossimilhança, Critério da informação de Bayesiano, Critério de informação de Akaike e Critério de informação de Akaike Corrigido. Os três últimos critérios foram multiplicados por $-1 / 2$ para ficar na mesma base de comparação do Logaritmo da Função Verossimilhança. Ao analisar os efeitos fixos, verificou-se influência das covariáveis idade do animal, peso de nascimento e idade da vaca ao parto (linear e quadrática), além disso, houveram interações entre mês e ano da 
desmama, assim como entre sexo, propriedade e ano da desmama. Na parte aleatória foi testado o modelo completo, contendo os efeitos genéticos direto e materno, além do efeito permanente materno. E contrastado com modelos reduzidos em que removeu-se os efeitos genéticos e/ou permanente materno. Observou-se que em todos os critérios a melhor avaliação genética foi utilizando o modelo completo. Conclui-se que o melhor modelo para avaliação do peso ao desmame deve conter os efeitos fixos classificatórios que combinam sexo, mês e ano da desmama, propriedade e ano da desmama, além das covariáveis peso ao nascimento, idade ao desmame e idade da vaca ao parto (linear e quadrática). Já para os efeitos aleatórios além da genética do animal devem ser incluídos os efeitos genético e permanente maternos.

PALAVRAS-CHAVE: melhoramento genético; nelore; modelagem.

AGRADECIMENTOS: EMBRAPA Gado de Corte, UFMT. 


\section{NÚMERO MÍNIMO DE OBSERVAÇÕES POR GRUPO DE CONTEMPORÂNEOS}

Thais Ferreira dos Santos ${ }^{1}$, Lorena Zulian Andreotti ${ }^{1}$, Herta de Oliveira Monteiro Ribeiro' ${ }^{2}$, Renata Cruz e Sousa ${ }^{1}$, Gilberto Romeiro de Oliveira Menezes ${ }^{3}$, Felipe Gomes da Silva ${ }^{4}$

${ }^{1}$ Discente de graduação em Zootecnia na UFMT; ${ }^{1}$ Discente de graduação em Zootecnia na UFMT; ${ }^{2}$ Discente de Mestrado em Ciência Animal na UFMT.

${ }^{1}$ Discente de graduação em Zootecnia na UFMT; ${ }^{3}$ Doutor, pesquisador da Embrapa Gado de Corte ${ }^{4}$ Doutor, professor da UFMT

Para realizar avaliações genéticas mais acuradas é necessário corrigir para efeitos fixos, seja separadamente ou em grupo de contemporâneos. Contudo, apesar da formação de grupos de contemporâneos ser uma prática comum em avaliações genéticas, utilizar grupos com poucas repetições pode resultar em estimativas fixas errôneas, o que prejudica todo o estudo. O banco de dados utilizado nessa pesquisa foi disponibilizado pela Embrapa Gado de Corte (Campo Grande - MS), que após restrições forneceu informações de 17.182 animais da raça Nelore. Utilizou-se o software SAS University Edition para a edição dos dados, criação do grupo de contemporâneos e verificação de seus tamanhos. As avaliações genéticas foram feitas no software WOMBAT, versão 2017. E para criação de arquivos com números mínimos diferentes de repetições dentro de grupos de contemporâneos, fez-se uso do Calc da LibreOffice. Em seguida, cada arquivo foi submetido a avaliação genética e estimações de componentes de variância, e os resultados de cada arquivo foram relacionados. Apurou-se que para praticar apenas a estimação de componentes de variância, não há necessidade de eliminar grupos de contemporâneos com número reduzido de indivíduos, isto porque tal ação não influencia na população como um todo. Porém, a exclusão pode afetar a predição de valores genéticos dos indivíduos alocados em grupos muito pequenos, e talvez, seus parentes mais próximos. Considerando o critério de informação Bayesiana, quanto maior a quantidade de indivíduos descartados, melhor. Em discordância, a partir da exclusão de grupos com até 10 animais, ocorrem animais 
sem predição de valores genéticos, isto é, a elevada eliminação de informações ocasiona a poda de indivíduos sem nenhum parente com informação (nem ele mesmo). Com isso, preocupa-se que tal fato exclua bons animais e seus parentes, ou que essa menor quantidade de informações para o valor genético predito reduza a acurácia seletiva de muitos animais. Dessa forma, critérios de informação não devem ser utilizados para determinar este tamanho, pois quanto menor o volume de dados, melhores tem sido seus valores. Em relação a porcentagem de grupos e indivíduos eliminados, sugere-se a utilização de no mínimo 6 animais por grupo de contemporâneo, isto porque se perderia $29 \%$ dos grupos, mas apenas $1,6 \%$ dos registros. Ademais, haveria redução significativa no erro padrão médio de estimação dos efeitos dos grupos. Considerando apenas essa redução, dividido pelo número de fenótipos eliminados, seria benéfico optar por grupos de ao menos 8 indivíduos. Conclui-se que cada critério utilizado obteve um resultado diferente, mas a partir de 9 animais, observa-se perdas nos valores genéticos preditos para muitos indivíduos, por isso, tal quantidade não deve ser imposta como limite. Também não recomenda-se a utilização de grupos menores do que 6 animais, pois resultam em um erro padrão de estimação elevado.

PALAVRAS-CHAVE: efeitos fixos; animais; avaliações genéticas.

AGRADECIMENTOS: Embrapa Gado de Corte. 


\title{
PARÂMETROS RUMINAIS DE NOVILHOS SUPLEMENTADOS COM MONENSINA E, OU ÓLEO DE COPAÍBA
}

\author{
Wagner Sousa Alves ${ }^{1}$, Rafael Henrique de Tonissi e Buschinelli de Goes ${ }^{2}$, \\ Jefferson Rodrigues Gandra ${ }^{2}$, Rodrigo Augusto Gressler ${ }^{2}$, Thaiano \\ Iranildo de Sousa Silva ${ }^{2}$, Maiara Aparecida Flores Balbueno ${ }^{2}$, Alberto \\ Jefferson da Silva Macêdo ${ }^{1}$ \\ ${ }^{1}$ Universidade Federal de Viçosa; ${ }^{2}$ Universidade Federal da Grande Dourados.
}

Moduladores da fermentação ruminal alternativos aos ionóforos estão sendo pesquisados. O óleo de copaíba por ter mecanismo de ação sobre bactérias gram-positivas semelhante aos ionóforos surge como uma alternativa para ser utilizado na nutrição animal. Objetivou-se avaliar neste trabalho o $\mathrm{pH}$ e a concentração de nitrogênio amoniacal (N-NH3) ruminal de novilhos suplementados com monensina e, ou óleo de copaíba. Foram utilizados quatro novilhos da raça Jersey castrados, com peso corporal médio de $212 \pm 20 \mathrm{~kg}$, providos de cânula ruminal e mantidos em baias individuais e em consumo de manutenção. Foram avaliados quatro tratamentos, controle (CON), suplementação com $0,9 \mathrm{mg} / \mathrm{kg}$ de peso vivo (PV) de monensina (MON), 1,0 g/kg PV de óleo de copaíba (COP) e monensina associada com óleo de copaíba (MC). A dieta base era constituída de silagem de milho e suplemento proteico com $38 \%$ de proteína bruta. O liquido ruminal foi coletado no $13^{\circ}$ dia do período experimental antes da alimentação e após 2, 4, 6 e 8 horas após a primeira refeição. A coleta foi realizada na interface liquido/sólido do ambiente ruminal. Imediatamente à coleta, foi realizada a leitura de $\mathrm{pH}$. Outra parte do liquido ruminal foi congelada para posterior determinação dos teores de $\mathrm{N}-\mathrm{NH} 3$ ruminal. O delineamento utilizado foi quadrado latino $4 \times 4$ em arranjo fatorial $2 \times 2$ com período experimental de 15 dias (dez dias de adaptação e cinco de coleta). Os dados foram submetidos para análise de variância e verificaram-se efeitos individuais ou de interação entre MON e COP a $5 \%$ de probabilidade. Houve efeito da monensina $(P<0,049)$ 
sobre os valores de $\mathrm{pH}$. O tratamento $\mathrm{MON}$ apresentou valor médio de $\mathrm{pH}$ 6,72, enquanto o $\mathrm{CON}, \mathrm{COP}$ e MC apresentaram valores de $\mathrm{pH}$ de 6,58,6,53 e 6,63, respectivamente. Houve efeito do tempo $(\mathrm{P}<0,001)$ sobre os valores de $\mathrm{pH}$ ruminal, observando um declínio no $\mathrm{pH}$ com o passar das horas após a ingestão de alimentos. Quando comparado entre os tratamentos, observou-se que MON apresentou uma redução mais lenta do $\mathrm{pH}$ ruminal em relação aos demais, reduzindo o pH após duas horas da ingestão de alimento, enquanto para os demais tratamentos, os valores de $\mathrm{pH}$ declinaram logo após a ingestão. Para a concentração de N-NH3 ruminal, foi observado efeito de interação entre monensina e óleo de copaíba $(\mathrm{P}<0,05)$, apresentando o menor valor de $\mathrm{N}-\mathrm{NH} 3$ ruminal $(7,51$ $\mathrm{mg} / \mathrm{dl}$ ). Ao observar os valores de $\mathrm{N}-\mathrm{NH} 3$ nos diferentes tempos de coleta, observou-se que o tratamento MON e COP apresentaram padrões semelhantes, com o pico máximo $(18 \mathrm{mg} / \mathrm{dl}) \mathrm{de} \mathrm{N}-\mathrm{NH} 3$ duas horas após a ingestão de alimentos, decrescendo após esse tempo. O tratamento MC apresentou o menor pico de N-NH3 que foi de $11 \mathrm{mg} / \mathrm{dl}$. Quatro horas após a ingestão de alimentos os valores de $\mathrm{N}-\mathrm{NH} 3$ tenderam a se estabilizar dentro dos tratamentos. A substituição da monensina por óleo de copaíba não compromete a fermentação ruminal, e a combinação dos aditivos promoveu uma maior eficiência na utilização do nitrogênio pelos animais.

PALAVRAS-CHAVE: nitrogênio amoniacal; Ph; aditivos.

AGRADECIMENTOS: Universidade Federal da Grande Dourados (UFGD) e CAPES. 


\title{
DIGESTIBILIDADE DA DIETA DE NOVILHOS SUPLEMENTADOS COM MONENSINA E, OU ÓLEO DE COPAÍBA
}

\author{
Wagner Sousa Alves ${ }^{1}$, Rafael Henrique de Tonissi e Buschinelli de Goes ${ }^{2}$, \\ Jefferson Rodrigues Gandra ${ }^{2}$, Charles Jhonnatan dos Santos Souza ${ }^{2}$, \\ Thaiano Iranildo de Sousa Silva ${ }^{2}$, Janaina Aparecida de Lima ${ }^{2}$, Alberto \\ Jefferson da Silva Macêdo ${ }^{1}$ \\ ${ }^{1}$ Universidade Federal de Viçosa; ${ }^{2}$ Universidade Federal da Grande Dourados.
}

O uso de substâncias naturais, como o óleo de copaíba (Copaifera langsdorffii) em substituição aos ionóforos como moduladores da fermentação ruminal vem ganhando cada vez mais espaço na nutrição animal. Objetivou-se avaliar neste estudo a digestibilidade da dieta de novilhos suplementados com monensina e, ou óleo de copaíba. Foram utilizados quatro novilhos da raça Jersey castrados, com peso corporal médio de $212 \pm 20$ $\mathrm{kg}$, mantidos em baias individuais e consumo de manutenção. Foram avaliados quatro tratamentos, controle, suplementação com $0,9 \mathrm{mg} / \mathrm{kg}$ peso vivo (PV) de monensina (MON), 1,0 g/kg PV de óleo de copaíba (COP), e monensina associada com óleo de copaíba. A dieta dos animais foi composta por silagem de milho e suplemento proteico com $38 \%$ de proteína bruta (PB). As amostras de alimentos e fezes foram analisadas quanto a sua composição químico-bromatológica. O coeficiente de digestibilidade total da matéria seca (DMS) foi obtido pela diferença entre a quantidade de matéria seca (MS) ingerida e a MS fecal. O delineamento experimental utilizado foi quadrado latino $4 \times 4$ em arranjo fatorial 2x2, com período experimental de 15 dias (dez dias de adaptação e cinco de coleta). Os dados foram submetidos à análise de variância, comparados pelo teste Tukey e verificaram-se efeitos individuais ou de interação entre MON e COP a $5 \%$ de probabilidade. Houve efeito de interação entre a suplementação de monensina e óleo de copaíba sobre o coeficiente de DMS $(P<0,030)$ e da fibra insolúvel em detergente neutro (DFDN) $(P<0,006)$. A maior DMS foi proporcionada pela suplementação 
exclusiva com monensina (62,33\%), enquanto que a suplementação com a mistura de monensina e óleo de copaíba e o controle apresentaram as menores DMS (46,29 e 51,80\%, respectivamente), o uso exclusivo de óleo de copaíba apresentou DMS intermediária aos demais tratamentos (57,545\%). Houve efeito de interação entre a monensina e o óleo de copaíba para DFND $(\mathrm{P}<0,006)$, apresentando a menor DFDN com a mistura dos aditivos $(80,44 \%)$. Controle, monensina e óleo de copaída proporcionaram DFDN de $84,02,86,23$ e $86,41 \%$ respectivamente. Houve efeito apenas da monensina sobre a digestibilidade da matéria orgânica (DMO, $\mathrm{P}<0,010$ ), com $62,81 \%$ de digestibilidade. Não houve efeito do óleo de copaíba $(P>0,775)$ ou de interação $(P>0,861)$ sobre a DMO. Em relação à digestibilidade da $P B(D P B)$, foi observado efeito da monensina $(P<0,003)$ e do óleo de copaíba $(\mathrm{P}<0,001)$ com 84,06 e $83,72 \%$ para DPB. Para a digestibilidade dos carboidratos totais, também observou-se efeito da monensina $(P<0,034)$ e do óleo de copaíba $(P<0,004)$, com digestibilidade de 93,10 e $92,6 \%$, respectivamente. Não houve efeito sobre a digestibilidade do extrato étereo, com media de $89,89 \%$. Concluise com esse estudo que a substituição da monensina por óleo de copaíba não altera a digestibilidade aparente da dieta.

PALAVRAS-CHAVE: modulador ruminal; digestibilidade aparente; aditivos.

AGRADECIMENTOS: Universidade Federal da Grande Dourados (UFGD) e CAPES. 


\title{
INFLUENCE OF PARK7, PRDX6, PRDX2 AND PRDX1 PROTEINS ON MEAT TENDERNESS IN NELLORE CATTLE
}

\author{
Jessica Moraes Malheiros ${ }^{1}$, Wellington Luiz de Paula Araújo², José \\ Cavalcante Souza Vieira ${ }^{3}$, Camila Pereira Braga ${ }^{4}$, Cruz Elena Henriquez- \\ Valencia $^{5}$, Pedro de Magalhães Padilha ${ }^{3}$, Luis Artur Loyola Chardulo ${ }^{2}$ \\ ${ }^{1} F C A V$-UNESP, Jaboticabal, SP, Brazil; ${ }^{2} F M V Z-U N E S P$, Botucatu, SP, Brazil; ${ }^{3} I B-U N E S P$, \\ Botucatu, SP, Brazil; ${ }^{4}$ UNL, Lincoln, NE, USA; ${ }^{5}$ UFPSO, Norte de Santander, Colombia.
}

The objective of this study was to analyze the association of the proteomics with meat tenderness in Nellore cattle. A population of 90 animals of the Nellore breed with mean initial weight of $390 \pm$ $37 \mathrm{~kg}$ and age of approximately 24 months was used in an experimental feedlot. Next, the animals were sent for slaughter at a final weight of approximately $550 \pm 75 \mathrm{~kg}$ and 27 months of age and were slaughtered on the same batch of slaughter in accordance with guidelines for the Humane Slaughter of Cattle. After slaughter, the carcasses were cooled for $24 \mathrm{~h}$ and $2.54 \mathrm{~cm}$ thick Longissimus thoracis muscle samples were collected between the 12th and 13th rib of the left half-carcass of each animal. The population was separated in three experimental groups of moderately tender meat $(\mathrm{SF}=3.9 \pm 0.7 \mathrm{~kg}, \mathrm{MFI}=55.7 \pm 9.0, \mathrm{n}=15)$, moderately tough meat $(\mathrm{SF}=5.6 \pm 0.7 \mathrm{~kg}, \mathrm{MFI}=50.4 \pm 13.9, \mathrm{n}=20)$ and very tough meat (SF $=7.9 \pm 1.4, \mathrm{MFI}=40.1 \pm 8.9, \mathrm{n}=15)$ using shear force (SF) and myofibrillar fragmentation index (MFI) analysis. The groups were separated in subgroups using the principal component analysis (PCA) with 5 animals/each (pool): moderately tender meat (TE1, TE2 and TE3), moderately tough meat (MTO1, MTO2, MTO3 and MTO4) and very tough meat (TO1, TO2 and TO3). Proteomic analysis was performed based on the separation of proteins by twodimensional electrophoresis (2D-PAGE) and characterization by electrospray ionization mass spectrometry (ESI-MS/MS). In total 220 spots were detected by 2D-PAGE gel image analysis. A total of 34 proteins identified presented a significant difference $(P<0.05)$ in the comparative analysis between the groups. The proteins 
belonging to the metabolic pathway of oxidative stress Protein/nucleic acid deglycase DJ-1 (PARK7), Peroxiredoxin 6 (PRDX6), 2 (PRDX2) e 1 (PRDX1) showed up regulated $(P<0.05)$ in moderately tough meat and very tough meat when compared to moderately tender meat. These antioxidant proteins act in the control of oxidative stress against the toxicity of reactive oxygen species (ROS). The results of this study shows that these proteins possibly assisted in the process of preservation of myofibrillar proteins in Nellore cattle. The PARK7 protein has been reported up regulated in Longissimus muscle of other bovine breeds during the meat tenderness process, as well as the PRDX6 protein that has been implicated in a variety of processes, including metabolism, apoptosis, aged and meat tenderness. The PRDX2 e PRDX1 have important role in oxidative stress in elimination the peroxide produced during metabolism. The results of the present study showed that the meat tenderness in Nellore cattle depends on the expression of proteins of the metabolic pathway of oxidative stress and suggest the PRDX1 and PRDX2 as new biological markers.

PALAVRAS-CHAVE: beef cattle; shear force; 2D-page.

AGRADECIMENTOS: FAPESP, CAPES. 


\section{TWO-DIMENSIONAL ELECTROPHORESIS IN COMBINATION WITH MASS SPECTROMETRY TO STUDY NELLORE CATTLE DIVERGENTLY GROUPED FOR MEAT QUALITY OR FEED EFFICIENCY TRAITS}

\footnotetext{
Welder Angelo Baldassini ${ }^{1}$, Wellington Luiz de Paula Araújo², Ana Bárbara Domingues Sartor ${ }^{2}$, Renata Helena Branco ${ }^{3}$, Sarah Martins Figueiredo Bonilha $^{3}$, Dante Pazzanese Duarte Lanna ${ }^{1}$, Pedro de Magalhães Padilha ${ }^{4}$ ${ }^{1}$ Department of Animal Science, "Luiz de Queiroz" College of Agriculture, University of São Paulo (ESALQ-USP), Piracicaba, São Paulo, Brazil; '2 São Paulo State University (UNESP), School of Veterinary Medicine and Animal Science, Botucatu, Brazil; ${ }^{2}$ São Paulo State University (UNESP), School of Veterinary Medicine and Animal Science, Botucatu, Brazil; ${ }^{3}$ Institute of Animal Science and Pastures. Instituto de Zootecnia (IZ), Centro APTA Bovinos de Corte, Sertãozinho, São Paulo, Brazil; ${ }^{4}$ São Paulo State University (UNESP), Institute of Biosciences, Botucatu, São Paulo, Brazil.
}

Brazilian beef production is the second largest in the world, and $80 \%$ of the national herd has the influence of Bos indicus cattle, mainly Nellore breed. However, few studies have used a proteomic approach to investigate some important traits such as meat quality or feed efficiency (FE) of this breed. We described results two proteomic studies with Nellore cattle based on the separation of proteins (muscle or liver) by two-dimensional gel electrophoresis (2D-PAGE) and protein characterization by electrospray ionization mass spectrometry (ESI-MS). In study I, meat samples (L. thoracis) of 1084 animals were used and the meat tenderness was measured as shear force (SF). A total of 40 specimens were selected and divided into two groups: animals with tender meat (TE) or tough meat (TO), in which SF was $4.07 \pm 0.68$ and $7.58 \pm 1.53 \mathrm{~kg}$, respectively. In study II, Nellore cattle were classified according to FE as residual feed intake (RFI). After weaning, 128 Nellore cattle underwent a FE test to identify their RFI class (low or high). this total, 20 animals were assigned to the finishing period in individual pens. Low RFI animals (more efficient, $n=10$ ) consumed $-1.16 \mathrm{~kg}$ / day, whereas high RFI animals (less efficient, $n=10$ ) consumed $+1.22 \mathrm{~kg} /$ day. The animals were slaughtered with an average body weight of $557.65 \pm 10.39 \mathrm{~kg}$. In studies I and II, approximately $3 \mathrm{~g}$ of muscle and hepatic tissue each group were used for protein 
extraction. A $250 \mu \mathrm{g}$ protein mass was used for the first dimension of 2D-PAGE. Bovine muscle or liver extracts were loaded onto 13 $\mathrm{cm}$ isoelectric focusing strips with a $\mathrm{pH} 3-10$ and 4-7 gradient immobilized on ampholytes. The gels of the groups in both approaches (TO vs. TE; or High vs. Low-RFI) were scanned and the images were analyzed using the ImageMaster Platinum software to measure isoelectric point and molecular weight proteins parameters. The protein spots in which volume $(\mathrm{V} \%)$ and relative intensity differed $(P<0.05)$ among experimental groups were selected for characterization by ESI-MS methods. The tryptic digestion was performed using a DigestZP In-Gel kit and the ESIMS runs were processed using ProteinLynx Global Server (Waters) software and analyzed in the database using the MASCOT system (Matrix Science). In muscle, the mean number of protein spot found in the TE and the TO group gels were $186 \pm 20$ and $146.5 \pm 16.5$, respectively. In liver (study II), protein spot High and Low-RFI groups were $279 \pm 30$ and $215 \pm 26$, respectively. The 2D-PAGE and ESI-MS efficiently separated and allowed the identification of proteins in muscle and liver. Pyruvate kinase (PK) was inferred to be related to beef tenderness (TO vs. TE), whereas hemoglobin (HB) was related to FE (High vs. Low RFI) in liver. The biological functions of these proteins, such as glycolytic metabolism (PK) or oxygen transport activity (HB), may help to explain phenotypic differences in Nellore cattle.

PALAVRAS-CHAVE: beef quality; feed efficiency; proteomics.

AGRADECIMENTOS: CNPq, FAPESP, CAPES. 


\title{
PRINCIPAIS CAUSAS DE CONDENAÇÕES TOTAIS DE CARCAÇAS DE BOVINOS EM FRIGORÍFICOS NO ESTADO DE SÃO PAULO NO PERÍODO DE 2006 A 2016
}

\author{
Weyber Ferreira de Souza', Pamela Gracioli Vilas Boas², Diego Pierotti \\ Procópio ${ }^{3}$ \\ ${ }^{1}$ Graduando em Medicina Veterinária, Faculdade de Medicina Veterinária - FAVET, Universidade \\ Federal de Mato Grosso - UFMT. weyberfs@gmail.com; ${ }^{2}$ Graduanda em Medicina Veterinária, \\ Faculdade de Medicina Veterinária - FAVET, Universidade Federal de Mato Grosso; ${ }^{3}$ Professor do \\ Departamento de Zootecnia e Extensão Rural, Faculdade de Agronomia e Zootecnia - UFMT.
}

A condenação total de carcaças de bovinos que é realizada pelo Serviço de Inspeção Federal (SIF), órgão vinculado ao Ministério da Agricultura, Pecuária e Abastecimento (MAPA), ainda é comum nos frigoríficos brasileiros e está entre as principais causas de perdas econômicas do setor de bovinocultura de corte. A identificação das principais causas de condenação total de carcaças é importante, pois, subsidia o aprimoramento do processo produtivo, possibilitando a redução de perdas ao longo do processo de agregação de valor ao produto. O presente estudo teve por objetivo o de identificar as principais causas de condenação total de carcaças bovinas que são abatidas em frigoríficos localizados no estado do São Paulo. O estado de São Paulo registrou em 2016 um quantitativo de 11,03 milhões de cabeças de bovinos (5\% do total nacional) e um total de 2,4 milhões de abates $(9,9 \%$ do total nacional). Para a obtenção das principais causas de condenação total foram analisados os registros de ocorrência de condenações totais, armazenados na base de dados do SIF do estado de São Paulo, referentes ao período de 2006 a 2016. Nesse período foram abatidos 35.188.742 bovinos, destes, a condenação total de carcaças ocorreu em 1.743.473 (4,95\% do total) dos abates. Entre as principais causas de condenação total estão a contaminação $(52,5 \%)$, o cisto urinário $(8,1 \%)$ e o abcesso $(5,9 \%)$. Entre os fatores que podem estar associados à condenação por contaminação em bovinos destacam-se: (i) o tempo inadequado de jejum na etapa de 
pré-abate; (ii) a lavagem inadequada do animal e da carcaça para a etapa do abate; (iii) falhas nas operações de abate; (iv) a falta de treinamento dos colaboradores, principalmente na realização das atividades de corte da carcaça. Já para as condenações totais ocasionadas por cisto urinário, estes podem estar associadas com a ocorrência de doenças infectocontagiosas e parasitárias no animal. Por fim, as condenações por abcesso podem estar relacionadas à execução inadequada da etapa de vacinação no rebanho da propriedade e ao manejo inadequado dos animais no curral, bem como no transporte do animal da propriedade até o frigorífico. Destaca-se que as técnicas produtivas adotadas na propriedade rural, nos processos de pré-abate e abate do animal são de fundamental importância para a manutenção da qualidade sanitária dos rebanhos e também para a produção de produtos derivados da carcaça bovina possam atender aos critérios de segurança alimentar impostos pelos países (para o caso de exportação) e também para o mercado nacional. O presente estudo indica aplicabilidade, pois fornece subsídios que podem auxiliar no aperfeiçoamento dos processos de abates dos bovinos, bem como reduzir as perdas por condenação total, a partir da melhoria de manejos nas etapas de criação, pré-abate e abate.

PALAVRAS-CHAVE: abates; bovinocultura de Corte; contaminação.

AGRADECIMENTOS: UFMT. 


\title{
COMPACTAÇÃO DE PRÉ-ESTÔMAGOS EM BOVINOS DECORRENTE DA INGESTÃO DE PANICUM MAXIMUM CV. MOMBAÇA
}

\author{
Weyber Ferreira de Souza ${ }^{1}$, Aline de Jesus da Silva², Pamela Gracioli Vilas \\ Boas $^{3}$, Rones Goulart de Paula Júnior ${ }^{4}$, Carlos Eduardo Pereira dos Santos ${ }^{5}$ \\ ${ }^{1}$ Graduando em Medicina Veterinária, Faculdade de Medicina Veterinária - FAVET, Universidade \\ Federal de Mato Grosso - UFMT|. weyberfs@gmail.com; ${ }^{2}$ Mestranda no Departamento de Clínica \\ Veterinária da FMVZ/USP; ${ }^{3}$ Graduanda em Medicina Veterinária, Faculdade de Medicina \\ Veterinária - FAVET, Universidade Federal de Mato Grosso; ${ }^{4}$ Doutorando em Ciência Animal pela \\ Universidade Federal de Mato Grosso; ${ }^{5}$ Professor da Faculdade de Medicina Veterinária - FAVET \\ - Universidade Federal de Mato Grosso.
}

A compactação dos pré-estômagos dos ruminantes está associada à ingestão de elevada quantidade de matéria seca advinda principalmente de forragens, podendo ainda, estar aliada à restrição hídrica, envolvimento do nervo vagal e ser agravada por gestação concomitante. O objetivo desse trabalho é relatar um surto de compactação rumino-omasal associado ao consumo de Panicum maximum em bovinos no município de Barra do Garças MT. O caso ocorreu em propriedade de exploração extensiva, em janeiro de 2017, onde 150 animais da raça Nelore eram mantidos em um piquete constituído de Panicum maximum cv. Mombaça. Após um mês de introdução em piquete com essa forrageira, sete vacas no terço final de gestação, foram encontradas em decúbito esternal e lateral. Ao examinar esses animais, foi constatada taquipnéia, hipomotilidade ruminal, com conteúdo firme à palpação, lacrimejamento e sinais clínicos de cólica tais como contrações abdominais e espasticidade de membros. Durante vistoria, observaram-se avarias nos bebedouros e foi estimada uma restrição hídrica em torno de 48 a 72 horas. Para os animais em tais condições, foi ofertada água e no mesmo momento, estes a ingeriram avidamente. Naqueles que já se encontravam em decúbito lateral, aplicou-se solução fisiológica com gluconato de cálcio por via endovenosa e posterior a isso foi possível notar uma discreta melhora no quadro clínico. No entanto, pouco tempo depois, os animais retornaram ao decúbito lateral evoluindo para 
óbito. Um dos animais foi eutanasiado in extremis e o mesmo foi necropsiado sendo o material coletado acondicionado em formol a $10 \%$ e submetido ao exame histopatológico. Os casos ocorreram no mês de Janeiro de 2017, um período com alto índice pluviométrico, em consonância com os registros de cólica em equinos e bovinos descritos na literatura. Foram identificadas alterações significavas no trato gastrointestinal, onde o conteúdo ruminal estava extremamente ressecado e o conteúdo do omaso estava demasiadamente compactado. No intestino delgado havia enterite mononuclear leve, já o intestino grosso não apresentava conteúdo, o que indica interrupção do trânsito intestinal, ocasionado pela compactação nos compartimentos anteriores. Embora os casos descritos relacionem dilatação gástrica com presença de conteúdo líquido em equinos e timpanismo em bovinos, nesse surto a compactação dos pré-estômagos foi o principal achado. Desse modo, concluí-sse que a causa da compactação foi o consumo da cultivar da Panicum maximum cv. Mombaça associado com a restrição hídrica. Considerando ser um período chuvoso com forragem verde em crescimento, a princípio de boa digestibilidade, chama atenção a velocidade deste agravo, sendo necessária atenção quanto à disponibilidade de aporte hídrico aos animais quando da escolha desse tipo de cultivar.

PALAVRAS-CHAVE: restrição hídrica; bovinocultura de corte; cólica.

AGRADECIMENTOS: UFMT. 


\title{
AVALIAÇÃO DA SUPLEMENTAÇÃO MINERAL E VITAMÍNICA INJETÁVEL (KIT ADAPTADOR® MIN E VIT, BIOGÉNESIS BAGÓ) NA MELHORIA DO DESEMPENHO EM CONFINAMENTOS DE BOVINOS DE CORTE
}

\author{
Milton Maturana Filho', João Paulo Lollato ${ }^{2}$, Reuel Luis Gonçalves ${ }^{2}$, Bruno \\ Di Rienzo², Ed Hoffmann Madureira ${ }^{3}$, Guilhermo Mattioli ${ }^{4}$, Juan Rodriguez \\ Pérsico ${ }^{2}$ \\ ${ }^{1}$ MF Vetplan Consultoria Agropecuária; ${ }^{2}$ Biogenesis Bagó Saúde Animal; ${ }^{3}$ Universidade de São \\ Paulo; ${ }^{4}$ Universidade de La Plata
}

A suplementação estratégica de vitaminas e minerais durante o período de confinamento pode auxiliar no aumento da atividade de enzimas antioxidativas como a superóxido dismutase, que são dependentes de microminerais e vitaminas lipossolúveis. A suplementação injetável estratégica pode melhorar a adaptação e consequentemente o desempenho dos bovinos em confinamento para terminação. O Objetivo desse estudo foi verificar a eficiência da utilização de suplementação mineral e vitamínica injetável (Kit Adaptador $®$ MIN e VIT, Biogénesis Bagó) na entrada de confinamento para melhoria do ganho de peso em garrotes cruzados. O experimento foi conduzido na Fazenda Gaivota, na cidade de Bebedouro -SP. Os grupos experimentais foram G1) Suplementação, que recebeu 1 dose do Kit Adaptador na entrada do confinamento e outra dose 30 dias após, na realização da primeira pesagem $(\mathrm{N}=300)$ e; $\mathrm{G} 2$ ) controle (placebo, $\mathrm{N}=300$ ), totalizando 600 animais distribuídos aleatoriamente nos grupos do estudo. A composição do produto (KIT ADAPTADOR) é de: 5.950.000 UI de vitamina A; $5000 \mathrm{UI}$ de vitamina $\mathrm{E}, 1 \mathrm{~g}$ de edetato de Cobre, $4 \mathrm{~g}$ de edetato de zinco, $1 \mathrm{~g}$ de edetato de manganês e $0,5 \mathrm{~g}$ de selênio na forma de selenito de sódio para cada $100 \mathrm{~mL}$ de excipientes q.s.p. A dose aplicada nos animais foi de $1 \mathrm{~mL}$ de cada produto para cada $75 \mathrm{~kg}$ de peso vivo, sendo que o peso médio dos animais no início do experimento era de 368 e 368,5 kg para o G1 e $\mathrm{G} 2$, respectivamente. A avaliação de peso foi realizada aos dias 
0, 30 dias após entrada no confinamento e na saída para o abate. Os ganhos em energia metabolizável foram calculados de acordo com o NRC (2000). Os dados obtidos foram submetidos à análise de variância e normalidade dos resíduos e posteriormente pelo teste PROC MIXED, utilizando-se o programa Statistical Analyses System (SAS, 9.3) adotando-se nível de significância de 5\%. A suplementação injetável melhorou $(p<0,001)$ o peso dos animais aos 30 dias ( $\mathrm{G} 1=458,4 \pm 3,7 \mathrm{~kg}$ vs $\mathrm{G} 2452,9 \pm 3,9 \mathrm{~kg})$ e ao final do confinamento ( $\mathrm{G} 1=516,8 \pm 3,8 \mathrm{~kg}$ vs $\mathrm{G} 2497,6 \pm 3,3 \mathrm{~kg})$. O ganho de peso foi maior tanto na primeira ( $G 1=458,4 \pm 3,7 \mathrm{~kg}$ vs $\mathrm{G} 2452,9$ $\pm 3,9 \mathrm{~kg}$ ) como na segunda etapa do estudo ( $\mathrm{G} 1=90,4 \pm 2,7 \mathrm{~kg}$ vs $\mathrm{G} 279,0 \pm 3,1 \mathrm{~kg}$ ) para os animais suplementados $(p<0,05)$. $O$ ganho de peso médio diário foi maior $(p<0,05)$ nos dois períodos para os animais suplementados ( $\mathrm{G} 1=1,9 \pm 0,4 \mathrm{~kg}$ vs $\mathrm{G} 2=1,4 \pm 0,1$ $\mathrm{kg}$ ). Portanto, a suplementação estratégica com Kit Adaptador MIN e VIT (Biogénesis Bagó) colaborou com a melhoria do desempenho de garrotes cruzados em confinamento.

PALAVRAS-CHAVE: ganho de peso; confinamento; suplementação injetável.

AGRADECIMENTOS: Fazenda Gaivota- Bebedouro-SP. 


\section{AVALIAÇÃO DA UTILIZAÇÃO DE DOIS SUPLEMENTADOS INJETÁVEIS PARA MELHORIA DE DESEMPENHO GARROTES EM CONFINAMENTOS}

Milton Maturana Filho ${ }^{1}$, João Paulo Lollato ${ }^{2}$, Reuel Luis Gonçalves ${ }^{2}$, Bruno Di
Rienzo ${ }^{2}$, Elias José Oliveira $\mathrm{Da}^{2}$, Guilhermo Mattioli ${ }^{3}$, Juan Rodriguez Pérsico ${ }^{2}$
${ }^{1}$ MF Vetplan Consultoria Agropecuária; ${ }^{2}$ Biogenesis Bagó Saúde Animal; ${ }^{3}$ Universidade de La Plata

A suplementação estratégica de vitaminas, minerais e aminoácidos injetáveis, durante o período de confinamento pode melhorar a atividade metabólica, por diminuir os gastos energéticos e a produção exacerbada de radicais livres, bem como aumentar a atividade de enzimas. O Objetivo desse estudo foi comparar dois suplementos injetáveis utilizados em entrada de confinamento (Kit Adaptador MIN e VIT, Biogénesis Bagó e; Robofortet $\circledast$, Hertape) na melhoria do ganho de garrotes. O experimento foi conduzido na Fazenda Gameleira, da Agropecuária Brunozzi, na cidade de Campina Verde-MG. Os grupos experimentais foram G1) Kit Adaptador $(\mathrm{N}=300)$ e; $\mathrm{G} 2)$ Roboforte $(\mathrm{N}=300)$, totalizando 600 animais distribuídos aleatoriamente. A suplementação injetável foi realizada na entrada do confinamento e outra dose 45 dias após, na realização da primeira pesagem. As doses de cada um dos produtos foi realizada de acordo com a recomendação dos laboratórios. A composição do produto KIT ADAPTADOR é de: 5.950.000 UI de vitamina A; $5000 \mathrm{UI}$ de vitamina $\mathrm{E}, 1 \mathrm{~g}$ de edetato de Cobre, $4 \mathrm{~g}$ de edetato de zinco, $1 \mathrm{~g}$ de edetato de manganês e $0,5 \mathrm{~g}$ de selênio na forma de selenito de sódio para cada $100 \mathrm{~mL}$ de excipientes q.s.p. A composição do produto Roboforte ${ }^{\circledR}$ é de: $5 \mathrm{~g}$ Cálcio-fosforilcloreto de colina, $5 \mathrm{~g}$ de Caseína-peptídeos e $5 \mathrm{mg}$ de vitamina B12 (cianocobalamina) para cada $100 \mathrm{~mL}$ de excipientes q.s.p. O peso médio dos animais no início do experimento foi de 368 e 368,5 para o G1 e G2, respectivamente. A segunda avaliação de peso foi realizada aos dias 45 dias após entrada no confinamento e também na saída para o abate. Os ganhos em energia metabolizável e liquida foram calculados de acordo com o 
NRC (2000). Os dados obtidos foram submetidos à análise de variância e normalidade dos resíduos e posteriormente pelo teste PROC MIXED, utilizando-se o programa Statistical Analyses System (SAS, 9.3) adotando-se nível de significância de $5 \%$. Os animais do $G 1$, tiveram maior peso $(p<0,05)$ aos 45 dias $(G 1=458,4$ $\pm 3,7 \mathrm{~kg}$ vs $\mathrm{G} 2447,6 \pm 3,9 \mathrm{~kg}$ ) e ao final do confinamento ( $\mathrm{G} 1=$ $516,8 \pm 3,8 \mathrm{~kg}$ vs $\mathrm{G} 2=478,4 \pm 2,6 \mathrm{~kg}$ ), devido a um maior ganho de peso na primeira $(\mathrm{G} 1=90,4 \pm 2,6 \mathrm{~kg}$ vs $79 \pm 3,2 \mathrm{~kg})$ e na segunda etapa do estudo ( $\mathrm{G} 1=58,4 \pm 3,2 \mathrm{~kg}$ vs $30,9 \pm 3,3 \mathrm{~kg}$ ), o que está relacionado a uma diminuição das condições de estresse oxidativo, devido aos terrores mais elevados de vitaminas e microminerais do suplemento Kit Adaptador, que consequentemente, colaborou com a melhor adaptabilidade e ganho de peso desses animais. Portanto, a suplementação estratégica com Kit Adaptador (Biogénesis Bagó) colaborou com a melhoria do desempenho de garrotes em confinamento e foi superior ao desempenho de suplementos injetáveis à base de colina e peptídeos.

PALAVRAS-CHAVE: confinamento; garrotes; suplementação injetável.

AGRADECIMENTOS: Fazenda Gameleira da agropecuária Brunnozi - Campina Verde-MG. 


\title{
PRODUÇÃO DE PASTAGEM SOBRESSEMEADA COM FORRAGEIRAS DE INVERNO
}

\author{
Danilo Silva Amaral ${ }^{1}$, Cíntia Cármen de Faria Meloํㅜㄴ Luís César Dias \\ Drumond $^{2}$, Filipe Henrique Gentil ${ }^{3}$ \\ ${ }^{1}$ Eng. Agrônomo, Pós-Graduando em Produção Vegetal, Universidade Federal de Viçosa - Campus \\ Rio Paranaíba, MG; ${ }^{2}$ Eng. Agrônomo, Professor Adjunto da Universidade Federal de Viçosa - \\ Campus Rio Paranaíba, MG; ${ }^{3}$ Engenheiro Agrônomo, Mestre em Produção Vegetal.
}

As forrageiras de clima tropical predominam nas pastagens brasileiras, porém, apresentam uma oscilação de crescimento ao longo do ano, o que caracteriza a estacionalidade de produção, assim a produção de massa é menor nos períodos frios e/ou secos. Para minimizar os impactos desse fenômeno, pode-se utilizar a adubação, a irrigação e a sobressemeadura de forrageiras de clima temperado em pastagens de clima tropical durante o outono e o inverno. Buscando avaliar o potencial da sobressemeadura na mitigação da estacionalidade, a partir da determinação da taxa de acúmulo de forragem (TAF) e capacidade de suporte (CS), foi conduzido um experimento em área de pastagem irrigada, no município de Rio Paranaíba-MG. O clima da região é caracterizado por duas estações definidas, sendo uma quente e chuvosa e outra fria e seca. Foi utilizado delineamento em blocos ao acaso, em esquema fatorial $3 \times 3$, com três repetições, sendo três tipos de cultivo: tifton 85 (Cynodon spp.) sem sobremessemeadura, tifton 85 sobressemeado com aveia preta (Avena strigosa Schreb) e tifton 85 sobressemeado com azevém (Lolium multiflorium Lam) e três níveis de adubação: sem adubação (1); $60 \mathrm{~kg}$ ha-1 de $\mathrm{P}_{2} \mathrm{O}_{5}$ na semeadura, $50 \mathrm{~kg}$ ha-1 de $\mathrm{K}_{2} \mathrm{O}$ e 150,0 kg ha-1 de N (2); e $100 \mathrm{~kg}$ ha-1 de $\mathrm{P}_{2} \mathrm{O}_{5}$ na semeadura, $150 \mathrm{~kg}$ ha-1 de $\mathrm{K}_{2} \mathrm{O}$ e $250 \mathrm{~kg}$ ha-1 de $\mathrm{N}$ (3). A pastagem de tifton 85 foi implantada em junho de $2012 \mathrm{e}$ as sobressemeaduras da aveia preta e do azevém realizadas em abril de 2013, após roçada. Nas parcelas de dimensões 2,5 x 1,5 $\mathrm{m}$ procedeu-se à coleta de dados durante sete ciclos no outonoinverno. Os cortes foram executados quando as plantas atingiam altura média de $25 \mathrm{~cm}$, em ponto aleatório definido através do 
arremesso de um quadrado de $0,25 \mathrm{~m}^{2}$. Foi realizada a análise de variância dos dados e para diferenças significativas utilizou-se 0 teste de Tukey a $5 \%$ de probabilidade utilizando o software SAS®. Houve diferença significativa para o fator forragem no primeiro e segundo ciclos, nos quais a sobressemeadura propiciou acréscimo médio de $30 \%$ em relação ao tifton 85 , saindo de uma TAF de 38,7 para 47,3 e de 58 para $81,4 \mathrm{~kg}$ ha-1 dia-1 de matéria seca (MS), respectivamente. Ainda nestes ciclos a CS variou de 3,2 para 4 e de 4,9 para 6,8 UA ha-1, não havendo diferença entre as espécies aveia e azevém. Nos demais ciclos não houve diferença entre as forrageiras. O nível dois de adubação propiciou uma TAF de 70,3 kg ha-1 dia-1 de MS e 6 UA ha-1 na CS, superior ao encontrado no tratamento sem adubação, uma TAF de $36 \mathrm{~kg}$ ha-1 dia-1 de MS e 3 UA ha-1 na CS. Ressalta-se que o nível três de adubação não diferiu do nível dois, permitindo inferir que as doses de fertilizantes utilizadas neste, foram suficientes para maior produtividade. Conclui-se que a sobressemeadura, independente da espécie utilizada, foi eficiente em elevar a TAF e a CS, notadamente no período de inverno, com a adubação de $60 \mathrm{~kg}$ ha-1 de $\mathrm{P}_{2} \mathrm{O}_{5}$ na semeadura mais $50 \mathrm{~kg}$ ha- 1 de $\mathrm{K}_{2} \mathrm{O}$ e $150,0 \mathrm{~kg}$ ha- 1 de $\mathrm{N}$, nas condições avaliadas.

PALAVRAS-CHAVE: adubação; aveia; azevém. 


\title{
MACIEZ DE TRÊS CORTES COMERCIAIS DE NOVILHOS EM CRESCIMENTO COM DIFERENTES NÍVEIS DE DESEMPENHO
}

\author{
Mariana Teixeira Santana ${ }^{1}$, Patrícia Siqueira Leite ${ }^{1}$, Mauricio Miguel \\ Estrada $^{2}$, Luiz Henrique Pereira Silva ${ }^{2}$, Débora E. de Freitas Assis ${ }^{3}$, Pedro \\ Veiga Rodrigues Paulino ${ }^{4}$, Mário Luiz Chizzotti ${ }^{5}$ \\ ${ }^{1}$ Estudante de Graduação em Zootecnia - UFV e-mail: mariana.t.santana@ufv.br; ${ }^{2} E$ studante de \\ Doutorado em Zootecnia - UFV; ${ }^{3}$ Estudante de Mestrado em Zootecnia - UFV; ${ }^{4}$ Consultor \\ Técnico Nacional - Bovinos de Corte, Cargill Nutrição Animal; ${ }^{5}$ Professor Titular do Departamento \\ de Zootecnia, DZO/UFV, Viçosa - MG, Brasil.
}

A maciez é considerada a característica organoléptica que mais influencia na escolha da carne bovina por parte dos consumidores. Destacam-se como fatores que influenciam essa característica: genética, sexo, alimentação, idade ao abate e, manejo pré e pós-abate. O presente estudo objetivou avaliar a percentagem de perdas totais e força de cisalhamento de três cortes comerciais (filé mignon, picanha e lagarto) de bovinos no final da fase de recria em confinamento submetidos a dietas com diferentes níveis nutricionais. Foram utilizados 36 bezerros Nelore, machos não castrados, com idade e peso corporal inicial de 8 meses e $230 \mathrm{~kg}$, respectivamente. O experimento teve duração de 114 dias, sendo 24 de adaptação às dietas e 90 dias de fase de recria. Os animais foram confinados em baias coletivas e distribuídos ao acaso em 3 tratamentos, sendo as dietas constituídas de 19, 40 e $63 \%$ de concentrado na MS, objetivando baixo $(0,1 \mathrm{~kg} / \mathrm{d})$, médio $(0,65 \mathrm{~kg} / \mathrm{d})$ e alto $(1,0 \mathrm{~kg} / \mathrm{d})$ ganho de peso, respectivamente. Ao final do período experimental, os animais foram abatidos e as carcaças divididas longitudinalmente em duas metades e refrigeradas por 24 horas em câmara fria a $4^{\circ} \mathrm{C}$. O peso da carcaça quente dos animais em baixo, médio e alto ganho de peso foi de 122, 168 e $194 \mathrm{~kg}$, respectivamente. Da meia carcaça esquerda foram obtidos os cortes comerciais: filé mignon, picanha e lagarto; sendo de cada um destes retirado um bife de $2,5 \mathrm{~cm}$ de espessura que foi embalado a vácuo em sacola plástica e 
congelado a $-18^{\circ} \mathrm{C}$ até o momento das análises. Para avaliar as perdas totais e a força de cisalhamento, os bifes foram pesados congelados, colocados a descongelar a $4^{\circ} \mathrm{C}$ durante 16 horas, pesados novamente, assados em forno elétrico pré-aquecido a $150^{\circ} \mathrm{C}$ até atingir $71^{\circ} \mathrm{C}$ de temperatura interna, sendo monitorada mediante termômetro tipo K. Após assado, o bife foi pesado, sendo a diferença entre o peso do bife congelado e assado utilizada para determinar a percentagem de perdas totais. No seguinte dia, do bife resfriado foram obtidas 6 amostras cilíndricas de $1,27 \mathrm{~cm}$ de diâmetro, retiradas no sentido das fibras musculares e cisalhadas em texturômetro Warner-Bratzler ${ }^{\circledR}$ para a determinar a força de cisalhamento. Foram encontradas diferenças nas perdas totais entre os cortes estudados $(P<0,05)$, sendo que a picanha apresentou as maiores perdas $(30,56 \%)$, o filé mignon as menores $(27,67 \%)$, e o lagarto perdas intermediárias $(29,31 \%)$. Em relação aos tratamentos, não foram encontradas diferenças nas perdas totais $(P=0,6922)$. No tocante à força de cisalhamento, não foram encontradas diferenças nem entre cortes $(P=0,8070)$ nem entre tratamentos $(P=0,0753)$. Este resultado pode ser ocasionado pela baixa idade de abate dos animais (12 meses), que apresentam baixa quantidade de colágeno insolúvel e alta taxa de turnover muscular. Conclui-se que não há diferenças na força de cisalhamento entre cortes de carne de bovinos jovens abatidos ainda na fase de crescimento.

PALAVRAS-CHAVE: confinamento, cortes comerciais, nelore, recria. 